\title{
Photocatalytic Methane Reforming: Recent Advances
}

\author{
Yohei Cho (1), Akira Yamaguchi (1) and Masahiro Miyauchi *(1) \\ Department of Materials Science and Engineering, School of Materials and Chemical Technology, Tokyo Institute \\ of Technology, 2-12-1, Ookayama, Meguro-ku, Tokyo 152-8552, Japan; cho.y.ac@m.titech.ac.jp (Y.C.); \\ ayamaguchi@ceram.titech.ac.jp (A.Y.) \\ * Correspondence: mmiyauchi@ceram.titech.ac.jp; Tel.: +81-3-5734-2527
}

check for

updates

Citation: Cho, Y.; Yamaguchi, A.; Miyauchi, M. Photocatalytic Methane Reforming: Recent Advances. Catalysts 2021, 11, 18. https://dx.doi.org/10.3390/ catal11010018

Received: 11 December 2020 Accepted: 21 December 2020 Published: 25 December 2020

Publisher's Note: MDPI stays neutral with regard to jurisdictional claims in published maps and institutional affiliations.

Copyright: (c) 2020 by the authors. Licensee MDPI, Basel, Switzerland. This article is an open access article distributed under the terms and conditions of the Creative Commons Attribution (CC BY) license (https: / / creativecommons.org/ licenses/by/4.0/).
Abstract: Methane reforming is an important potential technology for solving both environmental and energy problems. This technology is important because methane is counted as a greenhouse gas, but on the other hand, it can be reformed into industrially valuable compounds. More research has focused on photocatalytic methane reforming, which has a higher activity than thermal catalysts under dark conditions. The reaction selectivity toward specific products in photocatalytic methane reforming is sometimes different from thermal catalyst systems. Herein, we discuss recent advances in photocatalytic methane reforming to provide various strategies for reforming.

Keywords: photocatalyst; electron; hole; methane; hydrogen; greenhouse gas; steam reforming; dry reforming; partial oxidation; non-oxidative coupling

\section{Introduction}

Methane is an important energy source that is abundant and easily obtained in natural feedstocks, such as shale gas. On the other hand, methane is a greenhouse gas, and its conversion to other species has been a significant issue over the last century. As a methane molecule contains carbon and hydrogen, by adding oxidant molecules, it can be reformed to high-value compounds, such as hydrogen $\left(\mathrm{H}_{2}\right)$, carbon monoxide $(\mathrm{CO})$, or other hydrocarbons. The mixture of $\mathrm{H}_{2}$ and $\mathrm{CO}$ is called syngas and can be further converted to higher carbon-containing molecules, which are more valuable. Three major oxidants are commonly used to reform methane, i.e., water, oxygen, and carbon dioxide. The steam reforming of methane (SRM, Equations (1) and (2)) has the largest $\mathrm{H}_{2}$ output compared to others because the water oxidant contains hydrogen ions. Thus, it is now commercialized as a way to produce $\mathrm{H}_{2}$ [1,2]. However, the side reaction of $\mathrm{CO}_{2}$ emission in SRM is a major problem. The same problem occurs in the partial oxidation of methane (POM, Equation (3)) when oxygen is used as an oxidant. Here, we define POM as oxidative methane reforming without using $\mathrm{H}_{2} \mathrm{O}$ or $\mathrm{CO}_{2}$ to distinguish it from others in the present paper. As oxygen is input directly, the reaction conditions must be carefully adjusted; otherwise, methane can be completely oxidized to carbon dioxide and water. On the other hand, the dry reforming of methane (DRM, Equation (4)) can convert $\mathrm{CO}_{2}$ as an oxidant. 


$$
\begin{gathered}
\text { Steam reforming } \mathrm{CH}_{4}+\mathrm{H}_{2} \mathrm{O} \rightleftharpoons 3 \mathrm{H}_{2}+\mathrm{CO} \quad \Delta H^{\circ}{ }_{298 \mathrm{~K}}=206 \mathrm{~kJ} / \mathrm{mol} \\
\text { Steam reforming } \quad \mathrm{CH}_{4}+2 \mathrm{H}_{2} \mathrm{O} \rightleftharpoons 4 \mathrm{H}_{2}+\mathrm{CO}_{2} \quad \Delta H^{\circ}{ }_{298 \mathrm{~K}}=165 \mathrm{~kJ} / \mathrm{mol} \\
\text { Partial oxidation (POM) with oxygen as the oxidant } \quad \mathrm{CH}_{4}+0.5 \mathrm{O}_{2} \rightleftharpoons 2 \mathrm{H}_{2}+\mathrm{CO} \quad \Delta H^{\circ}{ }_{298 \mathrm{~K}}=-38 \mathrm{~kJ} / \mathrm{mol} \\
\text { Dry reforming } \quad \mathrm{CH}_{4}+\mathrm{CO}_{2} \rightleftharpoons 2 \mathrm{H}_{2}+2 \mathrm{CO} \quad \Delta H^{\circ}{ }_{298 \mathrm{~K}}=247 \mathrm{~kJ} / \mathrm{mol}
\end{gathered}
$$

As presented in the equations, however, the highly positive value of enthalpy indicates the necessity of a high temperature [3,4]. This high temperature is due to the stability of methane. The bonding energy of $\mathrm{C}-\mathrm{H}$ in methane is $434-440 \mathrm{~kJ} / \mathrm{mol}$, which is usually regarded as a rate-determining step of the methane-reforming reaction [5,6]. Among these four reactions, DRM is the most difficult because of its high endothermic reaction and the high stability of the $\mathrm{CO}_{2}$ oxidant compared with the other reactions.

The theoretical maximum conversion efficiencies of chemical reactions under specific temperature and pressure conditions can be predicted by considering thermodynamic equilibrium. Figure 1 shows the calculated conversions of methane-reforming reactions using NASA-CEA software [7]. It can be understood that a significant amount of heat energy is necessary for methane conversion reactions. Even in $\mathrm{POM}$ with $\mathrm{O}_{2}$ as the oxidant, which is the easiest way to achieve methane conversion, a temperature higher than $550{ }^{\circ} \mathrm{C}$ is needed for a conversion rate of over $90 \%$. As fossil fuels are usually used to heat a reactor, the reaction system is not environmentally friendly.

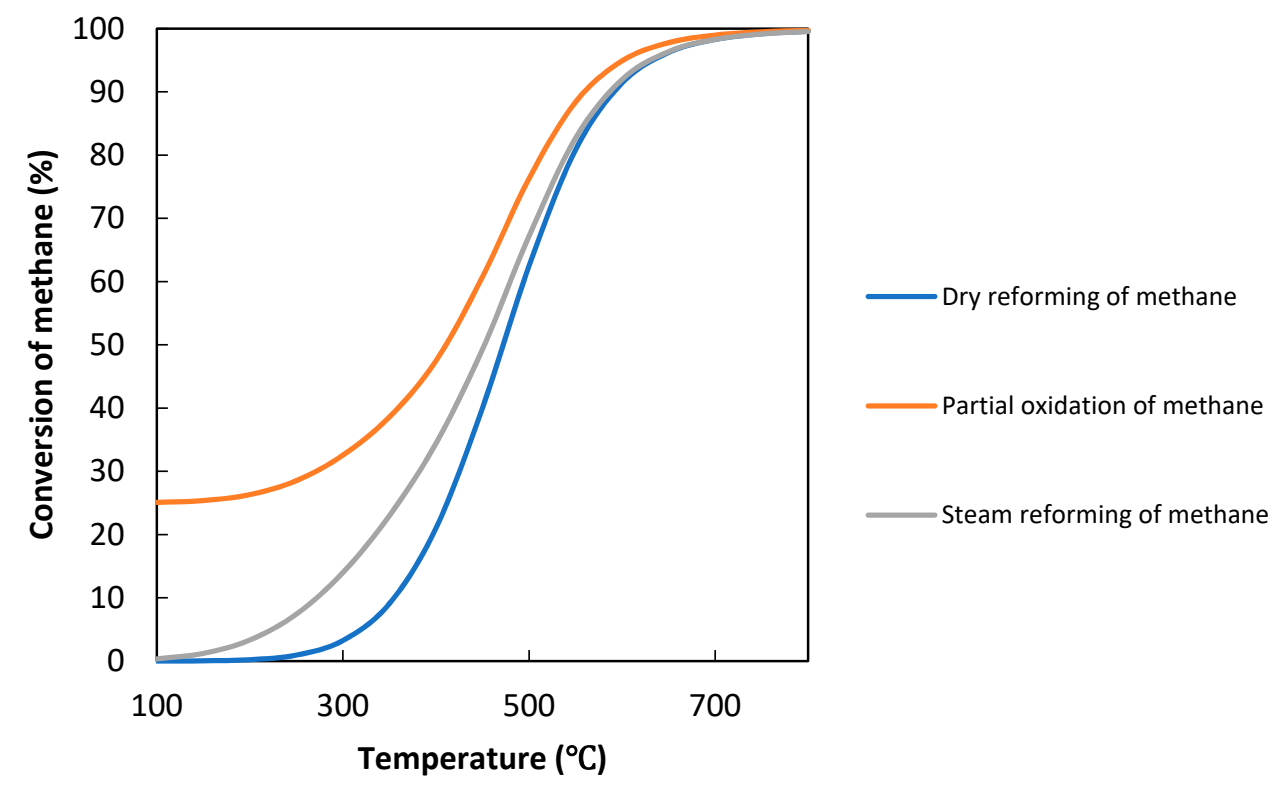

Figure 1. Calculated thermodynamic equilibrium of dry reforming of methane (blue line), partial oxidation of methane (using $\mathrm{O}_{2}$, orange line), and steam reforming of methane (gray line). Equation (1) was used to calculate the equilibrium for the steam reforming of methane. The input gas of methane and oxidant were both at $0.01 \mathrm{~atm}$ [7].

Another major problem encountered in methane conversion is carbon deposition $[1,2,8]$. When methane molecules are cracked at high temperatures, carbon species are generated. If these carbon species cannot react with the oxygen species supplied by oxidants, solid-state carbon species are precipitated on the surface of the catalyst. This phenomenon is known as coking, which deteriorates the catalytic activity. The catalyst is expanded by coking to cause a plug and may destroy a reactor. The time scale of coking phenomena usually corresponds to one day, which makes it difficult to commercialize. 
In addition to these methane conversions using oxidants, the non-oxidative reaction of methane is also attractive. Some reports indicate that only methane is introduced into the reactor, where methane coupling occurs, and organics such as ethane, ethylene, propane, or aromatics are produced (Equations (5) and (6)) [9-11]. Catalysts for promoting the direct reforming of these molecules are also required. However, low activity and high operating temperatures are crucial issues that prevent these methane coupling reactions from being practical.

$$
\begin{aligned}
2 \mathrm{CH}_{4} \rightleftharpoons \mathrm{C}_{2} \mathrm{H}_{6}+\mathrm{H}_{2} & \Delta H^{\circ}{ }_{298 \mathrm{~K}}=32.55 \mathrm{~kJ} / \mathrm{mol} \\
2 \mathrm{CH}_{4} \rightleftharpoons \mathrm{C}_{2} \mathrm{H}_{4}+2 \mathrm{H}_{2} & \Delta H^{\circ}{ }_{298 \mathrm{~K}}=101.1 \mathrm{~kJ} / \mathrm{mol}
\end{aligned}
$$

On the other hand, photons are a more attractive energy source than heat because of their high-quality quantum energy. In 1972, Fujishima et al. found that irradiating light with a certain wavelength makes it possible to drive uphill reactions, such as water splitting [12]. In this work, ultraviolet light was irradiated onto $\mathrm{TiO}_{2}$ in water, and hydrogen was released from water, even with a bias of $-0.6 \mathrm{~V}$. Since then, numerous studies have been performed to drive the uphill reaction by photocatalysis, such as water splitting or $\mathrm{CO}_{2}$ reduction without applying an electric bias [13,14]. Much research has proved that light energy can be converted into chemical energy, even if the chemical reaction is uphill.

$$
\mathrm{H}_{2} \mathrm{O} \rightarrow \mathrm{H}_{2}+0.5 \mathrm{O}_{2} \quad \Delta H^{\circ}{ }_{298 \mathrm{~K}}=237.13 \mathrm{~kJ} / \mathrm{mol}
$$

Recently, through utilizing the various routes of conversion from light energy to chemical energy, the field of methane reforming by photocatalysis has been studied. Figure 2 shows the number of publications found using the search terms "methane reforming" and "methane reforming photo" in Web of Science [15]. As can be seen, the study of methane reforming increased since around 1990, and the publications related to "photo" started very recently.

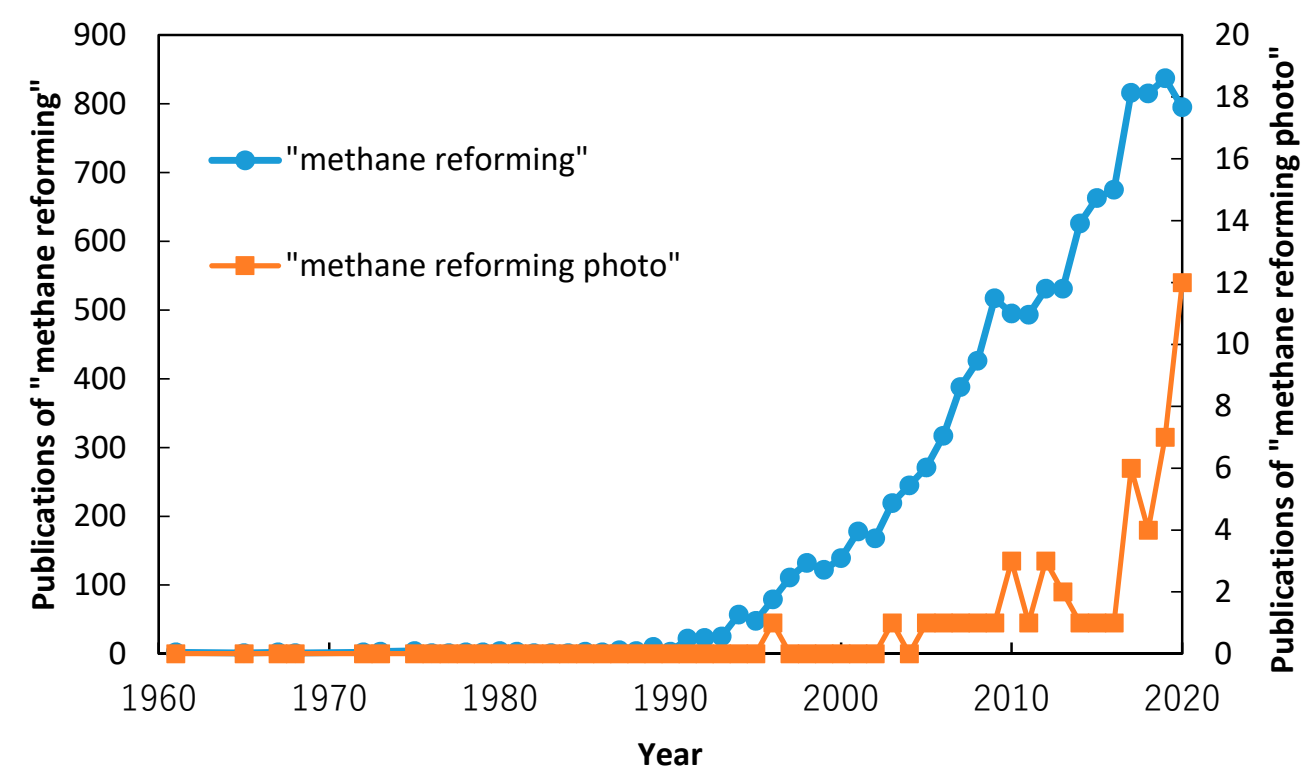

Figure 2. Number of publications found using the search terms "methane reforming" and "methane reforming photo" in Web of Science [15].

As photocatalytic methane conversion studies have attracted many researchers, a comprehensive review of these studies helps many readers understand the current achievements and photocatalytic methane-conversion mechanisms. This review article aims to 
introduce photocatalysts for various methane-conversion reactions and their working mechanisms. Furthermore, we discuss the prospects of photocatalytic methane conversions.

In Section 2, we explain the general concept of photocatalytic methane reforming. In addition, a strategy for material design is introduced. Section 3 introduces various reactors used in photocatalytic methane reforming, which helps readers to start learning the photocatalytic methane-reforming topic and optimize reactor design. In Sections 4-7, various methane-reforming reactions are introduced: steam reforming (Section 4), dry reforming (Section 5), partial oxidation (Section 6), and non-oxidative coupling (Section 7). In each section, an overview of the reaction, materials, and mechanism are described. In Section 8, other important factors that should be considered in photocatalytic methane reforming are explained. This section focuses on hot carriers, another important electron transfer pathway, and the phenomenon of the bandgap shift caused by thermal energy. In Section 9, we conclude the recent advances in methane reforming and propose prospects.

\section{The Concept of Photocatalytic Methane Reforming}

Following the bandgap excitation mechanism found by Fujishima et al. [12], many reports adapt this concept to methane reforming. Generally, in the field of photocatalysis, materials are composed of semiconductors with metal co-catalysts, as shown in Figure $3[14,16]$. Metal particles are deposited on the surface of a semiconductor to avoid recombination and produce active sites. When we focus on methane reforming, methane is oxidized by a hole generated at the semiconductor, while oxidants receive electrons from the metal catalyst.
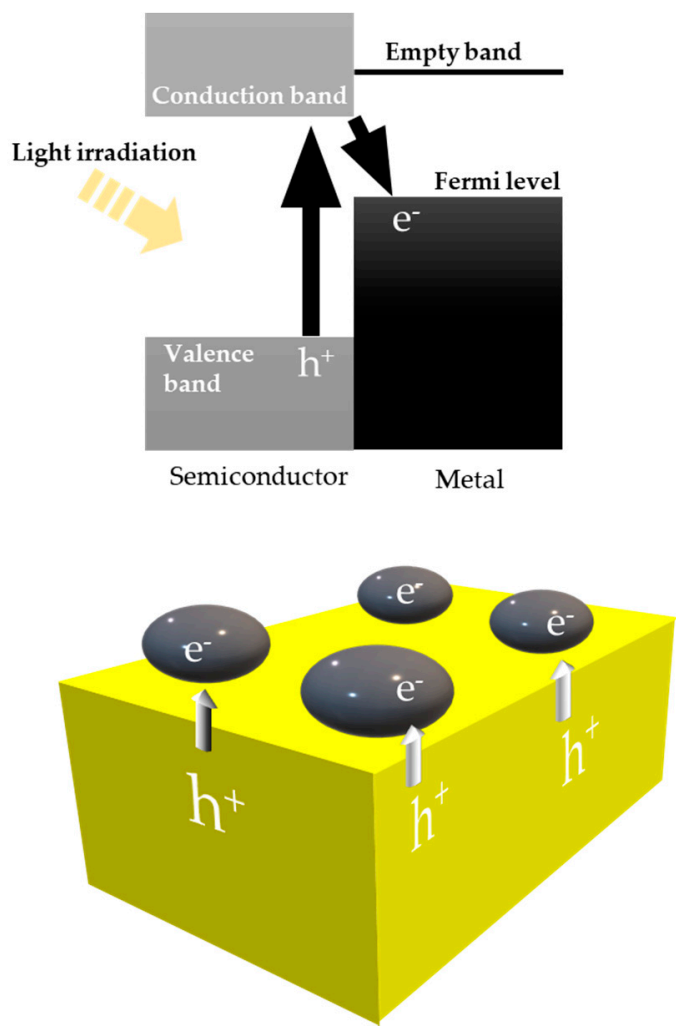

Figure 3. General electron transfer pathway in a metal-loaded semiconductor after light irradiation.

As for the semiconductor choice, it must meet the criteria of (1) stability against light, temperature, and the atmosphere of methane and other oxidants, and (2) the capability to reduce oxidants and oxidize methane reductants. To drive a photocatalytic reaction, the conduction band position must be higher than the redox potential of the oxidant and the valence band position must be lower than the redox potential of the reductant. As is already known, in aqueous solutions, carbon dioxide reduction requires a high conduction band position rather than proton reduction $[17,18]$. The same requirement should also be adapted 
for photocatalytic methane reforming. Further requirements should be considered, namely, (3) basicity and (4) reducibility, which are important factors that determine catalytic activity in thermal catalysts for methane reforming [19-21]. Furthermore, to make it practical, (5) visible light sensitivity, (6) an abundance of the photocatalyst materials, and (7) a facile catalyst fabrication process are required. Furthermore, the basicity of the semiconductor is an important factor that determines the catalytic activity under dark and light irradiation conditions. For example, $\mathrm{MgO}$ is one of the most widely used supports in methane reforming. Following this strategy, alkaline elements can be introduced into light absorbers, such as the reported examples of $\mathrm{SrTiO}_{3}, \mathrm{NaTiO}_{3}$, or $\mathrm{K}_{2} \mathrm{Ti}_{6} \mathrm{O}_{13}$.

As sunlight includes only a little ultraviolet light, it is necessary to make the semiconductor visible-light sensitive. However, when researchers try to make photocatalysts visible-light sensitive, they always confront a tradeoff of the decreasing relationship between visible-light absorbability and the high potential of electrons and holes to drive efficient chemical reactions.

Our group screened various visible-light-sensitive semiconductors to drive photocatalytic DRM [22]. We used a flow reactor and evaluated pristine photocatalysts and $\mathrm{Rh}$ - or Ru-loaded photocatalysts; however, almost all the catalysts showed no notable activity, as shown in Table 1. There are some reasons that can account for these results. One is the instability of the catalysts. The surface temperature of a photocatalyst increases when it is irradiated by light without water-cooling. Thus, sulfides or unstable oxides tend to change their structure, resulting in no significant conversion. Second, as Ruckenstein et al. pointed out in their paper, catalytic activity is deeply related to catalytic support. They compared the catalytic activity in dark conditions using rhodium loaded on various supports. They found that the order of the catalytic activity was $\mathrm{SiO}_{2} \approx \mathrm{MgO} \approx$ $\gamma-\mathrm{Al}_{2} \mathrm{O}_{3}>\mathrm{Y}_{2} \mathrm{O}_{3}>\mathrm{Ta}_{2} \mathrm{O}_{5} \approx \mathrm{La}_{2} \mathrm{O}_{3}>\mathrm{TiO}_{2}>\mathrm{ZrO}_{2}>\mathrm{Nb}_{2} \mathrm{O}_{5}>\mathrm{CeO}_{2}$. We further expanded our knowledge of photocatalysts.

Table 1. $\mathrm{H}_{2}$ yield (\%) over visible-light-sensitive catalysts with and without visible light irradiation at $450{ }^{\circ} \mathrm{C} . \mathrm{N} . \mathrm{D} .=\mathrm{not}$ detected. Reproduced from [22] with permission from The Royal Society of Chemistry.

\begin{tabular}{|c|c|c|c|c|c|c|c|c|c|c|}
\hline Light & $\mathrm{CdS}$ & $\mathrm{Bi}_{2} \mathrm{~S}_{3}$ & $\mathrm{TaON}$ & $\mathrm{Ta}_{3} \mathrm{~N}_{5}$ & $\begin{array}{c}\text { Rh-Dope } \\
\text { SrTiO }_{3}\end{array}$ & g- $\mathrm{C}_{3} \mathrm{~N}_{4}$ & $\mathrm{Bi}_{2} \mathrm{WO}_{6}$ & $\mathrm{MgFe}_{2} \mathrm{O}_{4}$ & $\mathrm{ZnFe}_{2} \mathrm{O}_{4}$ & $\mathrm{CaFe}_{2} \mathrm{O}_{4}$ \\
\hline $\begin{array}{l}\text { OFF } \\
\text { ON }\end{array}$ & $\begin{array}{l}\text { N.D. } \\
1.2\end{array}$ & $\begin{array}{c}\text { N.D. } \\
0.2\end{array}$ & $\begin{array}{l}\text { N.D. } \\
\text { N.D. }\end{array}$ & $\begin{array}{l}\text { N.D. } \\
\text { N.D. }\end{array}$ & $\begin{array}{l}\text { N.D. } \\
\text { N.D. }\end{array}$ & $\begin{array}{c}\text { N.D. } \\
0.2\end{array}$ & $\begin{array}{c}1.6 \\
\text { N.D. }\end{array}$ & $\begin{array}{c}0.1 \\
\text { N.D. }\end{array}$ & $\begin{array}{l}\text { N.D. } \\
\text { N.D. }\end{array}$ & $\begin{array}{l}\text { N.D. } \\
\text { N.D. }\end{array}$ \\
\hline Light & $\mathrm{Cu}_{2} \mathrm{O}$ & $\mathrm{Rh} / \mathrm{Bi}_{2} \mathrm{WO}_{6}$ & \multicolumn{2}{|c|}{$\mathrm{Ru} / \mathrm{ZnFe}_{2} \mathrm{O}_{4}$} & $\mathrm{Ru} / \mathrm{CaFe}_{2} \mathrm{O}_{4}$ & $\mathrm{Rh} / \mathrm{Cu}_{2} \mathrm{O}$ & $\mathrm{Rh} / \mathrm{g}-\mathrm{C}_{3} \mathrm{~N}_{4}$ & $\mathrm{Rh} / \mathrm{TaON}$ & $\mathrm{Rh} / \mathrm{Ta}_{3} \mathrm{~N}_{5}$ & $\begin{array}{l}\text { Thermal } \\
\text { Catalyst } \\
\text { Limit }\end{array}$ \\
\hline $\begin{array}{l}\text { OFF } \\
\text { ON }\end{array}$ & $\begin{array}{c}\text { N.D. } \\
0.6\end{array}$ & $\begin{array}{l}\text { N.D. } \\
\text { N.D. }\end{array}$ & \multicolumn{2}{|c|}{$\begin{array}{l}\text { N.D. } \\
2.2\end{array}$} & $\begin{array}{c}\text { N.D. } \\
2.4\end{array}$ & $\begin{array}{l}\text { N.D. } \\
\text { N.D. }\end{array}$ & $\begin{array}{c}\text { N.D. } \\
0.1\end{array}$ & $\begin{array}{l}15.6 \\
50.3\end{array}$ & $\begin{array}{l}22.8 \\
33.6\end{array}$ & $\begin{array}{c}36.3 \\
-\end{array}$ \\
\hline
\end{tabular}

As for co-catalysts, the most commonly used metals are rhodium, ruthenium, platinum, iridium, gold, silver, nickel, and cobalt [23,24]. These materials are also reported as being used in thermal catalysts [25-27]. The fabrication methods can affect the activity significantly. Our group used an impregnation method and a hydrothermal method to make $\mathrm{Rh} / \mathrm{TaON}$ [22]. Here, the particle size of the Rh was around 2-3 nm in the case of the hydrothermal method, while it was much larger and ununiformly loaded from 2 to $15 \mathrm{~nm}$ on TaON using the impregnation method. As a result, the samples prepared using the hydrothermal method exhibited higher activity.

The interaction between the semiconductor and co-catalyst is complicated, and the order of the co-catalyst performance cannot be uniquely determined. Figure 4 shows the $\mathrm{H}_{2}$ production rate, where steam reforming of methane was performed using lanthanumdoped $\mathrm{NaTaO}_{3}$ under light irradiation [23]. The order of the production rate of hydrogen is shown in this figure. On the other hand, the hydrogen production rate of the same reaction with another semiconductor $\left(\mathrm{K}_{2} \mathrm{Ti}_{6} \mathrm{O}_{13}\right)$ is presented in Figure 5 . This clearly shows that the activity tendencies over various metal catalysts are different from those seen in Figure 4, implying that the photocatalytic activity is not simply dependent on the co-catalyst metal 
element. In other words, the activity strongly depends on the interaction between the semiconductor photocatalyst support and the loaded metal co-catalyst. Indeed, the activity order of non-oxidative methane coupling on the metal loaded on $\mathrm{TiO}_{2}$ (Figure 6) was drastically different from those shown in Figures 4 and 5.

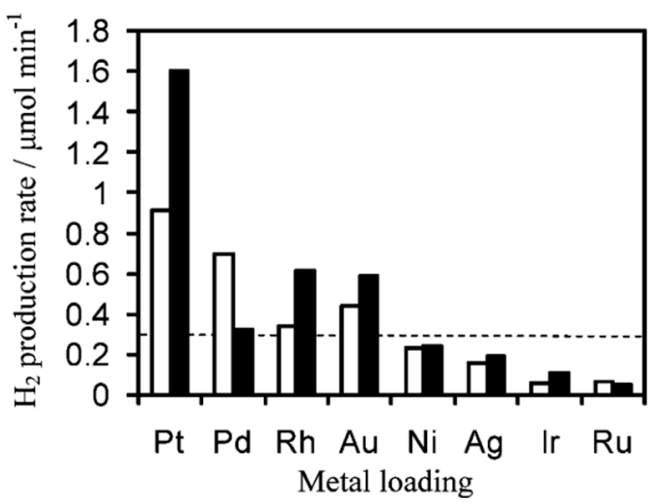

Figure 4. $\mathrm{H}_{2}$ production rate for metal-loaded La-doped $\mathrm{NaTaO}_{3}$ under light irradiation. The loaded amount is $0.01 \%$. The black bars represent the data of materials calcinated at $773 \mathrm{~K}$ in air and the white bars show the data of samples further reduced at $673 \mathrm{~K}$ under $\mathrm{H}_{2}$. The dotted line represents the $\mathrm{H}_{2}$ production rate of La-loaded $\mathrm{NaTaO}_{3}$ without any co-catalyst. Reprinted with permission from [23]. Copyright (2010), American Chemical Society.

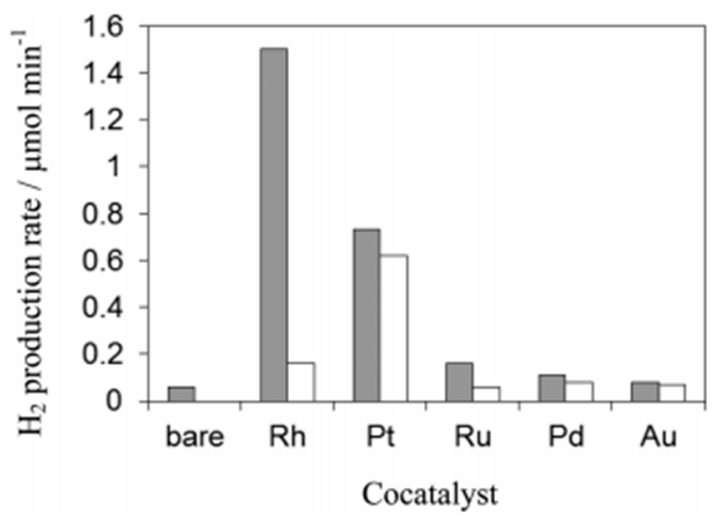

Figure 5. $\mathrm{H}_{2}$ production rate for metal-loaded La-loaded $\mathrm{K}_{2} \mathrm{Ti}_{6} \mathrm{O}_{13}$ under light irradiation. The loaded amount is $0.03 \%$. The gray bar shows the $\mathrm{H}_{2}$ production over various co-catalysts loaded using a photodeposition method and the white bar represents the impregnation method followed by calcination at 773 K. Reprinted with permission from [24]. Copyright (2010), American Chemical Society.

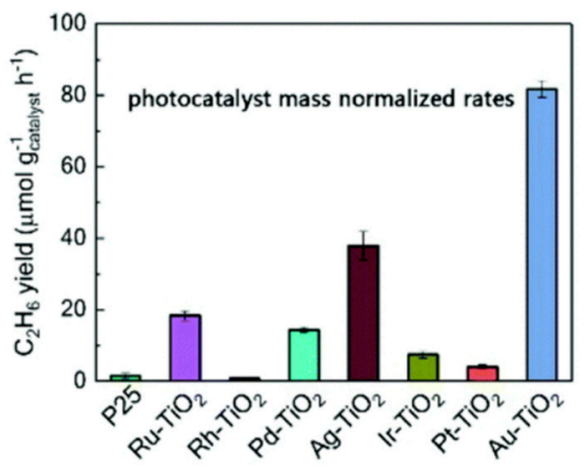

Figure 6. Ethane yield by non-oxidative methane coupling using various metal-loaded $\mathrm{TiO}_{2}$ catalysts. Reproduced from [28] with permission from The Royal Society of Chemistry. 
The interaction between the support and the co-catalyst also affects the catalyst stability. Balázs László et al. performed photocatalytic dry reforming of methane using titanate nanotubes that were modified with $\mathrm{Au}$ and $\mathrm{Rh}$ (Figure 7) [28]. They compared the photocatalytic activities under chopped light irradiation. As a result, the photocatalytic activity decreased in Rh-loaded titanate nanotubes, while it remained almost the same in the case of Au-loaded titanate nanotubes. Our group performed photocatalytic dry reforming of methane using $\mathrm{Rh} / \mathrm{TaON}$, but the catalytic activity remained stable during a similar time to the previous report (Figure 8) [22]. These results strongly suggest that the interaction between the semiconductor and the loaded catalyst is an important factor for stability. This work also implies the difficulty and importance of choosing an appropriate combination of the support and the loaded catalyst.

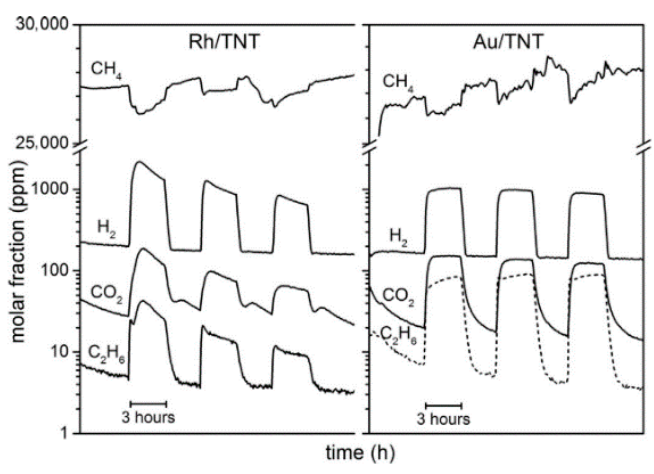

Figure 7. Conversion of methane and the formation of $\mathrm{H}_{2}, \mathrm{CO}$, and $\mathrm{C}_{2} \mathrm{H}_{6}$ with $\mathrm{Rh}$ and $\mathrm{Au}$ loaded on titanate nanotubes (TNT). Reprinted from [29] with permission from Elsevier.

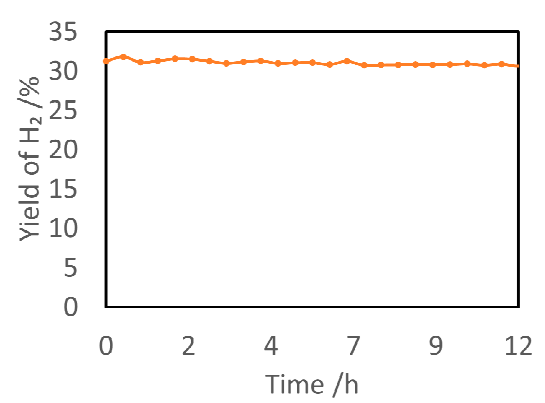

Figure 8. Stability test of $\mathrm{Rh} / \mathrm{TaON}$ performing photocatalytic dry reforming of methane (DRM). Reproduced from [22] with permission from The Royal Society of Chemistry.

This section introduced the photocatalyst design for methane reforming, including semiconductors, loaded co-catalysts, and the interaction between the two. In the next section, we introduce the actual experimental reactors, the reported catalysts, and the analyzed mechanism.

\section{Evaluation System for Photocatalytic Methane Conversion}

In photocatalytic methane reforming, there are many reactor designs [29-33]. Since there are various kinds of evaluation systems that have a strong influence on catalytic activity, it is important to examine the appropriate system before comparing it. A closed reactor was used in some previous reports, which has a longer time for compounds to react. In most cases, flow reactors are used so that gases are continuously renewed [29]. The use of a flow reactor makes it possible to remove products, which prevents unnecessary side reactions.

As the photocatalyst activity is strongly dependent on the irradiation area, some reactors are designed for large irradiation areas, as shown in Figures 9 and 10. One example of the further enhancement of the irradiation area is a monolith photoreactor. A mono- 
lith reactor is defined by a single structure with thin, vertical parallel channels that are separated from each other by walls (Figure 11) [34]. This design is particularly suited for photocatalytic gas reactions because light can penetrate deep inside the reactor; therefore, efficient light absorption is possible. In addition, an improved sorption process and larger catalyst loading can make the catalytic activity relatively high $[31,35,36]$.

A reactor that can measure surface temperature is shown in Figure 12. As the surface temperature increases when light is irradiated, the surface temperature data are important. It is also noted that the comparison of the catalysis performance between each report is extremely difficult because the degree of the photo-thermal effect is different in each report. As the surface temperature increases, the catalyst has a temperature gradient. Some previous studies reported that the temperature gradient affects catalytic properties [37]. Furthermore, if the reactor becomes complicated, such as the monolith reactor mentioned above, the comparison between the efficiencies of each material becomes far more difficult.

Quantum efficiency, which is one of the most important values when comparing photocatalyst performance, cannot be simply adapted for evaluation because it does not consider the thermal effects. Quantum efficiency is defined as the charge carriers used to generate products over the input photons. Thus, if there are thermal catalytic products, the value of quantum efficiency can easily be overestimated. It is important to measure the surface temperature at least so that the photothermal effect can be discussed.

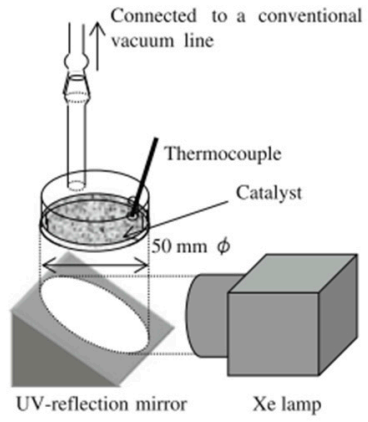

(a)

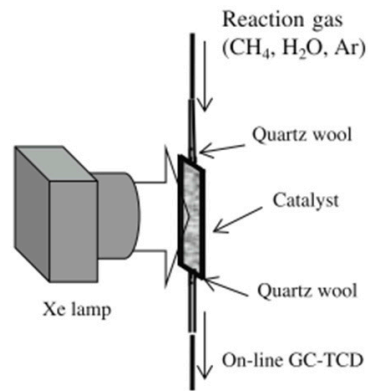

(b)

Figure 9. Example of a reactor for photocatalytic methane reforming: (a) a closed reactor and (b) a flow reactor [29]. Reprinted by permission from [30]. Copyright (2014), Springer Nature. GC-TCD: gas chromatography-thermal conductivity detector.

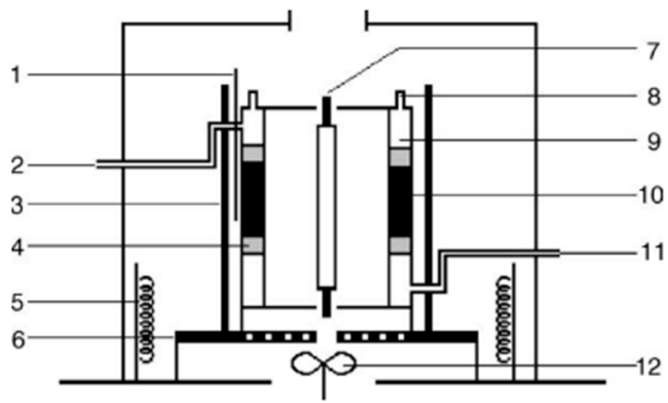

Figure 10. Another reactor design for photocatalytic methane reforming: (1) thermocouple, (2) gas outlet, (3) aluminum foil, (4) sieve plate, (5) heater, (6) graphite plate, (7) mercury lamp, (8) catalyst inlet, (9) quartz reactor, (10) catalyst bed, (11) gas inlet, and (12) fan [32]. Reprinted from [33], with permission from Elsevier. 


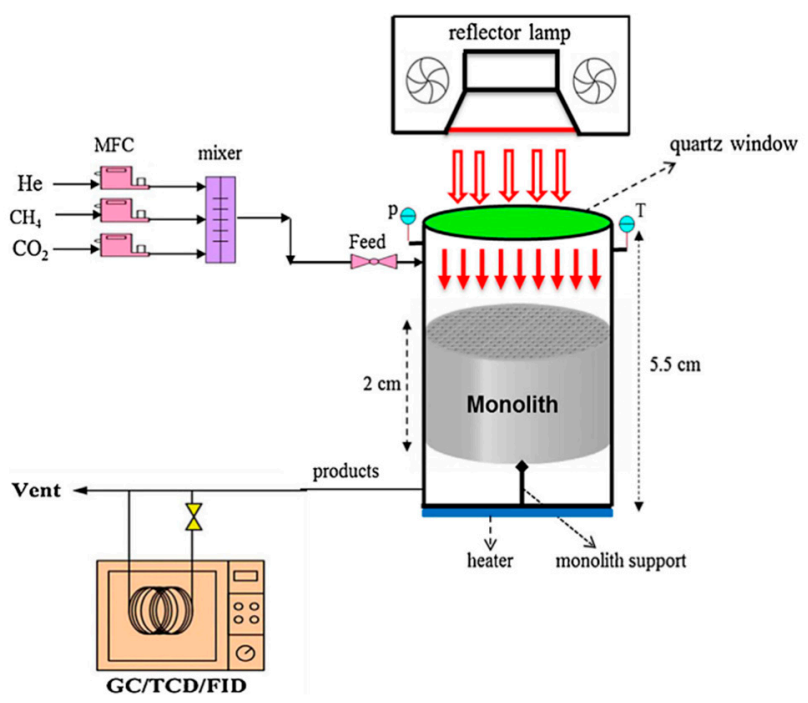

Figure 11. Monolith reactor used in photocatalytic methane reforming. Light can be irradiated deep into the reactor [31]. Reprinted from [32], with permission from Elsevier. FID: flame ionization detector, MFC: mass flow controller.

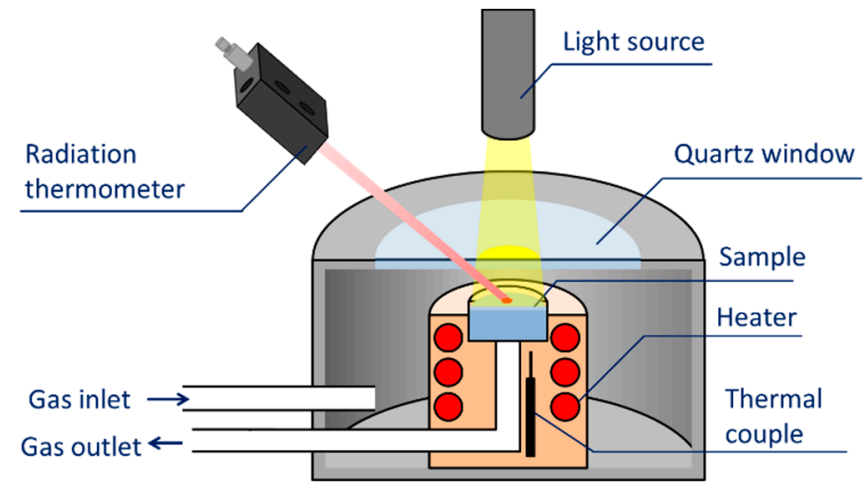

Figure 12. Example of a reactor for photocatalytic methane reforming. The heater and thermocouple are equipped and the surface temperature is also measured [22].

\section{Photocatalytic Steam Reforming of Methane}

\subsection{Overview of the Reaction}

SRM is a favorable reaction for producing $\mathrm{H}_{2}$ because $\mathrm{H}_{2}$ can be produced from both methane and water. The amount of hydrogen produced per methane is higher than that produced by the other methane-reforming reactions. The disadvantage is that the reaction produces not only $\mathrm{CO}$ but also $\mathrm{CO}_{2}$, as shown in Equations (1) and (2) in Section 1. The selectivity of the reaction is a major problem in SRM.

\subsection{Material}

Titanium dioxide $\left(\mathrm{TiO}_{2}\right)$, one of the most investigated photocatalysts, has been used by many researchers $[38,39]$. Although its photocatalysis ability was found in 1972 , even pristine $\mathrm{TiO}_{2}$ has high photocatalytic activity, low cost, abundant material, and nontoxic elements. Thus, it is also employed in various types of methane reforming.

Yoshida et al. loaded platinum onto $\mathrm{TiO}_{2}$ and performed steam reforming of methane (Table 2) [40]. In their reaction, only trace amounts of carbon monoxide were observed and the ratio of $\mathrm{H}_{2} / \mathrm{CO}_{2}$ was close to 4 , which means that the reaction proceeded according to Equation (2). It should be noted that they performed experiments where the amount of methane was $50 \%$ and water was around $1.5 \%$. 
Table 2. Comparison of $\mathrm{H}_{2}$ production rate using Pt-loaded and unloaded $\mathrm{TiO}_{2}$. Reprinted with permission from [40]. Copyright (2008), American Chemical Society.

\begin{tabular}{cccc}
\hline Entry & Catalyst & Feed Gas $^{\mathbf{a}}$ & $\mathbf{H}_{\mathbf{2}}$ Production $^{\text {Rate }}{ }^{\mathbf{b}}\left(\mu \mathbf{m o l ~ m i n}^{-\mathbf{1}}\right)$ \\
\hline 1 & $\mathrm{TiO}_{2}$ & $\mathrm{H}_{2} \mathrm{O}$ & n.d. \\
2 & - & $\mathrm{CH}_{4}$ & n.d. \\
3 & - & $\mathrm{H}_{2} \mathrm{O}+\mathrm{CH}_{4}$ & 0.004 \\
4 & $\mathrm{Pt}_{\mathrm{M}}(0.1) / \mathrm{TiO}_{2}$ & $\mathrm{H}_{2} \mathrm{O}$ & n.d. \\
5 & - & $\mathrm{CH}_{4}$ & $0.063^{\mathrm{c}}$ \\
6 & - & $\mathrm{H}_{2} \mathrm{O}+\mathrm{CH}_{4}$ & $0.76^{\mathrm{d}}$ \\
\hline
\end{tabular}

\footnotetext{
${ }^{\text {a }}$ Feed gas composition was $50 \%$ for $\mathrm{CH}_{4}$ and $1.6 \%$ for $\mathrm{H}_{2} \mathrm{O}$ with an $\mathrm{Ar}$ carrier. Total flow rate was $30 \mathrm{~mL} \mathrm{~min}^{-1}$. ${ }^{\mathrm{b}} \mathrm{H}_{2}$ production rate was the value after $6 \mathrm{~h}$ upon photoirradiation when it became almost constant. n.d.: not detected. ${ }^{\mathrm{c}} \mathrm{C}_{2} \mathrm{H}_{6}\left(0.031 \mu \mathrm{mol} \mathrm{min}{ }^{-1}\right)$ was also produced. ${ }^{\mathrm{d}} \mathrm{CO}_{2}$ $\left(0.18 \mu \mathrm{mol} \mathrm{min}{ }^{-1}\right), \mathrm{C}_{2} \mathrm{H}_{6}(0.014 \mu \mathrm{mol} \mathrm{min}-1)$, and $\mathrm{CO}\left(\mathrm{ca} .0 .003 \mu \mathrm{mol} \mathrm{min}{ }^{-1}\right)$ were also produced.
}

Yoshida et al. also reported that SRM could be driven by irradiating light on Pt-loaded La-doped $\mathrm{NaTaO}_{3}$ at room temperature (Table 3) [23]. They optimized various parameters, such as the crystallite size of $\mathrm{NaTaO}_{3}$, doping element, doping amount of the element, surface area loading of the co-catalyst, and its amount. They found that the optimal element to be doped is $\mathrm{La}$, to be loaded is $\mathrm{Pt}$, and the optimal amount for Pt onto $\mathrm{NaTaO}_{3}: \mathrm{La}(2 \%)$ was approximately $0.1 \%$.

Table 3. Result of photocatalytic reaction over various samples. Reprinted with permission from [23]. Copyright (2010), American Chemical Society.

\begin{tabular}{|c|c|c|c|c|c|c|c|}
\hline \multirow{3}{*}{ Entry } & \multirow{3}{*}{ Photocatalyst } & \multirow{3}{*}{$S_{\text {BET }}{ }^{a}\left(m^{2} g^{-1}\right)$} & \multirow{3}{*}{$D^{b}(n m)$} & \multicolumn{4}{|c|}{ Production Rate $\left(\mu \mathrm{mol} \min ^{-1}\right)$} \\
\hline & & & & \multirow{2}{*}{$\begin{array}{c}\text { Feed Gas } \\
\text { Product }\end{array}$} & \multirow{2}{*}{$\begin{array}{c}\mathrm{H}_{2} \mathrm{O} \\
\mathrm{H}_{2}\end{array}$} & \multicolumn{2}{|c|}{$\mathrm{H}_{2} \mathrm{O}+\mathrm{CH}_{4}$} \\
\hline & & & & & & $\mathbf{H}_{2}$ & $\mathrm{CO}_{2}$ \\
\hline 1 & $\mathrm{NaTaO}_{3}: \mathrm{La}_{C}(2 \%)^{\mathrm{c}}$ & 3.6 & 50 & - & 0.08 & 0.21 & $-d$ \\
\hline 2 & $\mathrm{NaTaO}_{3}: \mathrm{La}_{\mathrm{BM}}(2 \%)^{\mathrm{c}}$ & 1.9 & 62 & - & 0.12 & 0.29 & $-d$ \\
\hline 3 & $\mathrm{Pt}(0.1) / \mathrm{NaTaO}_{3}: \mathrm{La}_{C}(2 \%)^{\mathrm{c}, \mathrm{e}}$ & - & - & - & 0.00 & 1.5 & 0.39 \\
\hline 4 & $\mathrm{Pt}(0.05) / \mathrm{NaTaO}_{3}: \mathrm{La}_{\mathrm{BM}}(2 \%)^{\mathrm{c}, \mathrm{e}}$ & - & - & - & - & 1.8 & 0.46 \\
\hline 5 & $\mathrm{NiO}(0.2) / \mathrm{NaTaO}_{3}: \mathrm{La}_{C}(2 \%)^{\mathrm{c}}$ & - & - & - & 0.16 & 0.18 & $-f$ \\
\hline 6 & $\mathrm{Pt}(0.1) / \mathrm{TiO}_{2}{ }^{\mathrm{c}, \mathrm{g}}$ & 335 & - & - & 0.00 & 0.76 & 0.18 \\
\hline 7 & $\mathrm{NaTaO}_{3 \mathrm{BM}}{ }^{\mathrm{c}}$ & 0.67 & 58 & - & - & 0.06 & $-\mathrm{f}$ \\
\hline 8 & $\mathrm{KTaO}_{3 \mathrm{BM}}{ }^{\mathrm{c}}$ & 1.5 & 58 & - & - & 0.04 & $-f$ \\
\hline 9 & $\mathrm{LiTaO}_{3 \mathrm{BM}}{ }^{\mathrm{c}}$ & 0.48 & 57 & - & - & 0.02 & $-f$ \\
\hline 10 & $\operatorname{Pt}(0.01) \mathrm{KTaO}_{3}: \mathrm{La}_{\mathrm{BM}}(2 \%){ }^{\mathrm{c}, \mathrm{h}}$ & 5.1 & 58 & - & - & 0.28 & $-d$ \\
\hline 11 & $\mathrm{Pt}(0.03) / \mathrm{NaTaO}_{3}: \mathrm{La}_{\mathrm{BM}}(2 \%) \mathrm{e}^{\mathrm{e}, \mathrm{i}}$ & - & - & - & 0.00 & 4.5 & 1.2 \\
\hline
\end{tabular}

\footnotetext{
a BET specific surface area. ${ }^{\mathrm{b}}$ Crystallite diameter calculated from X-ray diffraction line at $22.8^{\circ}$ for $\mathrm{NaTaO}_{3}, 31.7^{\circ}$ for $\mathrm{KTaO}_{3}$ and $23.8^{\circ}$ for $\mathrm{LiTaO}_{3}$, respectively. ${ }^{\mathrm{c}}$ The light intensity measured in the range of $230-280 \mathrm{~nm}$ was $14 \mathrm{~mW} \mathrm{~cm}{ }^{-2}$. The feed gas was $\mathrm{H}_{2} \mathrm{O}(1.5 \%)$ or a mixture of $\mathrm{H}_{2} \mathrm{O}(1.5 \%)$ and $\mathrm{CH}_{4}(50 \%)$ with an $\mathrm{Ar}$ carrier. The total flow rate was $50 \mathrm{~mL} \mathrm{~min}^{-1}$. The amount of the catalyst used for filling up the reaction cell was $0.6 \mathrm{~g}$ for $\mathrm{Pt} / \mathrm{TiO}_{2}$ and $1.0 \mathrm{~g}$ for others. In the latter case, the catalyst was diluted with quartz granules $(0.8 \mathrm{~g}) .{ }^{\mathrm{d}} \mathrm{A}$ trace amount of $\mathrm{CO}_{2}$ was produced, which was lower than $0.08 \mu \mathrm{mol} \mathrm{min}{ }^{-1}$. ${ }^{\mathrm{e}} \mathrm{Pt}$ was loaded by impregnation method using $\mathrm{Pt}\left(\mathrm{NO}_{2}\right)_{2}\left(\mathrm{NH}_{3}\right)_{2}$ precursor followed by calcination and $\mathrm{H}_{2}$ reduction at $773 \mathrm{~K} .{ }^{\mathrm{f}} \mathrm{CO}_{2}$ was not detected. ${ }^{\mathrm{g}} \mathrm{Pt} / \mathrm{TiO} \mathrm{O}_{2}$ was prepared from $\mathrm{TiO}{ }_{2}$ (JRC-TIO-8) and an aqueous $\mathrm{H}_{2} \mathrm{PtCl}_{6}$ solution with $50 \%$ methanol by photodeposition method. ${ }^{\mathrm{h}} \mathrm{Pt}$ was loaded by impregnation method using $\mathrm{Pt}\left(\mathrm{NO}_{2}\right)_{2}\left(\mathrm{NH}_{3}\right)_{2}$ precursor followed by calcination at $773 \mathrm{~K}$ and $\mathrm{H}_{2}$ reduction at $573 \mathrm{~K}$. ${ }^{\mathrm{i}}$ The light intensity measured in the range of 230-280 nm was $116 \mathrm{~mW} \mathrm{~cm}{ }^{-2}$. The feed gas was $\mathrm{H}_{2} \mathrm{O}(1.0 \%)$ or a mixture of $\mathrm{H}_{2} \mathrm{O}(1.0 \%)$ and $\mathrm{CH}_{4}(10 \%)$ with an Ar carrier. The total flow rate was $50 \mathrm{~mL} \mathrm{~min}^{-1}$. The catalyst $(1.0 \mathrm{~g})$ was diluted with quartz granules $(0.8 \mathrm{~g})$.
}

Other than loading $\mathrm{Pt}$, Yoshida et al. incorporated potassium as an alkaline element and fabricated $\mathrm{Rh} / \mathrm{K}_{2} \mathrm{Ti}_{6} \mathrm{O}_{13}$ [24]. The catalytic activity of $\mathrm{Rh} / \mathrm{K}_{2} \mathrm{Ti}_{6} \mathrm{O}_{13}$ was comparable with that of $\mathrm{Pt} / \mathrm{NaTaO}_{3}$ mentioned above. They prepared samples using various methods and found that photodeposition was the best. 


\subsection{Mechanism of the Reaction}

In the paper by Shimura et al., the band structure of $\mathrm{K}_{2} \mathrm{Ti}_{6} \mathrm{O}_{13}$ combined with $\mathrm{Rh}$ metal and $\mathrm{Rh}_{2} \mathrm{O}_{3}$ was demonstrated [24]. They found that their samples consisted of metal state $\mathrm{Rh}$ and $\mathrm{Rh}_{2} \mathrm{O}_{3}$, which was shown using X-ray absorption near-edge structure (XANES) analysis. Thus, they described the schematic view of the movement of excited carriers, as shown in Figure 13.

Intermediates in photocatalytic SRM have also been discussed. Pale brown species were found on $\mathrm{Pt} / \mathrm{TiO}_{2}$, which was determined to be $\left[\mathrm{CH}_{2} \mathrm{O}\right]_{n}$ by Yoshida et al. [40]. They first performed photocatalytic SRM, and when the reaction became stable, i.e., the $\mathrm{H}_{2} / \mathrm{CO}_{2}$ ratio became the stoichiometric ratio of 4, they stopped supplying $\mathrm{CH}_{4}$ into their reactor, while they continued to introduce water (Figure 14). They observed pale brown species only when SRM gas was introduced, but it was consumed when water alone was introduced. Only $\mathrm{H}_{2}$ and $\mathrm{CO}_{2}$ were observed as the output gas. They recognized that the pale brown species were composed of only carbon, hydrogen, and oxygen. Combining the results of the products obtained, they determined the intermediate to be $\left[\mathrm{CH}_{2} \mathrm{O}\right]_{n}$. The consumption of $\left[\mathrm{CH}_{2} \mathrm{O}\right]_{n}$ is described in Equation (8):

$$
\left[\mathrm{CH}_{2} \mathrm{O}\right]_{n, \mathrm{ad}}+\mathrm{nH}_{2} \mathrm{O} \rightarrow 2 \mathrm{nH}_{2}+\mathrm{nCO}_{2} \text {. }
$$

They also experimented with changing the input gas concentration $(10 \% \rightarrow 50 \% \rightarrow 10 \%)$ (Figure 15). They found that at the first step, there was a low $\mathrm{H}_{2}$ production rate, but after reacting at $50 \%$, the production rate of $\mathrm{H}_{2}$ increased significantly, even though the same concentration of $\mathrm{CH}_{4}$ was fed. This phenomenon was attributed to the accumulation of the intermediate.

(A)

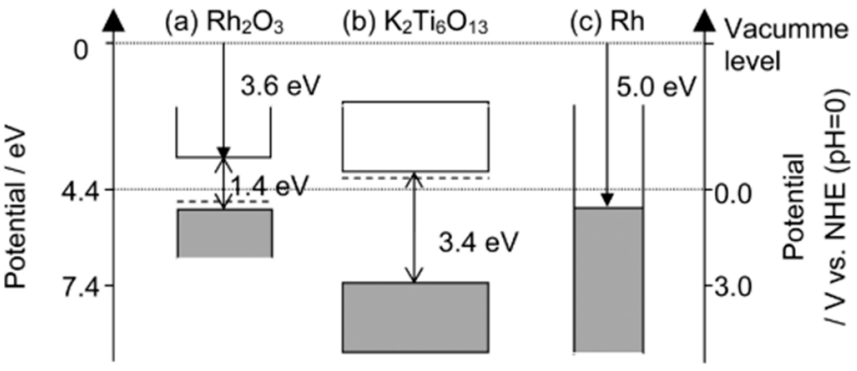

(B)

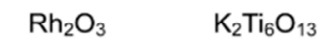

Rh

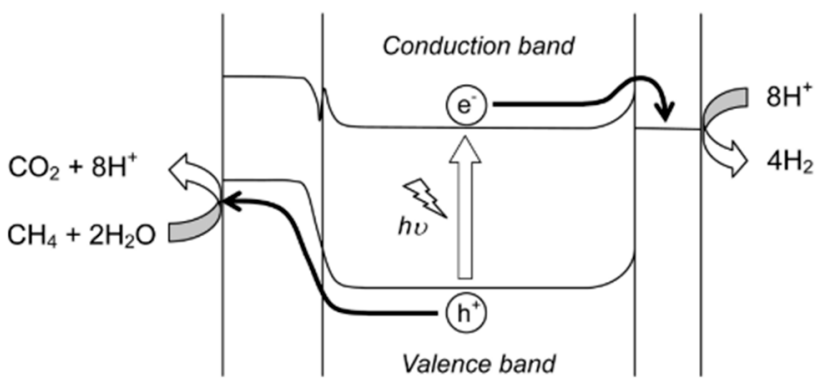

Figure 13. (A) Band structure of (a) $\mathrm{Rh}_{2} \mathrm{O}_{3}$, (b) $\mathrm{K}_{2} \mathrm{Ti}_{6} \mathrm{O}_{13}$, and (c) rhodium metal, and (B) the proposed mechanism of the photocatalytic steam reforming of methane over $\mathrm{Rh} / \mathrm{Rh}_{2} \mathrm{O}_{3} / \mathrm{K}_{2} \mathrm{Ti}_{6} \mathrm{O}_{13}$. Reprinted with permission from [24]. Copyright (2012), American Chemical Society. NHE: normal hydrogen electrode. 


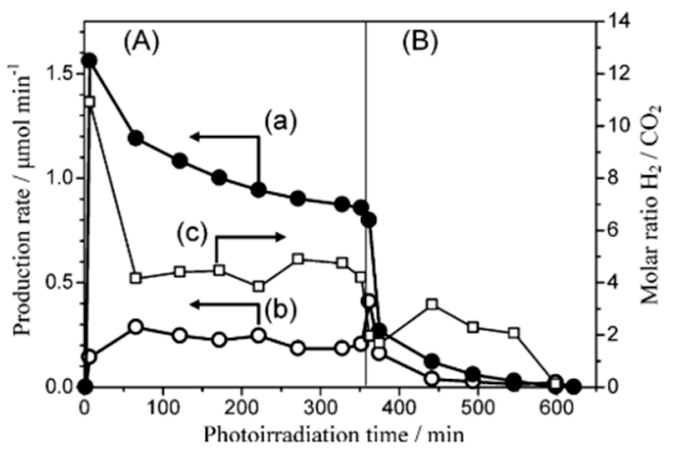

Figure 14. Production rates of (a) $\mathrm{H}_{2}$, (b) $\mathrm{CO}_{2}$, and a molar ratio of (c) $\mathrm{H}_{2} / \mathrm{CO}_{2}$, where the input gas was (A) $\mathrm{CH}_{4}(50 \%)+\mathrm{H}_{2} \mathrm{O}(1.6 \%)$ and $(\mathbf{B}) \mathrm{H}_{2} \mathrm{O}(1.6 \%)$. Reprinted with permission from [40]. Copyright (2008), American Chemical Society.

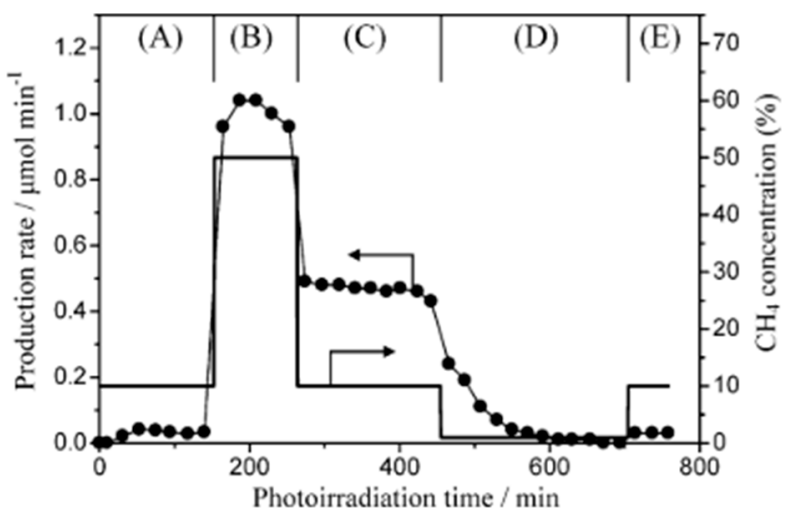

Figure 15. Time course of the production rate of $\mathrm{H}_{2}$ with the methane concentration controlled to be (A) 10\%, (B) 50\%, (C) 10\%, (D) 0\%, (E) 10\%. Reprinted with permission from [40]. Copyright (2008), American Chemical Society.

Regarding the mechanism of photocatalytic SRM, Yoshida et al. examined the temperature dependence of the catalytic activity and investigated the Arrhenius plot (Figure 17) [23]. Figure 16 indicates that below $348 \mathrm{~K}$, the amount of $\mathrm{H}_{2}$ produced increases as the temperature increases. The apparent activation energy was calculated to be $14 \mathrm{~kJ} \mathrm{~mol}^{-1}$, which is far smaller than the reported value of other thermal systems $\left(122 \mathrm{~kJ} \mathrm{~mol}^{-1}\right.$ using a Pt catalyst). This small activation energy should be different from the thermal catalysis mechanism of the SRM. At a temperature higher than $348 \mathrm{~K}$, the hydrogen production rate was constant versus temperature, which was explained by noting that only the photocatalytic reaction step exists in this region.

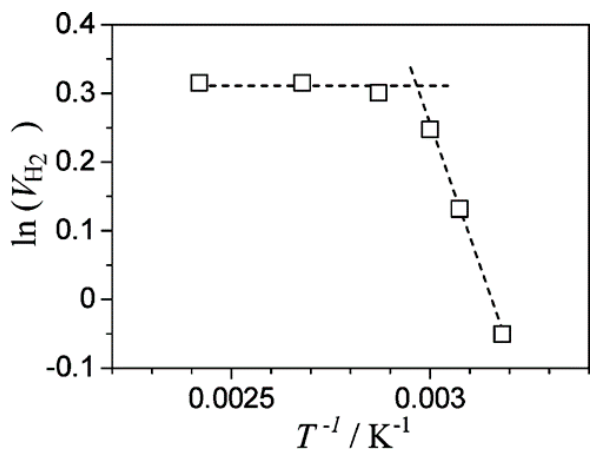

Figure 16. Arrhenius plot constructed using the production rate of $\mathrm{H}_{2}$. Reprinted with permission from [23]. Copyright (2010), American Chemical Society. 


\section{Photocatalytic Dry Reforming of Methane (DRM)}

\subsection{Overview of the Reaction}

Although the DRM reaction is attractive because it can use $\mathrm{CO}_{2}$ as a resource to produce syngas, DRM is the most difficult among the methane-reforming reactions, as shown in Figure 1. This difficulty occurs because of the stability of both methane and $\mathrm{CO}_{2}$. Dry reforming also suffers from a process of severe carbon deposition called coking. During the methane-cracking process, the completely cracked methane leaves carbon species on the surface, which can be oxidized and removed by the oxidant. In the case of $\mathrm{CO}_{2}$, it is less likely to be removed than other oxidants, such as $\mathrm{O}_{2}$ or $\mathrm{H}_{2} \mathrm{O}$, which accelerates the carbon deposition $[1,41,42]$. There is even research on mixing oxygen in DRM to prevent carbon deposition.

The side reactions usually discussed are listed (the primary reaction is written in Section 1, Equation (4)):

The water gas shift reaction $\mathrm{CO}_{2}+\mathrm{H}_{2} \rightleftharpoons \mathrm{CO}+\mathrm{H}_{2} \mathrm{O} \quad \Delta H^{\circ}{ }_{298 \mathrm{~K}}=41 \mathrm{~kJ} / \mathrm{mol}$,

Carbon deposition

$$
\mathrm{CH}_{4} \rightarrow \mathrm{C}+2 \mathrm{H}_{2}
$$$$
\Delta H^{\circ} 298 \mathrm{~K}=74.9 \mathrm{~kJ} / \mathrm{mol} \text {. }
$$

\subsection{Material}

As early as 2004, Daxin Shi et al. used a complicated material of $\mathrm{Cu} / \mathrm{CdS}-\mathrm{TiO}_{2} / \mathrm{SiO}_{2}$ to perform DRM. They observed a $1.47 \% \mathrm{CH}_{4}$ conversion, a $0.74 \% \mathrm{CO}_{2}$ conversion, and the selectivity of the acetone was 92.3\% (Figure 17, Table 4) [32]. Although they could successfully convert methane and carbon dioxide into acetone, the conversion became zero in approximately $2 \mathrm{~h}$. They attributed this to the photo-corrosion of CdS that was promoted by $\mathrm{TiO}_{2}$.

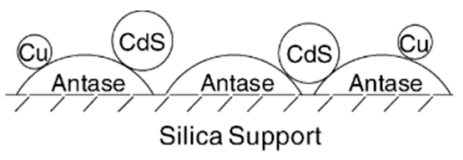

Figure 17. Illustrated material fabricated by Shi et al. Reprinted from [33], Copyright (2004), with permission from Elsevier.

Table 4. Photocatalytic conversion of methane and carbon dioxide over the catalyst in Figure 17. Reprinted from [33], Copyright (2004), with permission from Elsevier.

\begin{tabular}{ccccccc}
\hline \multirow{2}{*}{ Temperature $\left({ }^{\circ} \mathbf{C}\right)$} & \multicolumn{5}{c}{ Conversion $(\%)$} \\
\cline { 2 - 7 } & $\mathbf{C O}_{\mathbf{2}}$ & $\mathbf{C H}_{\mathbf{4}}$ & $\mathbf{C H}_{3} \mathbf{C O O H}$ & $\mathbf{C H}_{3} \mathbf{C H}_{3}$ & $\mathbf{C H}_{3} \mathbf{C O C H}_{3}$ & $\mathbf{C O}$ \\
\hline 30 & 0 & 0 & - & - & - & - \\
80 & 0.07 & 0.11 & - & 46.7 & 0 & 53.3 \\
120 & 0.74 & 1.47 & Trace & 3.1 & 92.3 & 4.6 \\
150 & 0.79 & 1.54 & Trace & 7.5 & 87.6 & 4.9 \\
\hline
\end{tabular}

Reaction conditions $=1 \mathrm{~atm}, \mathrm{CO} 2 / \mathrm{CH} 4=1 / 1$ (molar ratio), $\mathrm{UV}$ intensity $=20.0 \mathrm{~mW} \mathrm{~cm}^{-2}$, space velocity $=200 \mathrm{~h}^{-1}$.

As for bare photocatalysts, Wibowo et al. reported in 2018 that DRM was assisted by photon energy [43]. Employing each of $\mathrm{SrTiO}_{3}, \mathrm{TiO}_{2}, \mathrm{WO}_{3}$, and $\mathrm{SnO}_{2}$ as a photocatalyst, they found that the amount of $\mathrm{CO}$ observed significantly increased when only $\mathrm{SrTiO}_{3}$ was used, as shown in Figure 18. They further compared the activity and band position of the used photocatalyst and found that the conduction band position is an important factor (Figure 19). As $\mathrm{CO}_{2}$ is difficult to reduce in water, this is one reasonable explanation. 


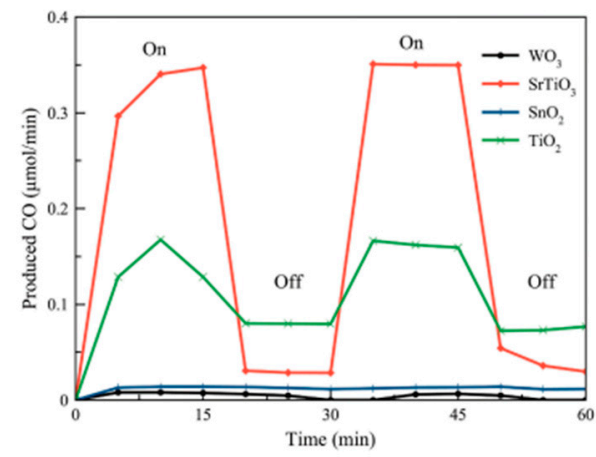

Figure 18. CO generation from a DRM reaction at $700{ }^{\circ} \mathrm{C}$ under UV light irradiation (On) and a dark condition (Off) using various metal oxide catalysts. Reprinted from [43] with permission from The Chemical Society of Japan.

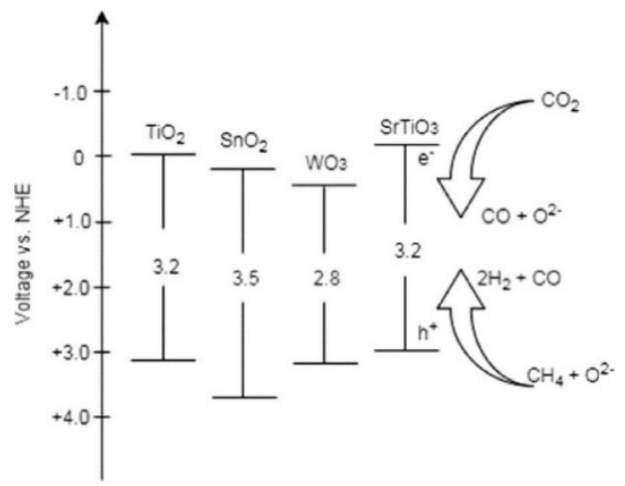

Figure 19. Schematic diagram of the band structure of each catalyst and CO production mechanism during a photocatalytic DRM reaction. Reprinted from [43] with permission from The Chemical Society of Japan.

The bare $\mathrm{MgO}$ insulator exhibited photocatalytic DRM activity, according to Teramura et al. [44]. To elucidate why $\mathrm{MgO}$ proceeds under light irradiation, they obtained a phosphorescence-exciting spectrum with and without the flow of $\mathrm{CO}_{2}$ (Figure 20A). As a result, they found a characteristic peak at $320 \mathrm{~nm}$, which can be assigned to the absorption due to a new acceptor level built between the valence band and conduction band. The yield of carbon monoxide is shown in Figure 20B. The rate of CO production decreased from $30 \mathrm{~h}$ onward.
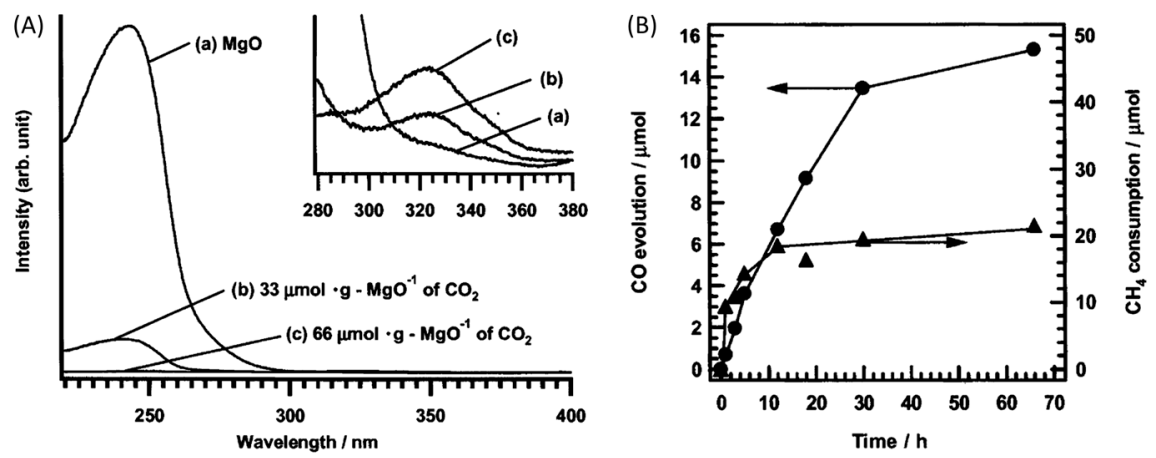

Figure 20. (A) Phosphorescence exciting spectra of MgO. (B) Time course of the CO yield and $\mathrm{CH}_{4}$ consumption over MgO. Reprinted with permission from [44]. Copyright (2004), American Chemical Society. 
Shoji et al. used rhodium metal as a co-catalyst for photocatalytic DRM because it is one of the most studied thermal DRM catalysts [30]. They compared dark conditions, UV light irradiation conditions, and thermodynamic limits calculated using the chemical equilibrium (Figure 21). As a matter of course, the catalytic activity did not surmount the limitation of the thermal system, but with UV light irradiation, methane and $\mathrm{CO}_{2}$ were effectively converted to $\mathrm{H}_{2}$ and $\mathrm{CO}$, even at $100{ }^{\circ} \mathrm{C}$.

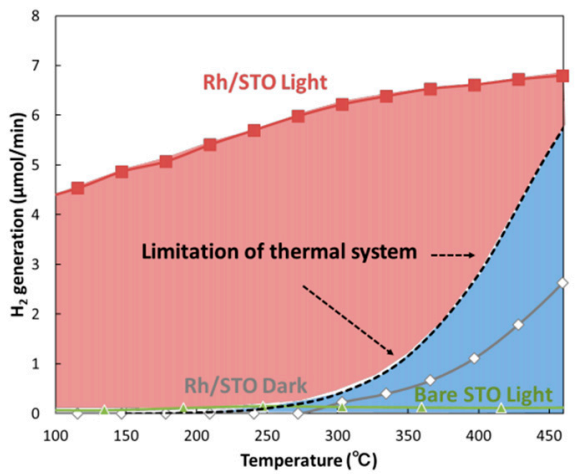

Figure 21. Photocatalytic activity of UV light-irradiated $\mathrm{Rh} / \mathrm{SrTiO}_{3}$. The reaction was DRM. Reprinted from [30]. STO: $\mathrm{SrTiO}_{3}$.

For a co-catalyst other than a noble metal, $\mathrm{Ti}_{3} \mathrm{AlC}_{2}$ was proposed by Tahir et al. for deposition onto $\mathrm{TiO}_{2}$ [36]. $\mathrm{Ti}_{3} \mathrm{AlC}_{2}$ is a piled structure made of graphite-like layers that has good electron transport characteristics. They performed dry reforming of methane, steam reforming of methane, and methane bi-reforming (Figure 22). They claimed in their paper that the conversion was high due to the electron conductivity of $\mathrm{Ti}_{3} \mathrm{AlC}_{2}$. In addition, this is the first attempt at utilizing $\mathrm{Ti}_{3} \mathrm{AlC}_{2}$ in photocatalytic reactions.

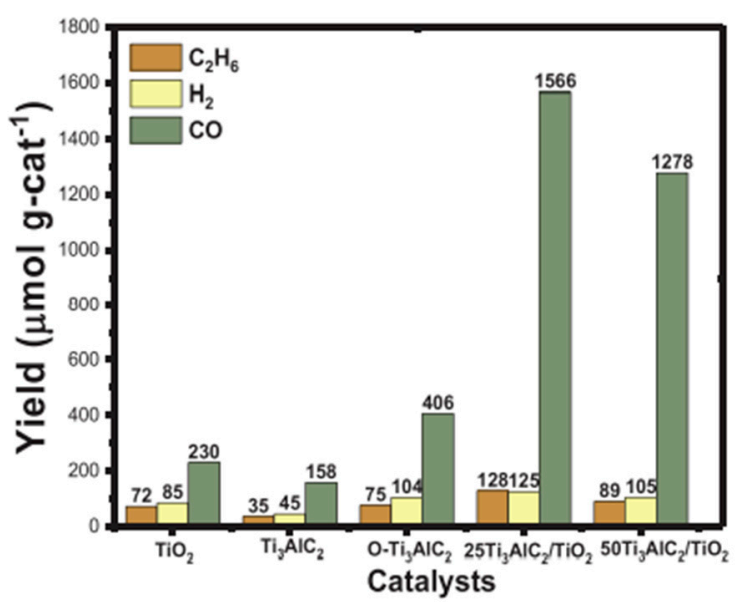

Figure 22. Effect of $\mathrm{Ti}_{3} \mathrm{AlC}_{2}$ loading on the performance of $\mathrm{TiO}_{2}$ for photocatalytic dry reforming of methane. Copyright (2020), reprinted from [36] with permission from Elsevier.

Employing $\mathrm{CeO}_{2}$ in photocatalytic methane reforming is promising because $\mathrm{CeO}_{2}$ is known to have many oxygen vacancies, which provides various merits in catalytic activity [45]. Pan et al. doped zinc ions into $\mathrm{CeO}_{2}$ and loaded $\mathrm{Pt}$, and finally coated it with atomic layer $\mathrm{MgO}$ (Figure 23) [46]. They focused on photocatalytic DRM, but they claimed that both the input of photon energy and thermal energy boosted the conversion. The strategy of doping zinc and coating the $\mathrm{MgO}$ atomic layer is beneficial in both thermocatalytic and photocatalytic DRM. As for the thermocatalytic viewpoint, $\mathrm{MgO}$ has a high affinity for $\mathrm{CO}_{2}$ and promotes reverse $\mathrm{CO}$ disproportionation. From a photocatalytic viewpoint, zinc can create localized band states and $\mathrm{MgO}$ can passivate the surface states of $\mathrm{CeO}_{2}$, 
which act as recombination centers. The optimized $\mathrm{Zn} / \mathrm{Ce}$ molar ratio and atomic layer deposition cycles of $\mathrm{MgO}$ and the ground were 0.10 and 5 cycles, respectively (Figure 24).

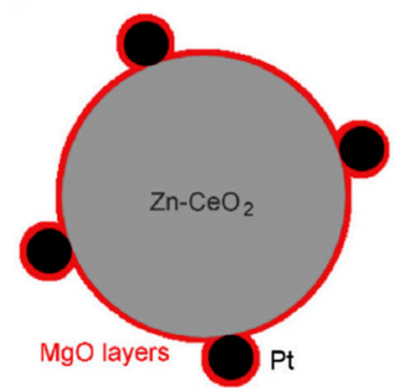

Figure 23. Illustration of the photocatalyst used by Pan et al. Copyright (2020), reprinted from [46] with permission from Elsevier.
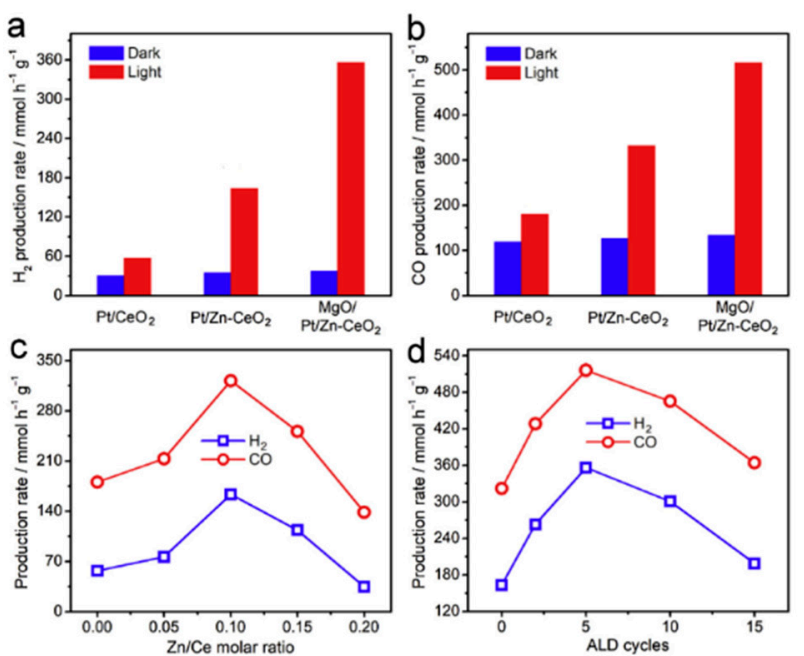

Figure 24. Photocatalytic activity of the material that is described in Figure 24 and the references. (a) $\mathrm{H}_{2}$ and (b) $\mathrm{CO}$ production rates at $600{ }^{\circ} \mathrm{C}$ in the dark and light irradiated condition. Molar ratio optimization of Zn-Ce is shown in (c), and the time of ALD cycles optimization is shown in (d). Copyright (2020), reprinted from [46] with permission from Elsevier. ALD: atomic layer deposition.

Moreover, they found that light-illuminated DRM has better stability than those without illumination (Figure 25). To elucidate the reason, they performed X-ray photoelectron spectroscopy (XPS) before and after photochemical and thermochemical DRM (Figure 26). As they compared $\mathrm{Ce}^{4+}$ and $\mathrm{Ce}^{3+}$, the concentration of $\mathrm{Ce}^{3+}$ decreased drastically after the test for dark conditions, but for the light-irradiated condition, the ratio remained almost the same. Since $\mathrm{Ce}^{3+}$ indirectly indicates the number of oxygen vacancies, and the number of oxygen vacancies corresponds to the unlikeliness of carbon deposition, it can be concluded that light illumination preserves oxygen vacancies and prevents carbon deposition. This sequence is an important function of light irradiation. 

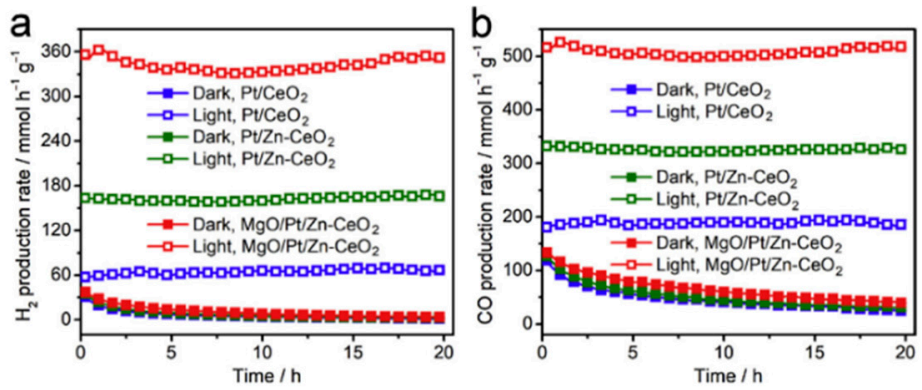

Figure 25. Stability test of DRM using the material described in Figure 23 and the references. The production rates of (a) $\mathrm{H}_{2}$ and (b) CO. Copyright (2020), reprinted from [46] with permission from Elsevier.
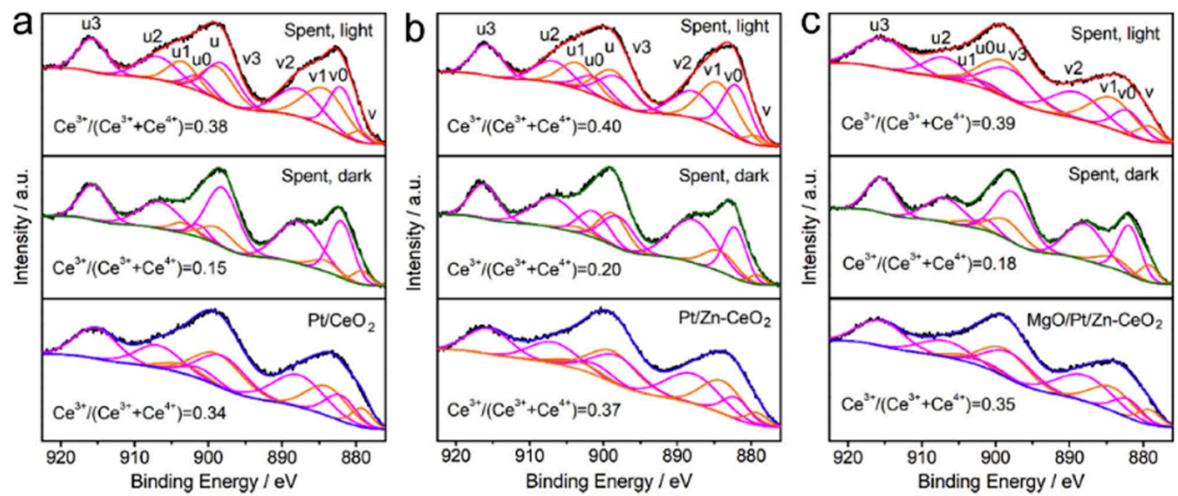

Figure 26. XPS profiles of (a) $\mathrm{Pt} / \mathrm{CeO}_{2}$, (b) $\mathrm{Pt} / \mathrm{Zn}-\mathrm{CeO}_{2}$, and (c) $\mathrm{MgO} / \mathrm{Pt} / \mathrm{Zn}-\mathrm{CeO}_{2}$. Each sample has spent data under dark light conditions and as a prepared sample. The ratio of $\mathrm{Ce}^{3+} /\left(\mathrm{Ce}^{3+}+\mathrm{Ce}^{4+}\right)$ was calculated from the data. Copyright (2020), reprinted from [46] with permission from Elsevier.

Very recently, we found that $\mathrm{Rh} / \mathrm{TaON}$ and $\mathrm{Rh} / \mathrm{Ta}_{3} \mathrm{~N}_{5}$ exhibited efficient activity, both in dark and visible light-irradiated conditions (Figure 27) [22]. As TaON was stable at higher temperatures and had better photocatalytic activity, we focused on $\mathrm{Rh} / \mathrm{TaON}$. The photocatalyst morphology was optimized and it was found that the photocatalyst prepared using the hydrothermal method had the best activity compared with those prepared using the impregnation and photodeposition methods. In addition, the activity was the highest on the $0.68 \mathrm{wt} \% \mathrm{Rh}$ loaded onto $\mathrm{TaON}$, which was prepared by adding $5 \mathrm{wt} \%$ of the precursor.

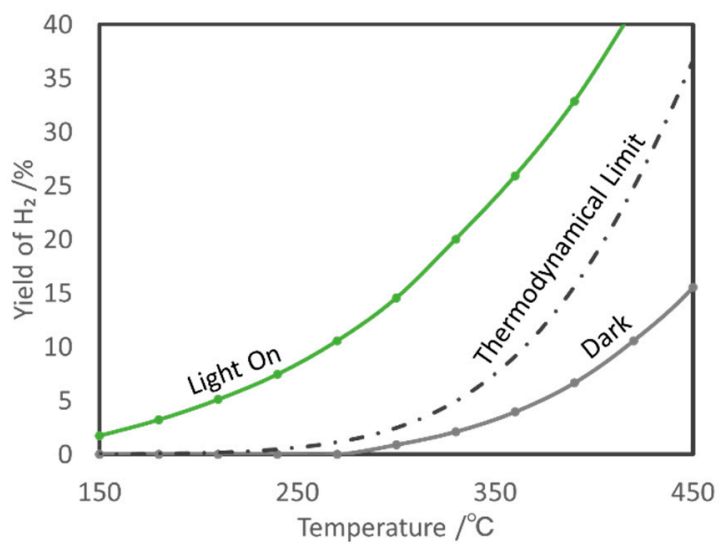

Figure 27. Catalytic activity under dark conditions, photocatalytic activity under visible light irradiated conditions, and thermodynamical limit calculated using the equilibrium [7]. Reproduced from [22] with permission from The Royal Society of Chemistry. 
Tahir et al. modified $\mathrm{TiO}_{2}$ using montmorillonite (MMT) [31]. They utilized MMT because MMT has a good affinity for $\mathrm{TiO}_{2}$ and it is a low-cost, abundant, and environmentally friendly material. Moreover, as MMT has a silicate layer-piled structure, polar molecules, such as water, can diffuse into MMT and expand the layer gap distance. $\mathrm{TiO}_{2}$ intercalates to the enlarged gap space and then silicate layers disperse and a nanocomposite can be produced.

They found in their experiment that the layered structure of MMT was destroyed during the intercalation process. In addition, the modification of $\mathrm{TiO}_{2}$ with $\mathrm{MMT}$ prevented the particle from undergoing crystal growth and resulted in the formation of nanocomposites. Since the crystallite size of $\mathrm{TiO}_{2}$ was small, it was formed by MMT, preventing crystallization. Photocatalytic activity using the photocatalyst is shown in Figure 28. In the first step of the reaction, they observed a significant amount of $\mathrm{C}_{2} \mathrm{H}_{6}$, but it disappeared as time went by. They also observed a small amount of $\mathrm{CH}_{3} \mathrm{OH}$ with a selectivity of less than $5 \%$.
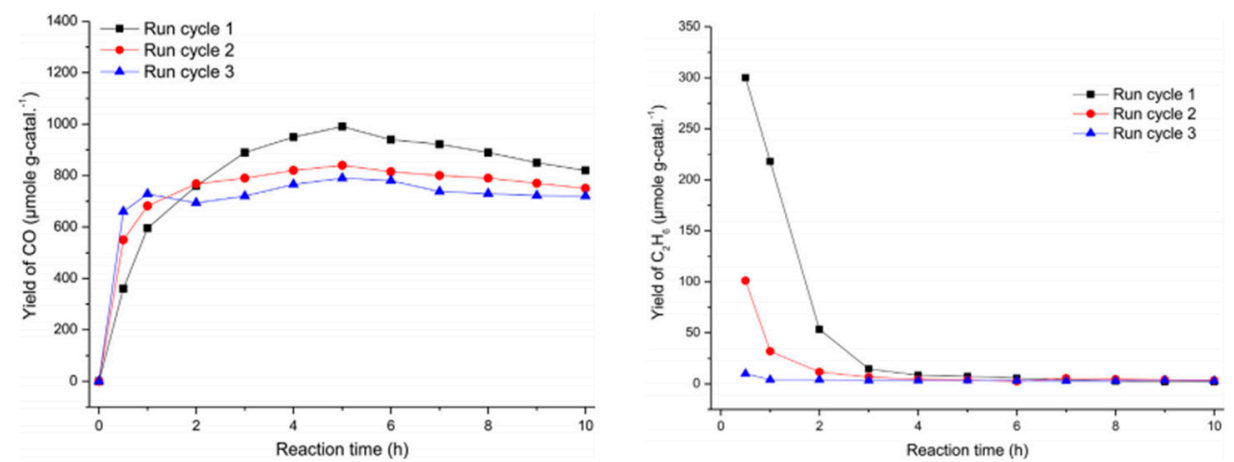

Figure 28. Yield of carbon monoxide and ethane under montmorillonite (MMT)-modified $\mathrm{TiO}_{2}$ performing photocatalytic methane reforming. Copyright (2015), reprinted from [32] with permission from Elsevier.

In 2018, Tahir et al. reported that loading Ni could further enhance the photocatalytic activity of DRM on $\mathrm{MMT} / \mathrm{TiO}_{2}$ [35]. They prepared Ni/MMT-modified $\mathrm{TiO}_{2}$ by adding $\mathrm{Ni}$ and $\mathrm{MMT}$ into a $\mathrm{TiO}_{2}$ sol, dipped it into their reactor, dried it at $110{ }^{\circ} \mathrm{C}$, and calcined it at $500{ }^{\circ} \mathrm{C}$ for $5 \mathrm{~h}$. They found that the yield rate of $\mathrm{CO}$ in photocatalytic DRM increased remarkably (Table 5).

Table 5. Performance of Ni/MMT-modified $\mathrm{TiO}_{2}$ with various loading amounts and references. Copyright (2019), reprinted from [35] with permission from Elsevier. CPSI stands for channels per square inch.

\begin{tabular}{ccc}
\hline \multirow{2}{*}{ Catalyst } & \multicolumn{2}{c}{ Yield Rate $^{\mathbf{a}}\left(\boldsymbol{\mu} \mathbf{m o l}\right.$ g-cat $\left.{ }^{-\mathbf{1}} \mathbf{h}^{-\mathbf{1}}\right)$} \\
\cline { 2 - 3 } & $\mathbf{C O}$ & $\mathbf{C H}_{\mathbf{4}}$ \\
\hline $\mathrm{TiO}_{2}$ & 19 & 0.74 \\
$5 \% \mathrm{MMT} / \mathrm{TiO}_{2}$ & 26 & 1.01 \\
$10 \% \mathrm{MMT} / \mathrm{TiO}_{2}$ & 51 & 1.06 \\
$15 \% \mathrm{MMT} / \mathrm{TiO}_{2}$ & 42 & 1.06 \\
$1 \% \mathrm{Ni}-10 \% \mathrm{MMT} / \mathrm{TiO}_{2}$ & 2236 & 3.69 \\
$3 \% \mathrm{Ni}-10 \% \mathrm{MMT} / \mathrm{TiO}_{2}$ & 3813 & 5.58 \\
$5 \% \mathrm{Ni}-10 \% \mathrm{MMT} / \mathrm{TiO}_{2}$ & 2958 & 4.56 \\
\hline
\end{tabular}

${ }^{\mathrm{a}} \mathrm{T}=100{ }^{\circ} \mathrm{C}$, Irradiation time $=2 \mathrm{~h}, \mathrm{CO}_{2} / \mathrm{H}_{2}$ feed ratio $=1.0$, Flow rate $=20 \mathrm{~mL} / \mathrm{min}, \mathrm{CPSI}=100$.

As our group has explored, $\mathrm{g}-\mathrm{C}_{3} \mathrm{~N}_{4}$ was explored as a light absorber for the DRM photocatalyst. As both carbon and nitrogen are abundant elements and light-weight, visible light-active photocatalysts, there is great merit in photocatalytic DRM. However, there is also a demerit in that $\mathrm{g}-\mathrm{C}_{3} \mathrm{~N}_{4}$ decomposes from 400 to $700{ }^{\circ} \mathrm{C}$ [47]. In addition, when 
analyzing the products, the carbon may come out of the photocatalyst itself. Tahir et al. loaded copper at the weight ratio of $3 \%$ on $g-C_{3} \mathrm{~N}_{4}$ [48]. They reported that there are other hydrocarbon products in addition to the main products, namely, carbon monoxide and hydrogen. At $100{ }^{\circ} \mathrm{C}, \mathrm{C}_{3} \mathrm{H}_{8}$ was observed (Figure 29).
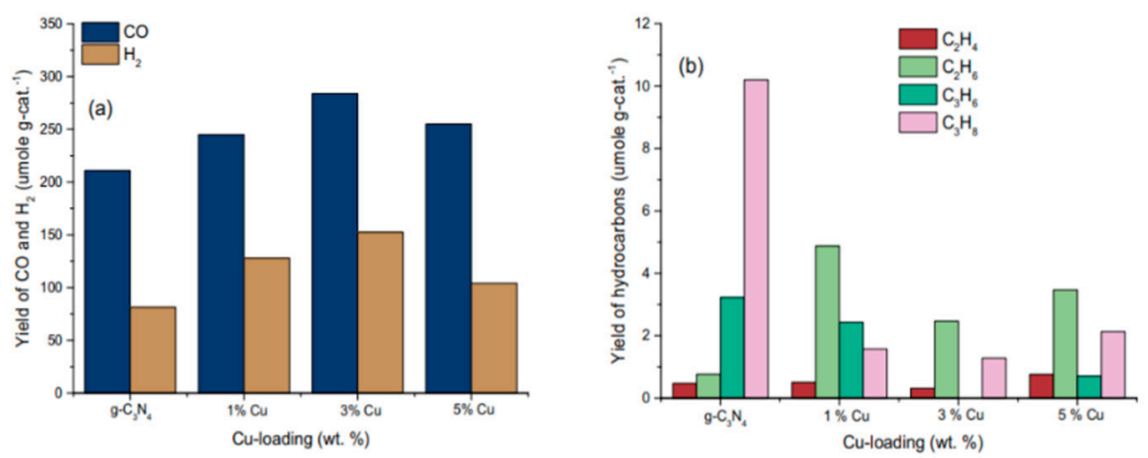

Figure 29. Yield of (a) $\mathrm{CO}$ and $\mathrm{H}_{2}$ and (b) higher hydrocarbons using $\mathrm{Cu} / \mathrm{g}-\mathrm{C}_{3} \mathrm{~N}_{4}$. Copyright (2017), reprinted from [48] with permission from Elsevier.

In 2019, Tahir et al. reported the loading of silver nanoparticles onto protonated g$\mathrm{C}_{3} \mathrm{~N}_{4}$. The formation of $\mathrm{C}_{2} \mathrm{H}_{6}$ and methanol was confirmed [49]. After synthesizing g- $\mathrm{C}_{3} \mathrm{~N}_{4}$ using melamine as a precursor, they protonated the surface by immersing their catalyst into a nitric acid solution. Afterward, silver was deposited on the protonated g- $\mathrm{C}_{3} \mathrm{~N}_{4}$ using the sonication-assisted photodeposition method. They explained in their paper that the significantly increased amount of $\mathrm{CH}_{3} \mathrm{OH}$ produced was caused by reducing protons at the surface of the catalyst. In addition, the reaction follows the equation presented below:

$$
2 \mathrm{CH}_{4}+2 \mathrm{CO}_{2} \rightarrow 3 \mathrm{CO}+2 \mathrm{H}_{2}+\mathrm{CH}_{3} \mathrm{OH} \text {. }
$$

This result not only has the impact of producing methanol at low temperatures but it gives rise to the possibility of a proton becoming an intermediate.

Han et al. used Pt loaded onto black $\mathrm{TiO}_{2}$ to perform photocatalytic DRM [50]. Black $\mathrm{TiO}_{2}$ is a material that includes a high amount of $\mathrm{Ti}^{3+}$ defects and oxygen vacancies, which create interband levels in $\mathrm{TiO}_{2}$. They prepared the sample by reducing Pt-loaded $\mathrm{TiO}_{2}$ (P25, Degussa) at $200^{\circ} \mathrm{C}$ for $24 \mathrm{~h}$ under an atmosphere of $\mathrm{H}_{2}$. The catalytic activity obtained shows that when light was irradiated onto the sample, the catalytic activity was much higher at $400{ }^{\circ} \mathrm{C}$ (Figure 30). They explained why the redox potential changed when heat was input into their system (Figure 31). At $25^{\circ} \mathrm{C}, \mathrm{CO}_{2}$ cannot be reduced by $\mathrm{TiO}_{2}$ because the redox potential is more negative, but at higher temperatures, the potential decreases, which enables the photocatalytic DRM to proceed. It was noted that the yields of $\mathrm{H}_{2}$ and $\mathrm{CO}$ were almost the same in both the light-illuminated and dark conditions. They also reported almost the same phenomenon using the same material in photocatalytic SRM [51]. 
A

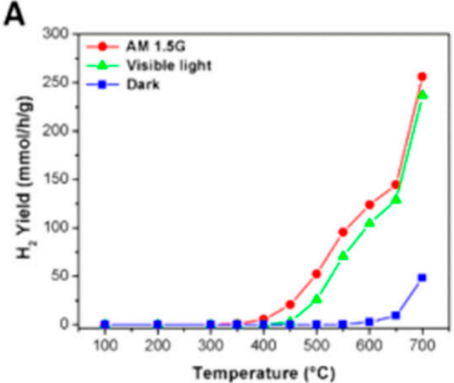

C

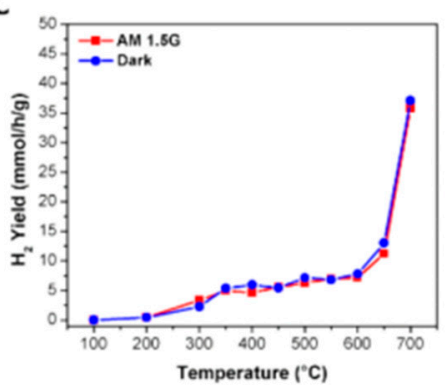

B

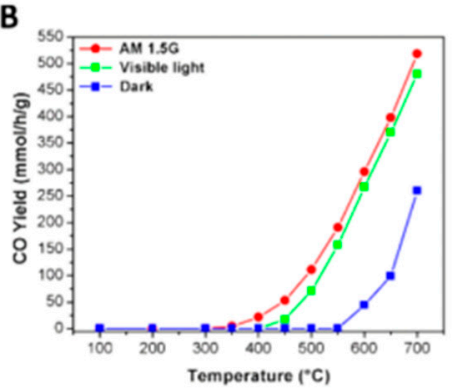

D

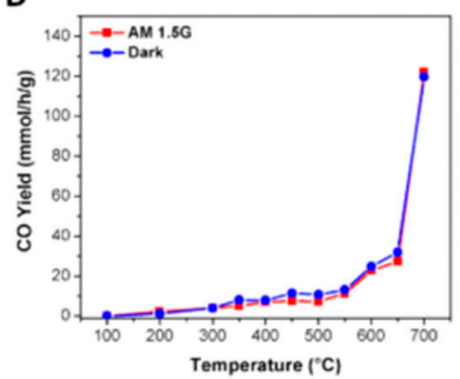

Figure 30. Yield of (A) $\mathrm{H}_{2}$ and (B) CO for DRM using Pt/black $\mathrm{TiO}_{2}$ under AM 1.5G (the global standard spectrum), visible light, and dark conditions, and (C) $\mathrm{H}_{2}$ and (D) CO using $\mathrm{Pt} / \mathrm{Al}_{2} \mathrm{O}_{3}$ as a reference. Reprinted with permission from [50]. Copyright (2015), American Chemical Society.

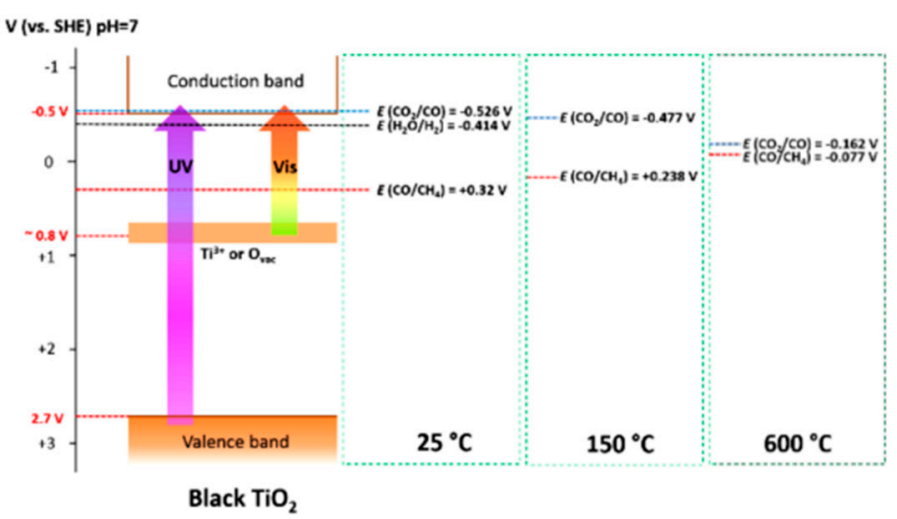

Figure 31. Band structure of $\mathrm{TiO}_{2}$, black $\mathrm{TiO}_{2}$, and various redox potentials at 25,150 , and $600{ }^{\circ} \mathrm{C}$. Reprinted with permission from [50]. Copyright (2015), American Chemical Society.

\subsection{Mechanism of the Reaction}

To confirm the nonthermal effect, our group compared the activity of light-irradiated conditions and only thermal conditions by controlling the surface temperature to the same value. As we carefully measured the surface temperature under the visible light irradiated condition, it showed $316^{\circ} \mathrm{C}$, while the thermometer below the catalyst showed $210{ }^{\circ} \mathrm{C}$. Thus, we controlled the temperature to $316^{\circ} \mathrm{C}$ in the dark. The activity under both conditions is shown in Figure 32. Here, it is demonstrated that there was a certain contribution of photon energy that was directly driving the reaction.

To clarify the photocatalytic DRM mechanism, Shoji et al. performed in situ electron spin resonance (ESR) measurements on $\mathrm{Rh} / \mathrm{SrTiO}_{3}$ photocatalysts. They found that electrons are injected from the conduction band of $\mathrm{SrTiO}_{3}$ to $\mathrm{Rh}$ nanoparticles under UV light irradiation because of the disappearance of the electron peak (Figure 33a,b). With the addition of methane, the number of excited holes decreased, indicating that the holes reacted with methane (Figure 33c). 


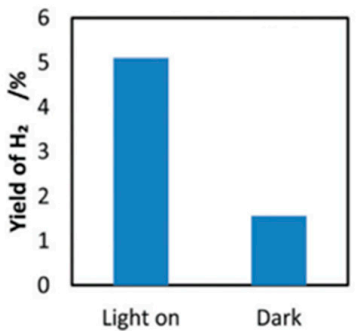

Figure 32. Comparison of activity under light irradiation conditions (surface temperature $=316^{\circ} \mathrm{C}$, operating temperature $=210^{\circ} \mathrm{C}$ ) vs. dark condition (surface temperature $=$ operating temperature $=$ $316^{\circ} \mathrm{C}$ ). Reproduced from [22] with permission from The Royal Society of Chemistry.

In addition, they performed isotope tests to identify the reaction intermediates. Before the isotope test, they confirmed that $\mathrm{CO}$ was generated when methane alone was input, where lattice oxygen was the only supplier of oxygen (Figure 34 ). Then, they $\mathrm{used}_{2}{ }^{18} \mathrm{O}$ to replace the surface oxygen with ${ }^{18} \mathrm{O}$, after which, they input methane. When light was irradiated onto the ${ }^{18} \mathrm{O}$-doped $\mathrm{SrTiO}_{3}$, there was a $\mathrm{C}^{18} \mathrm{O}$ product (Figure 35). As a reference, they performed the same experiment with no ${ }^{18} \mathrm{O}$ doping and found that the $\mathrm{C}^{18} \mathrm{O}$ originated from the lattice. Thus, they concluded that the reaction intermediate was lattice oxygen. $\mathrm{CO}_{2}$ continuously supplied oxygen into the lattice of $\mathrm{SrTiO}_{3}$, and the oxygen could react with methane to produce $\mathrm{CO}$ (Figure 36).
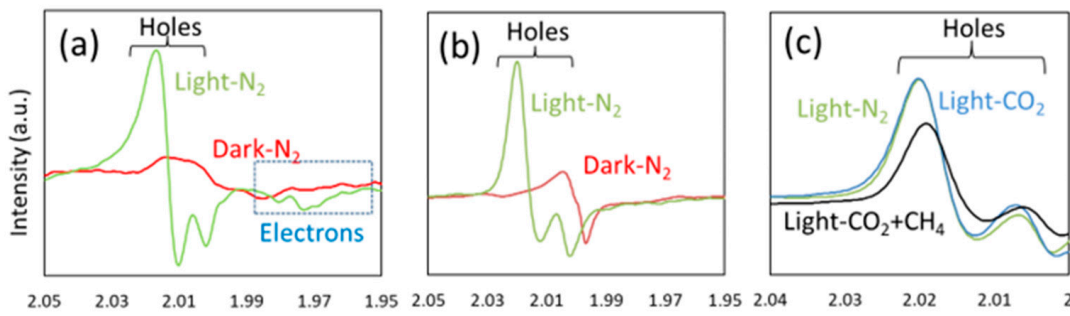

Figure 33. Electron spin resonance (ESR) spectra of (a) $\mathrm{SrTiO}_{3}$ under $\mathrm{N}_{2} ;$ (b) Rh/SrTiO 3 under $\mathrm{N}_{2}$; (c) $\mathrm{Rh} / \mathrm{SrTiO}_{3}$ under $\mathrm{UV} \mathrm{N}_{2}, \mathrm{CO}_{2}$, and $\mathrm{CO}_{2}+\mathrm{CH}_{4}$. Reprinted from [30].

(a)

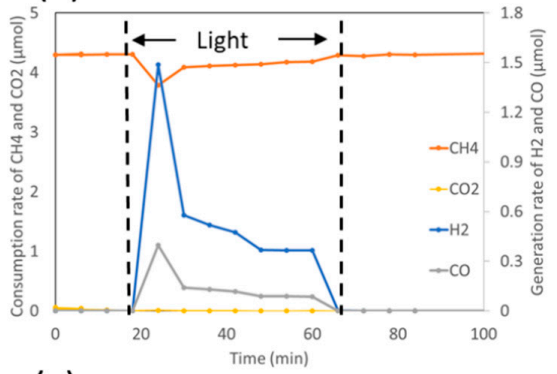

(c)

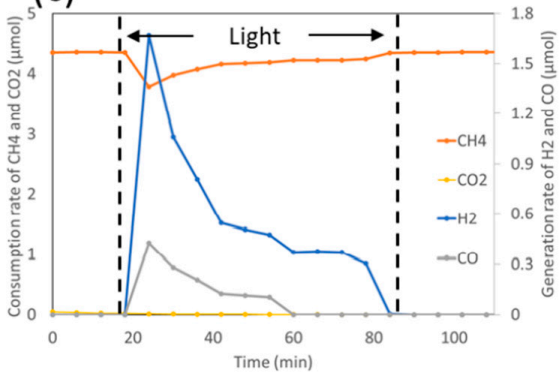

(b)

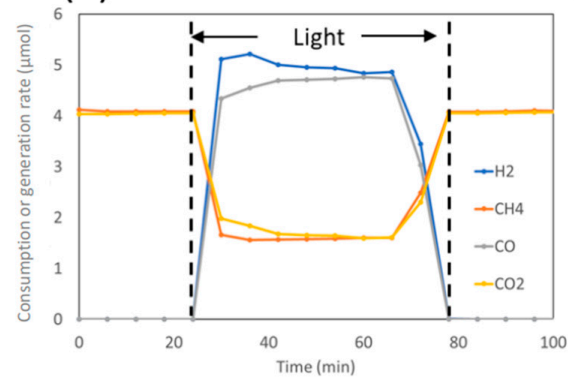

Figure 34. Sole gas experiment performed using $\mathrm{Rh} / \mathrm{SrTiO}_{3}$. First, (a) methane only; then, (b) a mixture of methane and carbon dioxide; finally, (c) methane again. Reprinted from [30]. 


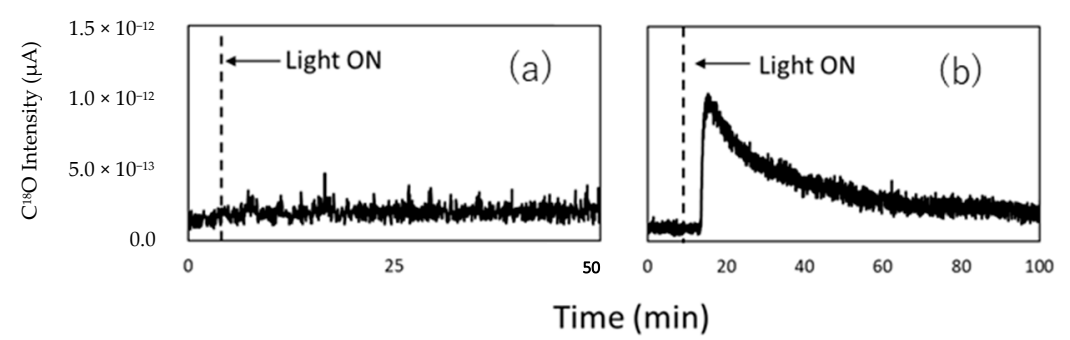

Figure 35. Yield of $\mathrm{C}^{18} \mathrm{O}$ after exchanging surface oxygen with $(\mathbf{a}) \mathrm{H}_{2}{ }^{16} \mathrm{O}$ and $(\mathbf{b}) \mathrm{H}_{2}{ }^{18} \mathrm{O}$. Reprinted from [30].

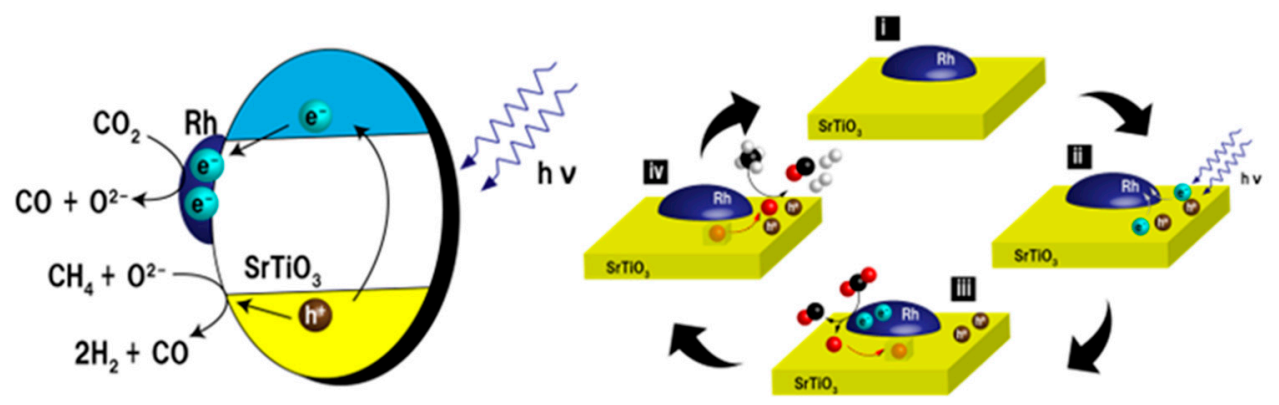

Figure 36. Speculated mechanism of photocatalytic DRM using $\mathrm{Rh} / \mathrm{SrTiO}_{3}$. Reprinted from [30].

To further investigate the photocatalytic DRM mechanism, Kushida et al. constructed a unique gas-phase photoelectrochemical system (Figure 37) [52]. They used yttria-stabilized zirconia (YSZ) pellets as an electrolyte to conduct oxygen ions inside. On both sides of the YSZ pellet, they deposited the Rh/YSZ photocatalyst, the target material for discussion. When using a powder photocatalyst, the redox reaction occurs at the powder, and there is no way to see the reaction separately. Thus, the system they constructed is important in discussing the mechanism.

They first introduced inert argon gas into the cathodic and anodic sides as a control experiment, where no reaction proceeded. They found no photocurrent, regardless of irradiating light (Figure 38). Afterward, they input carbon dioxide and methane into the cathodic and anodic sides, respectively. Immediately after introducing the gasses, a negative voltage appeared, suggesting that a thermal reaction occurred. Subsequently, they chopped with UV light and observed a further negative shift, suggesting that photon energy promoted the reaction. As the electrolyte works as an oxygen conductor only at temperatures $>600{ }^{\circ} \mathrm{C}$, they had to set the temperature that high, resulting in the detection of a significant number of thermally generated products under a stoichiometric reaction (Figure 39). Then, they irradiated UV light only on one side of their photoelectrochemical cell system, utilizing the divided field of the reduction and oxidation sites. Before experimenting, they checked that there was no leakage of light to the other side of the spectrometer. As a result, they found that the voltage change was evident when the light was especially irradiated onto the anodic side (Figure 40). This result shows that the bandgap excitation in the anode is important and methane reacts with the holes generated at the semiconductor. On the other hand, carbon dioxide reacts with electrons in rhodium metal. From the results obtained above, the mechanism is illustrated in Figure 41. 


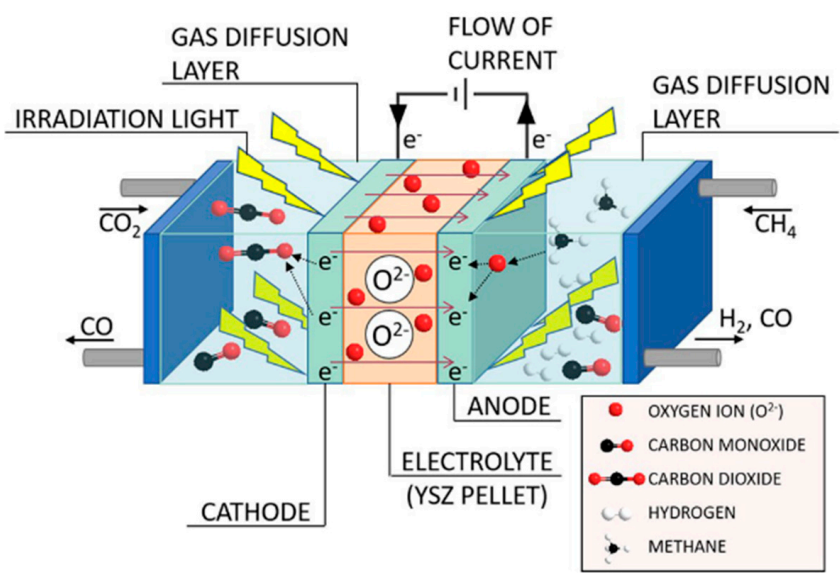

Figure 37. Gas-phase photoelectron chemical (GPEC) system. Reprinted from [52]. Copyright 2020 by John Wiley \& Sons, Inc. YSZ: yttria-stabilized zirconia.

a)

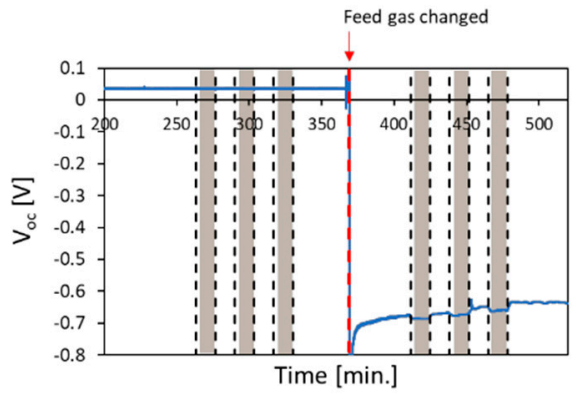

. . uv light irradiation to both anode and cathode side

b)

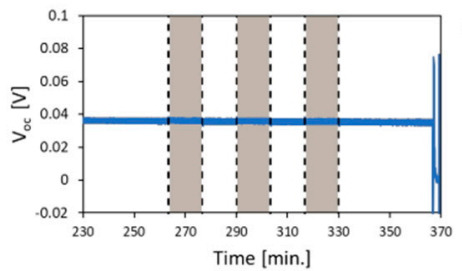

c)

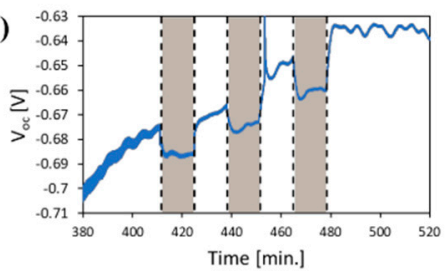

Figure 38. (a) Result of the open-circuit voltage measured under an Ar flow into the anodic and cathodic sides with the light on and off. The feed gas was changed to $\mathrm{CH}_{4}$ into the anodic side and $\mathrm{CO}_{2}$ into the cathodic side at $370 \mathrm{~nm}$. (b,c) The expanded view of (a). Reprinted from [52]. Copyright 2020 by John Wiley \& Sons, Inc.

(a)

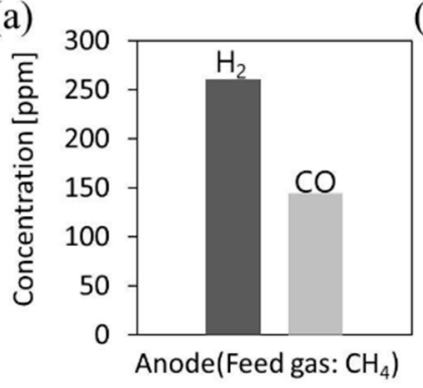

(b)

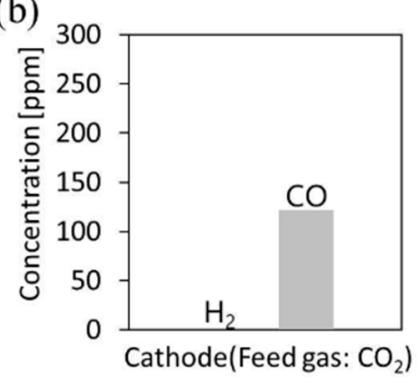

Figure 39. Products obtained in (a) the anodic side and (b) the cathodic side. The feed gas was $\mathrm{CH}_{4}$ into the anodic side and $\mathrm{CO}_{2}$ into the cathodic side. The reaction temperature was $600{ }^{\circ} \mathrm{C}$ and UV light was irradiated onto both sides. Reprinted from [52]. Copyright 2020 by John Wiley \& Sons, Inc. 


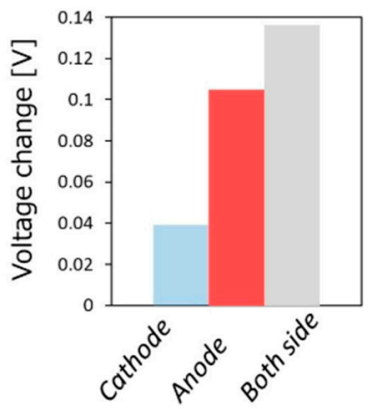

Figure 40. Voltage change due to light irradiation onto the cathodic side only, anodic side only, and both sides. Reprinted from [52]. Copyright 2020 by John Wiley \& Sons, Inc.

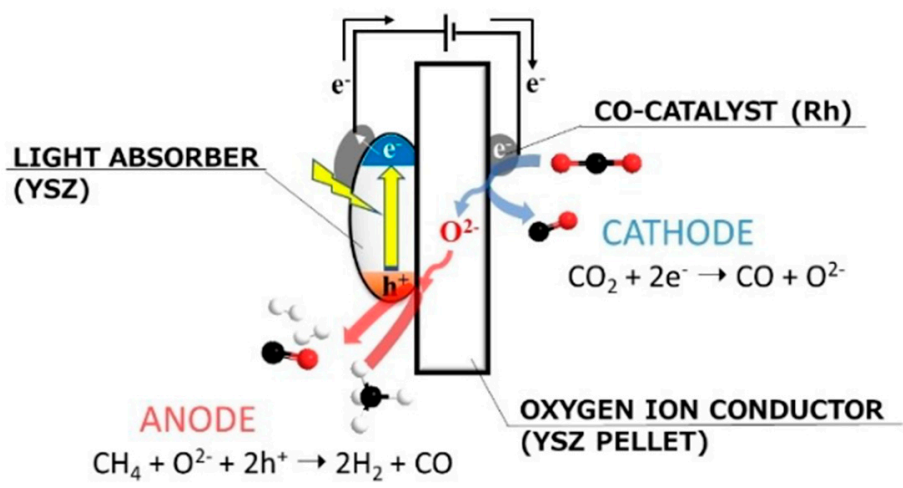

Figure 41. Speculated mechanism illustrated from the obtained results. Reprinted from [52]. Copyright 2020 by John Wiley \& Sons, Inc.

\section{Photocatalytic Partial Oxidation of Methane (POM)}

\subsection{Overview of the Reaction}

The definition of the POM should be considered in this review paper. As the valence state of carbon in methane is -4 , if it does not oxidize to the highest number of +4 in $\mathrm{CO}_{2}$, it can be called partial oxidation. In this review article, to differentiate between steam reforming and dry reforming, we define the partial oxidation of methane as not using $\mathrm{H}_{2} \mathrm{O}$ or $\mathrm{CO}_{2}$ as the oxidant. Thus, we include a liquid-phase reaction using metal ions or hydrogen peroxide and a gas-phase reaction utilizing $\mathrm{O}_{2}$ as the oxidant.

When using metal ions or other oxidants in the solvent, it is beneficial to control the ease of driving by choosing a relatively positive redox potential. Metal ions with a positive redox potential work as electron scavengers and make the carrier separation more efficient. Furthermore, the variety of oxidants has led to more discussion about the mechanism. In addition, if we choose an appropriate metal ion scavenger, a semiconductor photocatalyst with a low conduction band position can be used.

The selectivity of products is important, even if methane cannot be completely oxidized. Many researchers have focused on producing methanol in liquid phase studies, which is considered the "holy grail" of current catalysis research [53]. Methanol generation usually faces a significant problem of selectivity as it usually competes with ethane production. On the other hand, a gas-phase reaction utilizes oxygen as an oxidant, where $\mathrm{CO}$ and $\mathrm{H}_{2}$ are the main products.

\subsection{Material}

The partial oxidation of methane has been studied by utilizing photocatalysis. One important point relating to the band structure criteria is that the reduction potential of $\mathrm{O}_{2}$ is less positive compared to $\mathrm{CO}_{2}$ or $\mathrm{H}_{2} \mathrm{O}$. Therefore, semiconductors with a relatively low conduction band position, such as $\mathrm{WO}_{3}, \mathrm{~V}_{2} \mathrm{O}_{5}, \mathrm{BiVO}_{4}$, or $\mathrm{Bi}_{2} \mathrm{WO}_{6}$, were used in these stud- 
ies [54-59]. It is noted that $\mathrm{Bi}_{2} \mathrm{WO}_{6}$ has no significant activity in the case of photocatalytic DRM, probably because of the insufficient conduction band potential [22].

Another important point in the partial oxidation reaction is the selectivity of the products. If methane is completely oxidized to $\mathrm{CO}_{2}$, the reaction is not valuable. Instead, the oxidization should be terminated before the complete oxidation to $\mathrm{CO}_{2}$ to produce valuable compounds. To date, carbon monoxide, methanol, or ethane have been reported to be produced from methane. However, there is a considerable amount of $\mathrm{CO}_{2}$ as a product, which needs further selectivity enhancement.

Hu et al. used $\mathrm{NO}$ and $\mathrm{O}_{2}$ as oxidants and performed partial oxidation using vanadium (V)-containing mesoporous silica (MCM-41) [56]. They prepared the material under both acidic and basic conditions using tetraethyl orthosilicate as the silicon source and $\mathrm{HCl}$ for adjusting acidity. Under basic conditions, sodium silicate, as the silicon source, and sulfuric acid was used to buffer the acidity. From the characterization, vanadium in the sample was confirmed to be a polymeric species. The results of the $\mathrm{CO}_{2}$ and $\mathrm{CH}_{3} \mathrm{OH}$ yields are shown in Figure 42. When $\mathrm{O}_{2}$ was used as the oxidant, the product was only $\mathrm{CO}_{2}$, regardless of the preparation conditions. When $\mathrm{NO}$ gas was used as the oxidant, the yield of $\mathrm{CH}_{3} \mathrm{OH}$ increased significantly in the V-containing MCM-41 prepared under acidic conditions. The conversion of methane in the acid and base types was 6.0 and $0.7 \%$, respectively. Methanol was replaced as a product in the basic type with $\mathrm{C}_{2} \mathrm{Hx}$ species, acetaldehyde, and $\mathrm{CO}_{2}$. They explained the reason for the coordination of $\mathrm{V}$-oxide species and loading sites according to the $\mathrm{pH}$ during preparation.
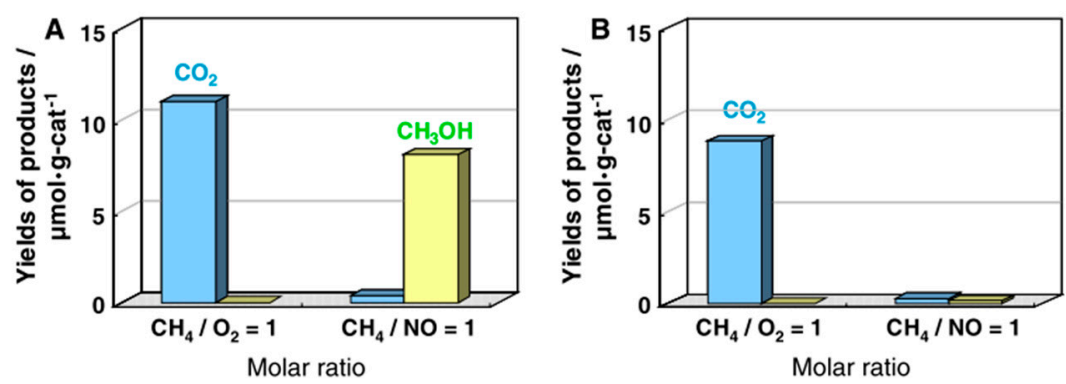

Figure 42. Yield of $\mathrm{CO}_{2}$ and methanol using (A) vanadium-containing mesoporous silica (V-MCM-41) (acid) and (B) V-MCM 41 (base) with different oxidants. The amount of $\mathrm{V}$ was $0.6 \%$, the reaction temperature was $295 \mathrm{~K}$, and the reaction time was $3 \mathrm{~h}$. Reprinted with permission from [56]. Copyright (2008), Springer Nature.

Villa et al. fabricated a $\mathrm{WO}_{3}$ photocatalyst on mesoporous silica as a template and performed the partial oxidation of methane in an aqueous solution using various electron scavengers, such as $\mathrm{Fe}^{3+}, \mathrm{Cu}^{2+}, \mathrm{Ag}^{+}$, and $\mathrm{H}_{2} \mathrm{O}_{2}$ [57]. Generally, the addition of scavengers improved the carrier separation. It can be observed from Figure $43 \mathrm{a}, \mathrm{b}$ that $\mathrm{Fe}^{3+}$ and $\mathrm{Cu}^{2+}$ enhanced the methanol production activity, but $\mathrm{Fe}^{3+}$ and $\mathrm{H}_{2} \mathrm{O}_{2}$ enhanced the activity of the ethane production. The authors explained that reaction selectivity occurred because the reactions proceeded through different intermediates between the methanol and ethane production. In the case of methanol production, the hydroxyl groups and $\mathrm{H}_{2} \mathrm{O}$ adsorbed on the surface of the catalyst are important (Equation (12)), whereas hydroxyl radicals are important in ethane production. This difference is because hydroxyl radicals react with methane and produce methyl radicals, which react with each other to generate ethane (Equations (13) and (14)). When $\mathrm{H}_{2} \mathrm{O}_{2}$ and $\mathrm{Fe}^{3+}$ were added, the selectivity of ethane increased because they produced hydroxyl radicals, as shown in Equations (15) and (16). The amount of $\mathrm{CO}$ produced is shown in Figure 43c.

$$
\begin{gathered}
\mathrm{CH}_{3}+\mathrm{H}_{2} \mathrm{O}_{\mathrm{ads}} \rightarrow \mathrm{CH}_{3} \mathrm{OH}+0.5 \mathrm{H}_{2} \\
\mathrm{CH}_{4}+\mathrm{HO} \cdot \text { ads }
\end{gathered}
$$




$$
\begin{gathered}
\mathrm{CH}_{3} \cdot+\mathrm{CH}_{3} \cdot \rightarrow \mathrm{C}_{2} \mathrm{H}_{6} \\
\mathrm{H}_{2} \mathrm{O}_{2}+\mathrm{e}^{-} \mathrm{CB} \rightarrow \mathrm{OH}^{-}+\mathrm{HO} \\
\mathrm{Fe}^{3+}+\mathrm{H}_{2} \mathrm{O} \rightarrow(\mathrm{hv}) \mathrm{Fe}^{2+}+\mathrm{HO} \cdot+\mathrm{H}^{+}
\end{gathered}
$$
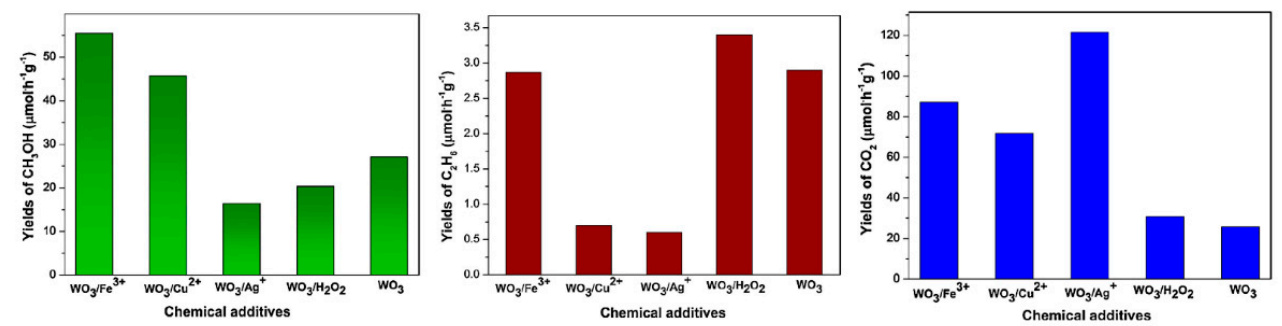

Figure 43. Yields of (a) methanol, (b) ethane, and (c) $\mathrm{CO}_{2}$ using various oxidants and $\mathrm{WO}_{3}$ as a photocatalyst. Copyright (2015), reprinted from [57] with permission from Elsevier.

Murcia-Lopez et al. performed the partial photocatalytic oxidation of methane to methanol using $\mathrm{BiVO}_{4}$ in the presence of nitrite ions $\left(\mathrm{NO}_{2}{ }^{-}\right)$[55]. As the result shows, when both $\mathrm{BiVO}_{4}$ and $\mathrm{NO}_{2}{ }^{-}$were present, the production of $\mathrm{CO}_{2}$ was suppressed, while the methanol production was relatively high (Figure 44). The roles of $\mathrm{NO}_{2}{ }^{-}$are also discussed in their report. As hydroxyl radicals can be generated by the photolysis of water, the generated hydroxyl radicals can lead to methyl radicals that produce ethane. It is better to suppress the number of existing hydroxyl radicals in the solution. To selectively produce methanol rather than ethane, the suppression of the production of hydroxyl radicals is important. Nitrite ions work as a UV filter because the nitrite ion absorbs a specific photon energy, otherwise generating hydroxyl radicals. This UV filtering effect was not very large since they only put in $1 \mathrm{mM}$ of nitrite ions. In addition, the produced oxygen radicals then reacted with water to supply hydroxyl radicals. Another role of nitrite ions is directly scavenging hydroxyl radicals (Equation (19)). The authors claimed the selective conversion of methane to methanol by explaining the effects induced by nitrite ions.

$$
\begin{gathered}
\mathrm{NO}_{2}{ }^{-}+\mathrm{hv} \rightarrow \mathrm{NO} \cdot+\mathrm{O}^{-} \\
\mathrm{O}^{-}{ }^{-}+\mathrm{H}_{2} \mathrm{O} \rightarrow \cdot \mathrm{OH}+\mathrm{OH}^{-} \\
\mathrm{NO}_{2}{ }^{-}+\cdot \mathrm{OH} \rightarrow \mathrm{NO}_{2} \cdot+\mathrm{OH}^{-} \\
\mathrm{NO}_{2}{ }^{-}+\mathrm{h}_{\mathrm{VB}}{ }^{+} \rightarrow \mathrm{NO}_{2} .
\end{gathered}
$$

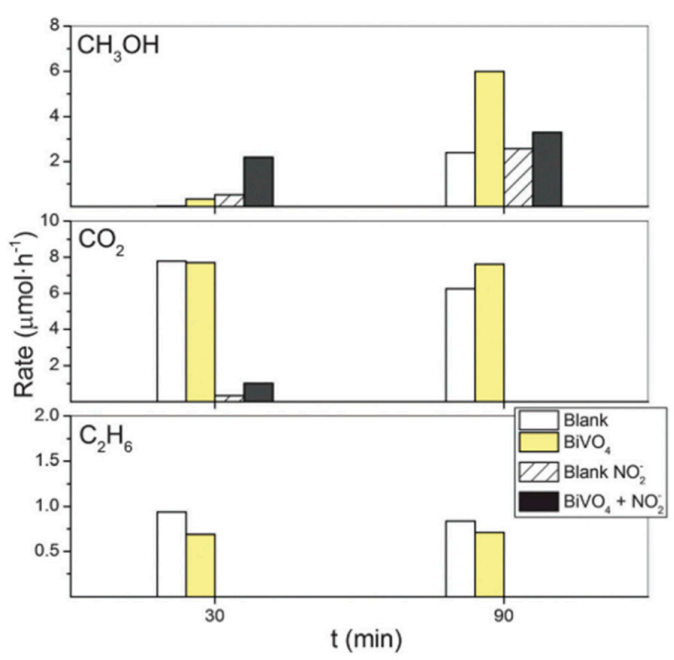

Figure 44. Production rate of methanol, ethane, and $\mathrm{CO}_{2}$ by $\mathrm{BiVO}_{4}$ at 30 and $90 \mathrm{~min}$. Reproduced from [55] with permission from The Royal Society of Chemistry. 


\subsection{Proposed Mechanism}

From the experimental results of photocatalytic POM using various oxidants, its mechanism has been thoroughly proposed. The result that the suppression of hydroxyl radicals promoted methanol and the increasing amount of hydroxyl radicals promoted ethane generation gives a rough mechanism outline, which is written as Equations (11)-(15).

The proposed mechanism provides a strategy to selectively produce methanol rather than ethane. First, as described above, the suppression of the number of hydroxyl radicals is important. There are two main ways to suppress their generation or to scavenge them. In other words, the possible strategies are (1) cutting off or not using photons with energy input, which can initiate the photolysis of water; (2) using a scavenger to decrease hydroxyl radicals; (3) avoiding compounds that have the possibility of generating hydroxyl radicals, such as $\mathrm{H}_{2} \mathrm{O}_{2}$. Another important point is the choice of oxidant. As the oxidant has strong reactivity, methane will be oxidized to $\mathrm{CO}_{2}$.

It is noted that most reports assert that methane is not directly oxidized by holes in a liquid-phase partial oxidation process. Instead, $\mathrm{H}_{2} \mathrm{O}$ or hydroxyl groups are intermediates and play an important role in methane oxidation. The reaction mechanism of POM is different from that of the SRM and DRM introduced in Sections 4 and 5. The liquidphase POM reaction is significantly different from gas-phase SRM and DRM, and the temperature in the POM system would be considerably lower than that in the gas-phase system. As an aqueous solution provides a reaction with abundant water, the intermediate can be sufficiently supplied. In addition, as in most cases, methane conversion is an endothermic reaction, and heat can directly assist in oxidizing methane.

\section{Photocatalytic Nonoxidative Coupling of Methane}

\subsection{Overview of the Reaction}

Non-oxidative coupling of methane (NOCM) is a desirable technique since industrially demanded $\mathrm{C}_{2}$ species can be directly made from methane [60]. However, its catalytic activity in dark conditions is extremely low compared to other methane-reforming techniques.

As for the mechanism, it is unique because it does not contain a reductant. In general, if there are oxidants and reductants, they consume holes and electrons, respectively. Since there is only methane, whose valence state of carbon is -4 , it is speculated that it works only as a reductant. Thus, electrons are consumed by some intermediates, or carbon itself will be further reduced to -5 . Furthermore, unlike other oxidative methane-reforming processes, there is no oxygen to remove carbon once it deposits onto the surface of the catalyst. This lack of oxygen makes it difficult for the reaction to proceed for a long time.

\subsection{Material}

Wu et al. reported on an efficient NOCM reaction using a Ga-doped Pt-loaded porous $\mathrm{TiO}_{2}-\mathrm{SiO}_{2}$ [61]. They introduced methane gas into their reactor and checked the output gas. According to their XPS results, the valence state of Pt was more cationic when more Ga was doped. Although Ga decreased the number of exciting carriers, they claimed that a larger amount of cation Pt benefited more and achieved higher photocatalytic activity. The results of the methane conversion, ethane selectivity, and yield are shown in Figure 45.

Yuliati et al. loaded various metals onto $\mathrm{SiO}_{2}$ and $\mathrm{Al}_{2} \mathrm{O}_{3}$ and performed non-oxidative methane reforming by introducing only methane (Figure 46) [62]. They found that only the cerium-loaded silica exhibited remarkable activity. They further performed experiments on the cerium amount dependence. As the amount increased, the ratio of $\mathrm{Ce}^{3+}$ decreased and $\mathrm{Ce}^{4+}$ increased. At the same time, the activity decreased as the loading amount increased. From this result, it was confirmed that $\mathrm{Ce}^{3+}$ was the active site. 


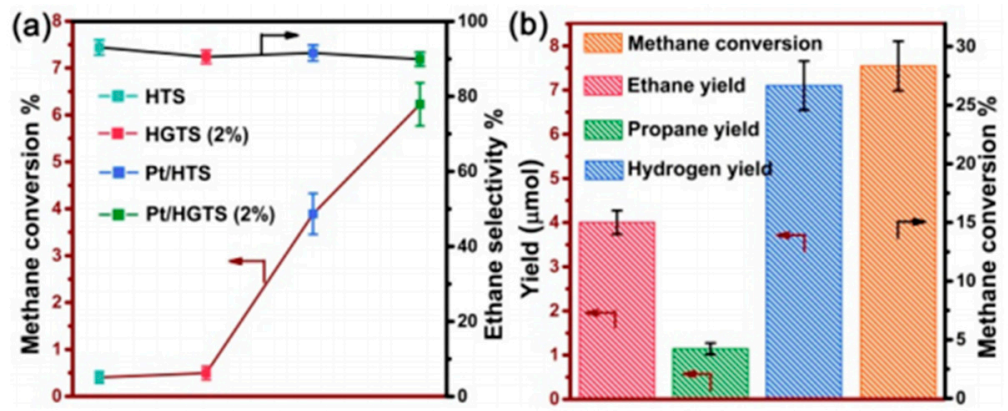

Figure 45. (a) Comparison of methane conversion and ethane selectivity using $\mathrm{TiO}_{2}-\mathrm{SiO}_{2}(\mathrm{HTS})$, Ga doped $\mathrm{TiO}_{2}-\mathrm{SiO}_{2}$ (HGTS), Pt/HTS, and Pt/HGTS. (b) Methane conversion, ethane, propane, and hydrogen yield performing non-oxidative coupling of methane (NOCM) using Pt/HGTS (2\%). The lamp used was a $300 \mathrm{~W}$ Xe lamp that irradiated for $32 \mathrm{~h}$. Reprinted with permission from [61]. Copyright (2019), American Chemical Society.

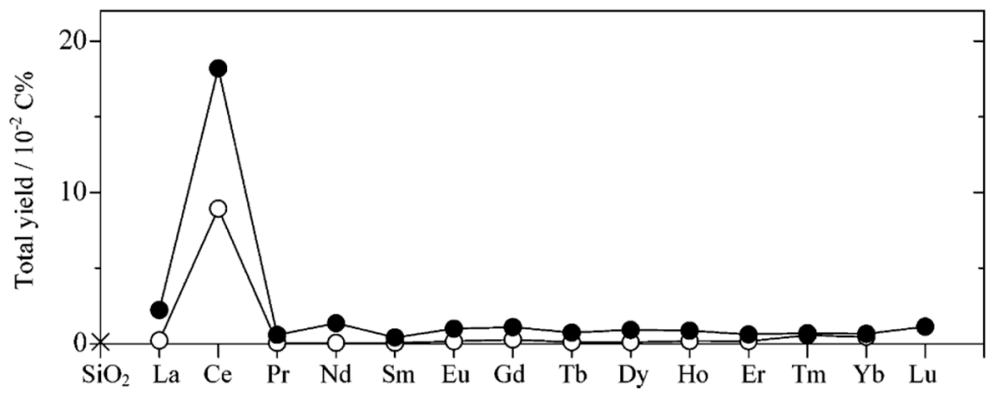

Figure 46. Total yield of hydrocarbons using 0.1 and $0.2 \%$ of various metals loaded on $\mathrm{SiO}_{2}$. Reprinted with permission from [62]. Copyright (2008), American Chemical Society.

$\mathrm{Ga}_{2} \mathrm{O}_{3}$ and $\mathrm{Ga}_{2} \mathrm{O}_{3} / \mathrm{SiO}_{2}$ were explored for photocatalytic non-oxidative methanereforming catalysts at room temperature by Yuliati et al. [63], who noted that the calculated equilibrium of ethane production was $0.0004 \%$. Their results showed that bare $\mathrm{Ga}_{2} \mathrm{O}_{3}$ had higher photocatalytic activity than any amount of Ga supported on silica. On the other hand, $0.1 \mathrm{~mol} \%$ Ga-loaded silica has a higher selectivity of ethane (94\%). The reason was attributed to the dispersion of Ga on the surface of silica, where a lower amount of Ga can drive photocatalytic reactions separately from neighboring Ga such that no other reaction would be likely to follow. They also performed X-ray absorption near-edge structure (XANES) analysis and found two structures of local Ga states: tetrahedral and octahedral. From the quantitative analysis, they found that the tetrahedral species exhibited high specific activity for selective ethane production.

Singh et al. further loaded palladium onto $\mathrm{Ga}_{2} \mathrm{O}_{3}$ and performed a non-oxidative conversion of methane [64]. The thermodynamic equilibrium of ethane generation from methane (Equation (5)) was calculated to be $0.0002 \%$. They achieved $0.006 \%$ and the stoichiometric reaction continued as the value of $\mathrm{C}_{2} \mathrm{H}_{6} / \mathrm{H}_{2}$ was almost unity in the case of $\mathrm{Pd}(0.5 \mathrm{wt} \%) / \mathrm{Ga}_{2} \mathrm{O}_{3}$, indicating that photons successfully drove the non-oxidative conversion of methane. However, they found some problems in which the catalyst became unstable if the temperature was higher than $320 \mathrm{~K}$, the light intensity was strong, or the methane concentration was high.

Lang et al. performed NOCM using various metals on $\mathrm{TiO}_{2}$ and found that $\mathrm{Au}-\mathrm{TiO}_{2}$ had the highest activity among various catalysts (Figure 6) [33]. The stability test is shown in Figure 47. The production rate of both ethane and $\mathrm{H}_{2}$ decreased by $21.5 \%$ from the initial performance, but it was noted that the rate of producing both ethane and $\mathrm{H}_{2}$ was sustained at the equivalent values during the reaction. This result is important because it can be said that the stoichiometric reaction proceeded and carbon deposition was suppressed. 


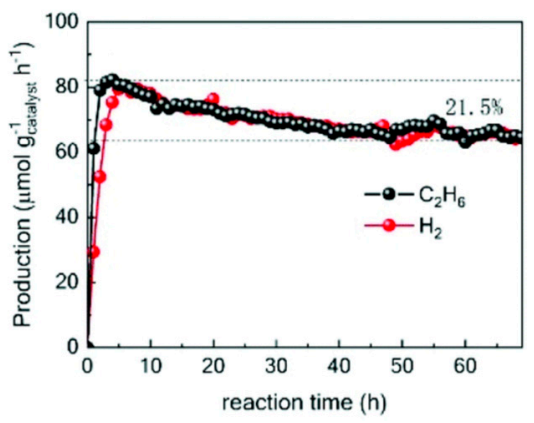

Figure 47. Time course of the production rate of ethane and $\mathrm{H}_{2}$. Reproduced from [28] with permission from The Royal Society of Chemistry.

\subsection{Proposed Mechanism}

From an analogy with other photocatalytic reactions, Singh et al. assumed the following mechanism [64]:

$$
\begin{gathered}
\mathrm{CH}_{4}+\mathrm{h}^{+} \rightarrow \cdot \mathrm{CH}_{3}+\mathrm{H}^{+}, \\
2 \cdot \mathrm{CH}_{3} \rightarrow \mathrm{C}_{2} \mathrm{H}_{6}, \\
2 \mathrm{H}^{+}+2 \mathrm{e}^{-} \rightarrow \mathrm{H}_{2} \\
\cdot \mathrm{CH}_{3}+3 \mathrm{~h}^{+} \rightarrow \mathrm{C}+3 \mathrm{H}^{+} .
\end{gathered}
$$

As the valence state of carbon in methane is -4 , they speculated that methane oxidation to methyl radicals would be the first step for the reaction (Equation (21)). Then, a proton will be reduced such that the reaction proceeds as Equations (22) and (23). Their results also observed carbon deposition, which can easily be predicted because of the absence of extra oxidants that remove carbon. The formation of carbon deposition is described by Equation (24).

Density function theory (DFT) calculations were performed by Lang et al. for a mechanism study [33] to clarify the $\mathrm{CH}_{3}$ species after the first step of an electron and hole transfer based on Bader charge analysis. As a result, they found that $\mathrm{CH}_{3}{ }^{-}$exists on $\mathrm{Au}$ and $\mathrm{CH}_{3}{ }^{-} / \mathrm{CH}_{3}{ }^{+}$exists on $\mathrm{TiO}_{2}$. Furthermore, they obtained a result showing that the activation barrier for methane reduction to $\mathrm{CH}_{3}{ }^{-}$at the $\mathrm{Au}$ site was $0.47 \mathrm{eV}$, while it was $1.1 \mathrm{eV}$ at the $\mathrm{TiO}_{2}$ site. Thus, it was assumed that $\mathrm{CH}_{4}$ would be reduced to $\mathrm{CH}_{3}{ }^{-}$ on $\mathrm{Au}$ and oxidized to $\mathrm{CH}_{3}{ }^{+}$on $\mathrm{TiO}_{2}$. It is noted from the calculations they performed that the methyl radicals are less likely to be generated. Furthermore, they investigated whether $\mathrm{CH}_{3}{ }^{+}$or $\mathrm{CH}_{3}{ }^{-}$would be methyl radicals that generate ethane. The results of the DFT calculations are shown in Figure 48. As the activation energy of methane to $\mathrm{CH}_{3}{ }^{+}$on $\mathrm{TiO}_{2}(1.57 \mathrm{eV})$ is much higher than that of $\mathrm{CH}_{3}{ }^{-}$on $\mathrm{Au}-\mathrm{TiO}_{2}(0.47 \mathrm{eV})$, the carbocation pathway is less likely to occur. Therefore, they concluded that NOCM proceeded via a methyl anion-radical mechanism (Figure 49). This mechanism was supported by their diffuse reflectance infrared Fourier transform (DRIFT) experiment, where $\mathrm{CH}_{3}{ }^{-}$anions were observed at approximately $600 \mathrm{~cm}^{-1}$.

Different mechanisms have been proposed by researchers with various catalyst materials. Thus, a single general mechanism of the POM reaction cannot be drawn. As only methane is used as an input in the NOCM process, methane or intermediates derived from methane act as an oxidant and a reductant. To elucidate the detailed reaction path, the discussion and characterization of the intermediates are important, including $\mathrm{CH}_{3}{ }^{+}$, $\mathrm{CH}_{3}{ }^{-}$, and methyl radicals. As the intermediate state analysis is difficult, further study is needed to understand the mechanism of NOCM fully. 


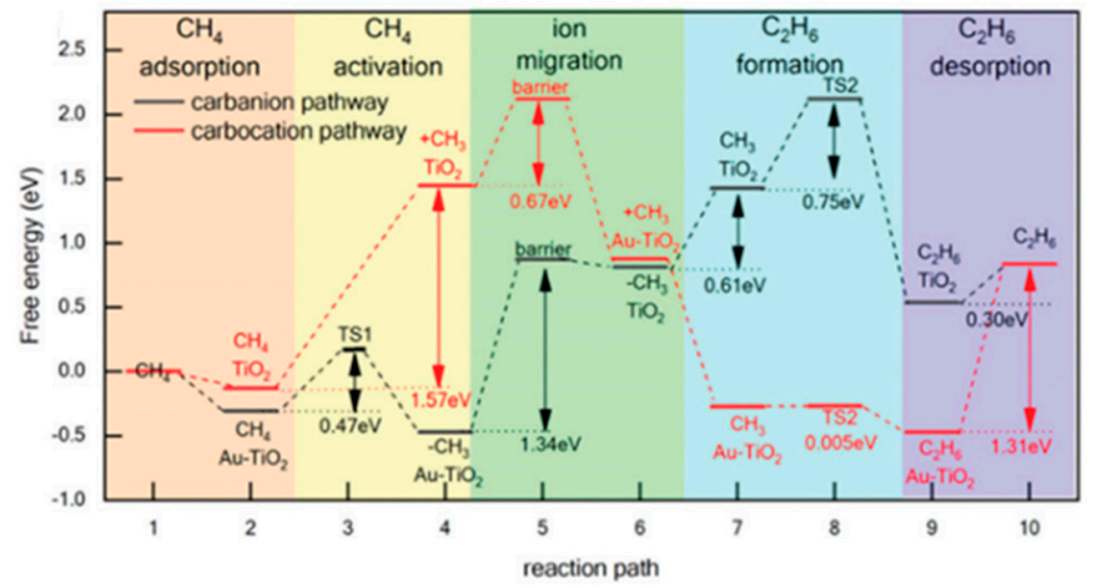

Figure 48. DFT calculation of the free energy of the carbanion pathway and the carbocation pathway. Reproduced from [28] with permission from The Royal Society of Chemistry. DFT: Density function theory.

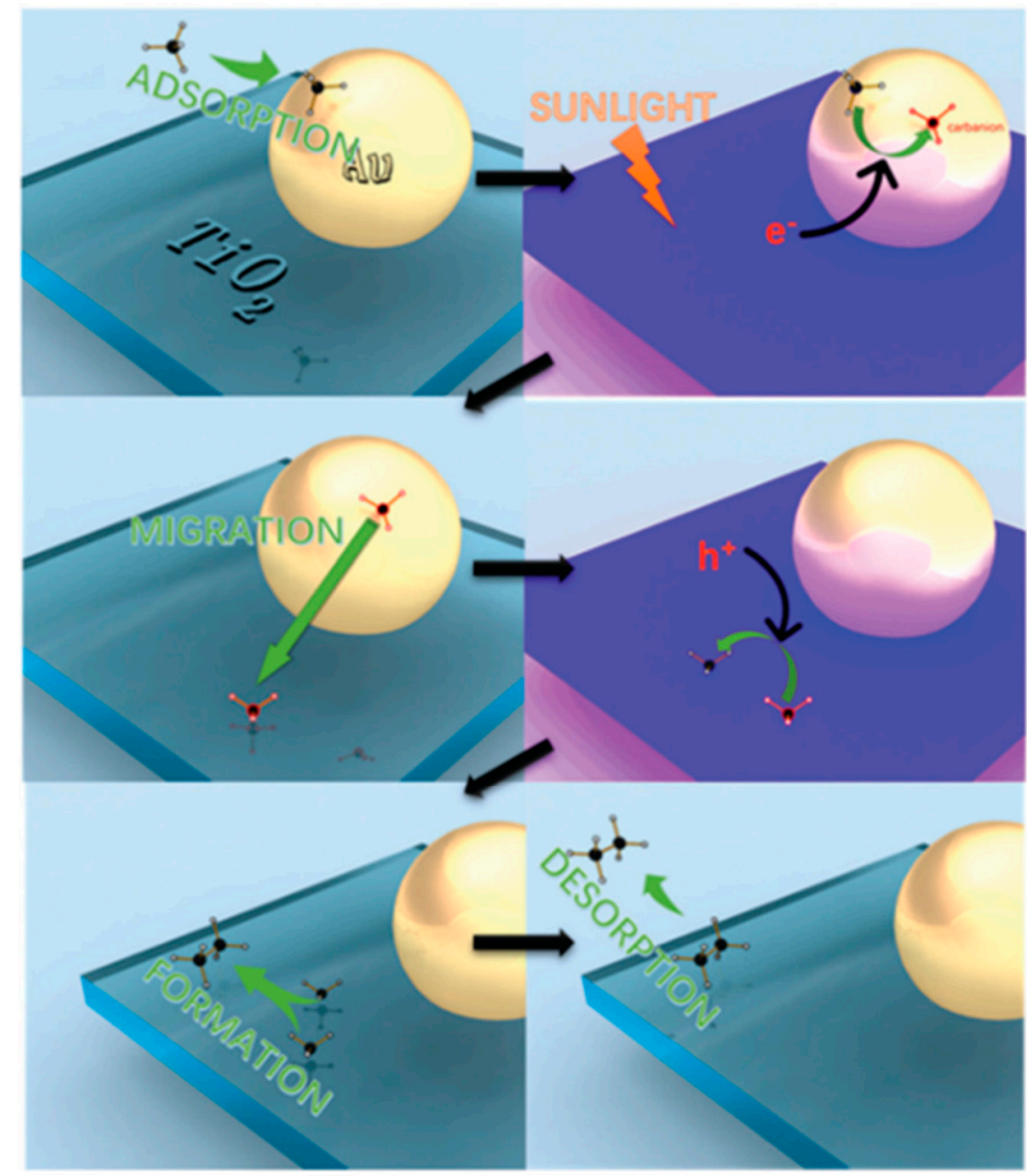

Figure 49. Mechanism of photocatalytic NOCM over $\mathrm{Au} / \mathrm{TiO}_{2}$ in a $\mathrm{CH}_{3}{ }^{-}$anion process. Reproduced from [28] with permission from The Royal Society of Chemistry. 


\section{Other Important Phenomena that Must Be Considered}

\subsection{Another Excitation Mechanism: Hot Carriers}

Recently, another excitation mechanism in semiconductor-metal combined materials, so-called hot carriers, has been reported by many researchers [65-69]. Hot carriers are generated when photons are irradiated onto metal, causing the excitation of electrons into unoccupied bands (Figure 50). The excitation of metal should be separately discussed with that of a semiconductor. Furthermore, the electron transfer path is different from the bandgap excitation in semiconductors. Notably, some studies have focused on hot carrier-driven methane reforming.
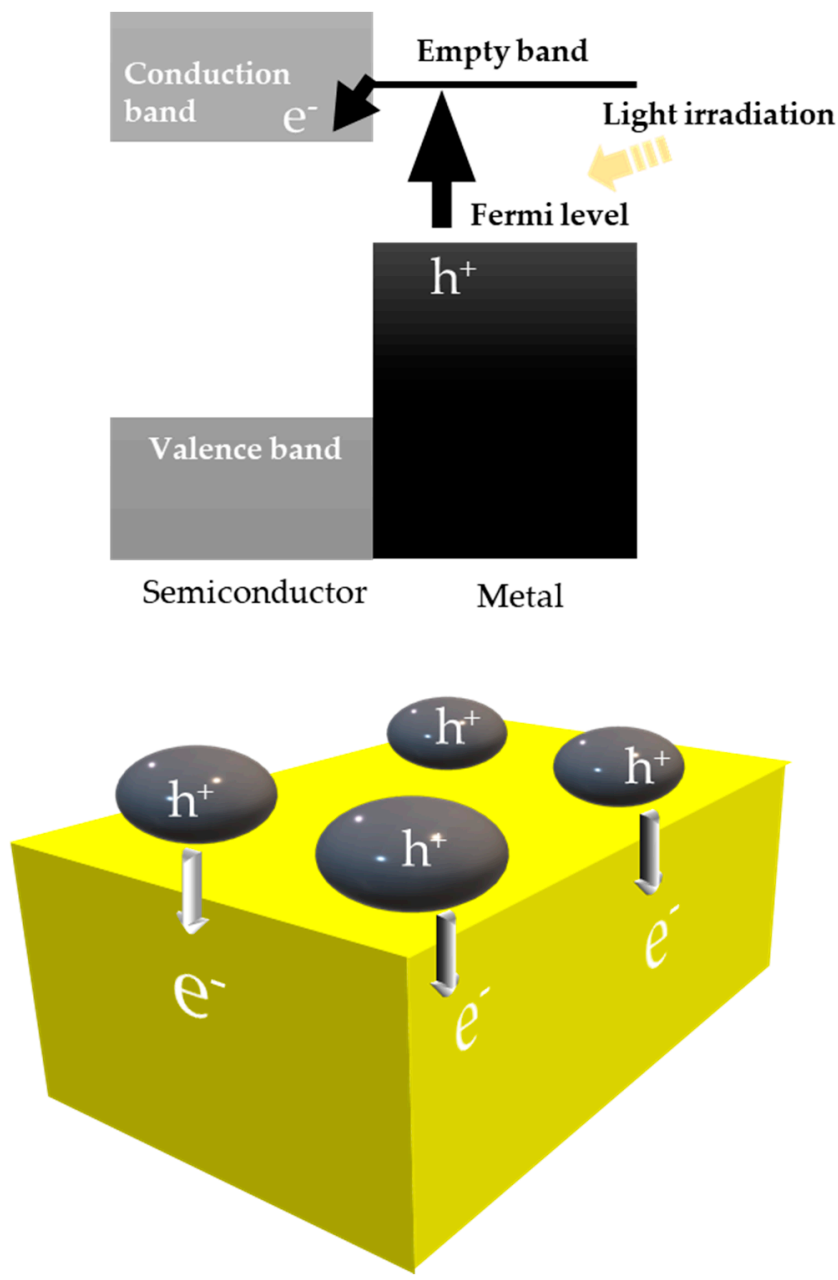

Figure 50. Excited carriers' pathway in the hot carrier mechanism.

Jiang et al. used $\mathrm{Sr}_{2} \mathrm{Ta}_{2} \mathrm{O}_{7}$, an ultrawide bandgap semiconductor, and loaded palladium onto it [70]. According to their UV-visible diffuse reflectance spectrum (UV-vis DRS), the bandgap of $\mathrm{Sr}_{2} \mathrm{Ta}_{2} \mathrm{O}_{7}$ was determined to be $4.6 \mathrm{eV}$. Photocatalytic partial oxidation of methane was performed and the result of the action spectrum using a long-wave pass

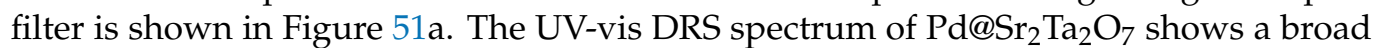
absorption of $\mathrm{Pd}$, which was assigned to the interband charge transition in $\mathrm{Pd}$, resulting in the generation of hot carriers. They found that there was no critical change between $\lambda \geq 250 \mathrm{~nm}$ and $\lambda \geq 300 \mathrm{~nm}$. These results indicate that the bandgap excitation of $\mathrm{Sr}_{2} \mathrm{Ta}_{2} \mathrm{O}_{7}$ is not a critical requirement to drive the reaction. The claim that the bandgap excitation was unnecessary was further verified by comparing the intensity using several long-wave pass filters and conversion or yield (Figure 51b). Because photon numbers through longwave pass filters cannot be set at equal values for each experiment, the irradiation power density varies when using different filters. These results concluded that the conversion of 
methane and the yield of carbon monoxide at both 423 and $623 \mathrm{~K}$ is only dependent on the irradiation power density, not on the wavelength.
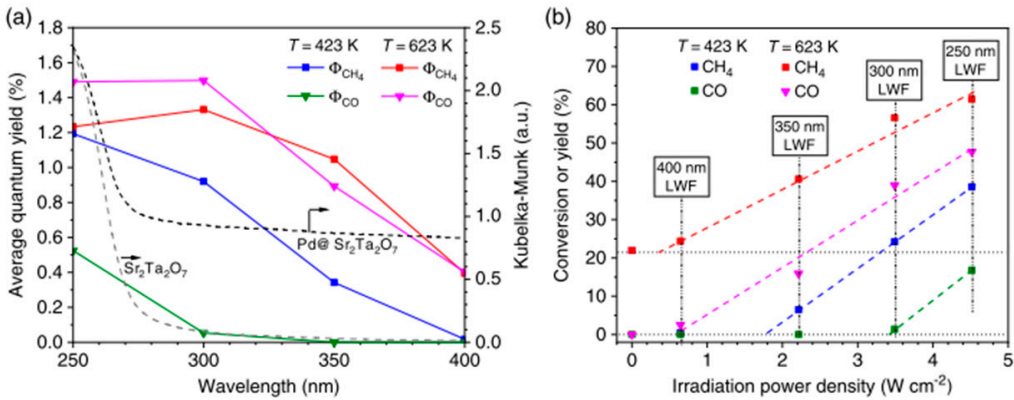

Figure 51. (a) UV-vis spectra of $\mathrm{Sr}_{2} \mathrm{Ta}_{2} \mathrm{O}_{7}$ and $\mathrm{Pd} / \mathrm{Sr}_{2} \mathrm{Ta}_{2} \mathrm{O}_{7}$ and the quantum efficiency of methane, carbon monoxide at 423 and $623 \mathrm{~K}$. (b) Conversion of methane and yield of carbon monoxide using various long-wavelength cutoff filters. The horizontal axis is irradiation power density with each cutoff filter. Reprinted from [70]. Copyright (2019) by John Wiley \& Sons, Inc.

To exclude the effect of bandgap excitation, they further used MCM-41 as a support material such that there was no possibility of bandgap excitation under the mercuryxenon lamp [71]. They employed partial photocatalytic oxidation using metal-loaded MCM-41. Figure 52 shows the UV-vis spectrum and action spectra. The absorption caused by metal (rhodium and palladium) overlapped with the average quantum yield of methane. They also compared the contributions of heat or photons as the surface temperature increased (Figure 53). The proportion of each contribution was determined by constructing an Arrhenius plot for each photocatalytic activity and the obtained apparent activation energies were compared. They found that in the case of rhodium, palladium, and ruthenium-loaded catalysts, the proportion was approximately 50\% in the nonthermal photocatalytic pathways, but zero in the case of platinum. These results suggest that there are two mechanisms in the photon-driven reaction, that is, a photo-thermal effect and hot carrier generation.
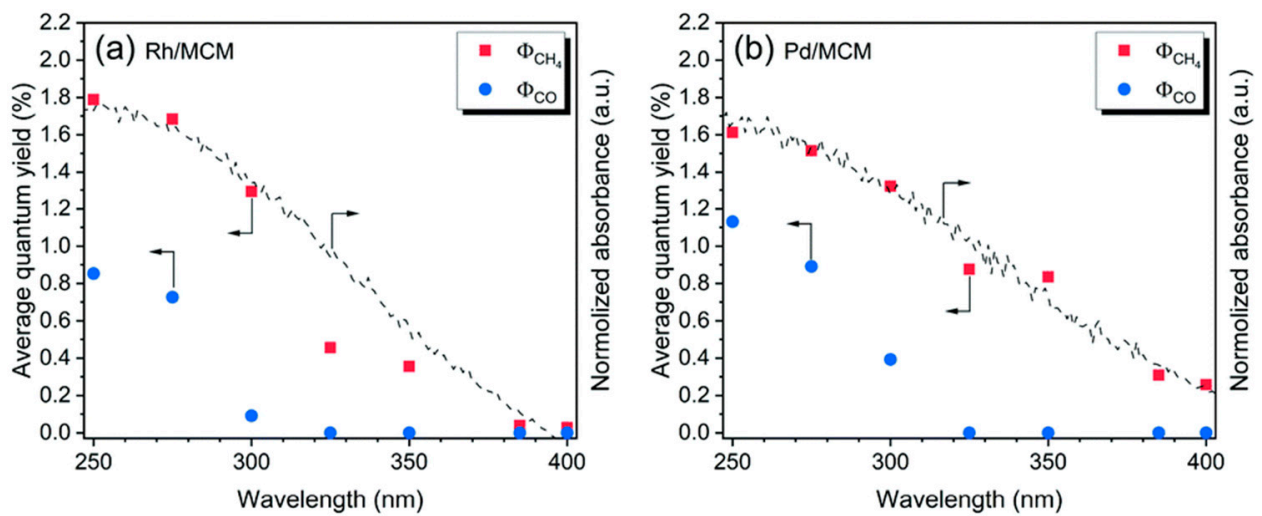

Figure 52. Action spectra of (a) Rh/MCM at $423 \mathrm{~K}$ and (b) $\mathrm{Pd} / \mathrm{MCM}$ at $523 \mathrm{~K}$ in the wavelength range from 250 to $400 \mathrm{~nm}$. Reproduced from [71] with permission from The Royal Society of Chemistry.

Ye et al. performed steam reforming of methane using $\mathrm{Rh} / \mathrm{TiO}_{2}$ and irradiated visible light $(420 \leq \lambda \leq 800)$ [72]. The hydrogen production rate was drastically improved, as shown in Figure 54a. Their action spectrum showed that the reaction occurred without bandgap excitation of $\mathrm{TiO}_{2}$ (Figure 54b). The apparent activation energy decreased when the light was irradiated on the sample (Figure 54c). 


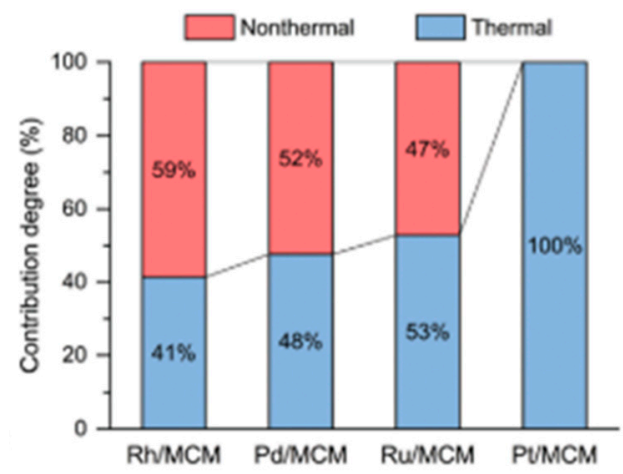

Figure 53. Contribution of thermal and nonthermal effects over various metal-loaded MCM-41's. Reproduced from [71] with permission from The Royal Society of Chemistry.

(a)

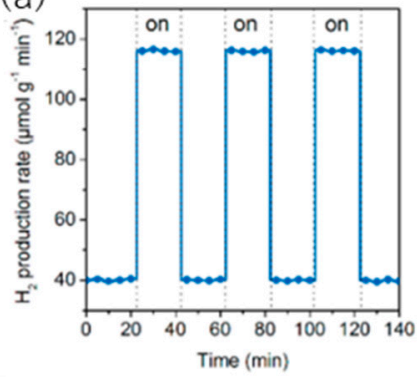

(b)

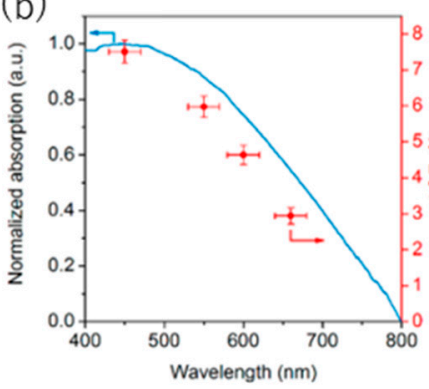

(c) 6

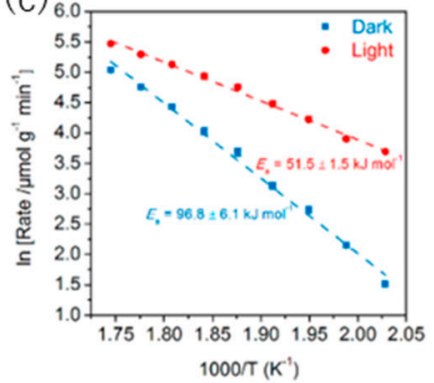

Figure 54. (a) Production rate of $\mathrm{H}_{2}$ with and without visible light. (b) Action spectrum and UV-vis spectrum of $\mathrm{Rh} / \mathrm{TiO}_{2}$. (c) Arrhenius plot constructed using the production rate. Reprinted with permission from [72]. Copyright (2018), American Chemical Society.

As shown above, some previous studies reported that photons could drive the reaction with longer wavelengths, which is unexpected when considering the bandgap gap energies of these reports. The action spectrum analyses provide us with more knowledge that the bandgap excitation is not a sole reaction path in methane reforming. Thus, we must focus on hot carrier generation in metals. It is important to separately discuss the contribution of bandgap excitation and hot carrier generation. Action spectrum analysis and spectroscopic analysis is helpful for understanding the mechanism of photocatalytic methane reforming. In addition, the surface temperature increase due to the plasmonic effect in metal under photon irradiation is not negligible, as mentioned in the next section.

\subsection{Bandgap Shift due to Thermal Energy}

Regardless of the excitation mechanism, that is, bandgap excitation or hot carrier, relaxation after the excitation will contribute to increasing the surface temperature of the photocatalysts. As we have introduced in this review, many researchers perform methane reforming in the gas phase; thus, a temperature increase is not avoidable. In addition, in some studies, heat energy was intentionally added and the photocatalytic activity increased as the temperature increased.

Our group evaluated the surface temperature of the $\mathrm{Rh} / \mathrm{TaON}$ photocatalyst using a long-wavelength cutoff filter under a Xenon lamp (Figure 55) [22]. As a control group, $\mathrm{Rh} / \mathrm{Al}_{2} \mathrm{O}_{3}$ was prepared. In $\mathrm{Rh} / \mathrm{Al}_{2} \mathrm{O}_{3}$, since there is no absorbance in the range of $350 \mathrm{~nm} \leq \lambda \leq 600 \mathrm{~nm}$, the temperature increase due to rhodium was confirmed to be $49^{\circ} \mathrm{C}$. In the case of $\mathrm{Rh} / \mathrm{TaON}$, the temperature increased by $56^{\circ} \mathrm{C}$. This result shows that TaON contributed to a further $7{ }^{\circ} \mathrm{C}$ increase in addition to Rh. These results show that both rhodium and $\mathrm{TaON}$ act as converters of light into heat, enhancing the photocatalytic reaction. The temperature dependence of the photocatalytic activity is shown in Figure 27 in Section 5.2. 


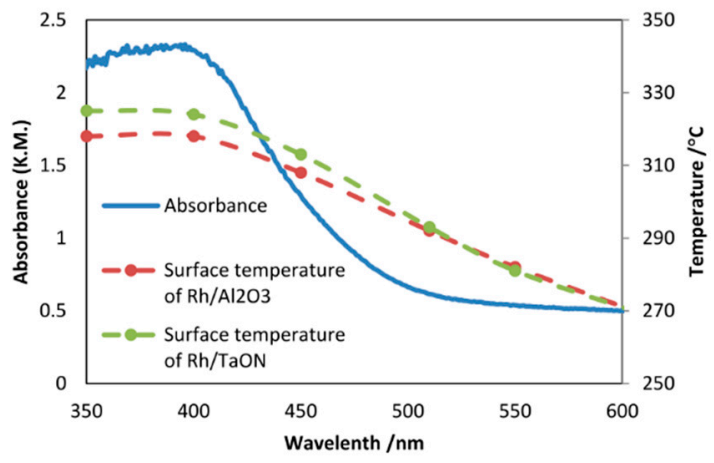

Figure 55. Overlay of the absorbance of $\mathrm{Rh} / \mathrm{TaON}$ and the surface temperatures of $\mathrm{Rh} / \mathrm{TaON}$ and $\mathrm{Rh} / \mathrm{Al}_{2} \mathrm{O}_{3}$. Reproduced from [22] with permission from The Royal Society of Chemistry.

Various other reports also indicated the importance of adding heat in the photocatalytic methane reforming process. As mentioned in Section 6, Jiang et al. measured the surface temperature of the photocatalyst while performing partial oxidation of methane in the gas phase [71]. The strong light increased the surface temperature of the photocatalyst, which increased the photocatalytic activity. It is noted that they claimed that almost half of the products could not be explained only by the increased surface temperature. Pan et al. [46] and Han et al. [51] also found that photocatalytic activity increased as they induced heat energy (Figure 56).
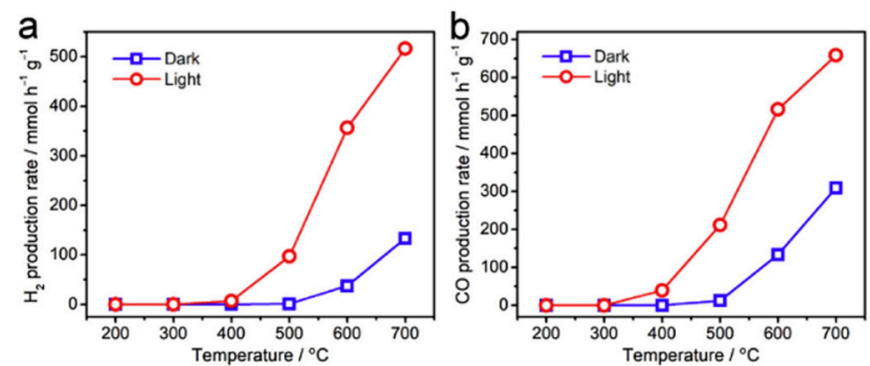

Figure 56. Production rate of (a) $\mathrm{H}_{2}$ and (b) $\mathrm{CO}$ over $\mathrm{MgO} / \mathrm{Pt} / \mathrm{Zn}-\mathrm{CeO}_{2}$ under light irradiation and dark conditions. Copyright (2020), reprinted from [46] with permission from Elsevier.

Very recently, we found that the absorption spectra of semiconductors are largely changed under heat treatment, which was analyzed by operando UV-vis spectroscopy [73]. This bandgap shift phenomenon should be considered since the surface temperature of most of the photocatalysts increases, especially for gas-phase reactions, such as methane conversion. The temperature increase is remarkable when there is plasmonic absorption of the metal. It is a problem that the absorption spectra are usually recorded under room temperature, which is different from the actual catalysis evaluation condition. Therefore, an evaluation of the absorption spectra under heat input (operando UV-vis absorption spectra) is very important for determining the photocatalytic performance factors, such as internal quantum efficiency.

The operando UV-vis was constructed by our group, and the spectra were measured from 22 to $500{ }^{\circ} \mathrm{C}$ on various metal semiconductors (Figure 57). As we estimated bandgaps from Tauc plots, we found that the bandgap values for each semiconductor decreased linearly in this temperature range (Figure 58a). The narrowing of the bandgap was large; for example, in the case of $\mathrm{TiO}_{2}$, the bandgap decreased from 3.02 to $2.78 \mathrm{eV}$ as the temperature increased from 22 to $500{ }^{\circ} \mathrm{C}$. In the case of $\mathrm{CeO}_{2}$ and $\mathrm{Nb}_{2} \mathrm{O}_{5}$, white powder at room temperature turned to a vivid yellow at high temperature. It was also discovered that the effect of bandgap narrowing is more remarkable when the metal-oxygen ion distance in a crystal lattice is large (Figure 58b). 

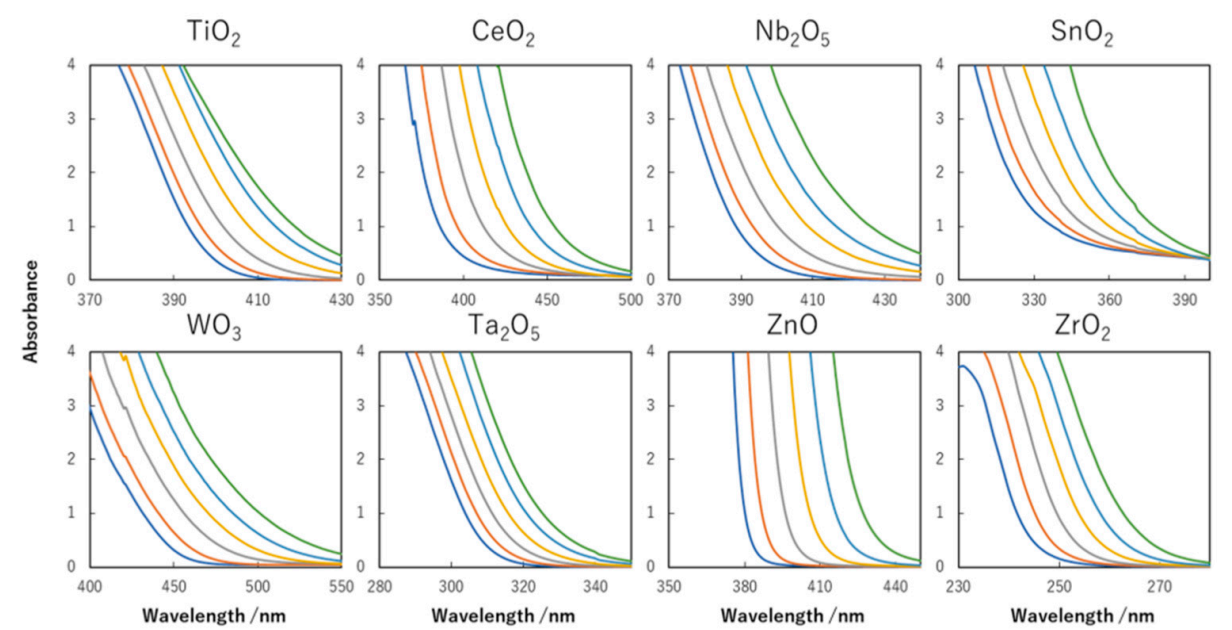

$-22^{\circ} \mathrm{C}$

$-100^{\circ} \mathrm{C}$

$-200^{\circ} \mathrm{C}$
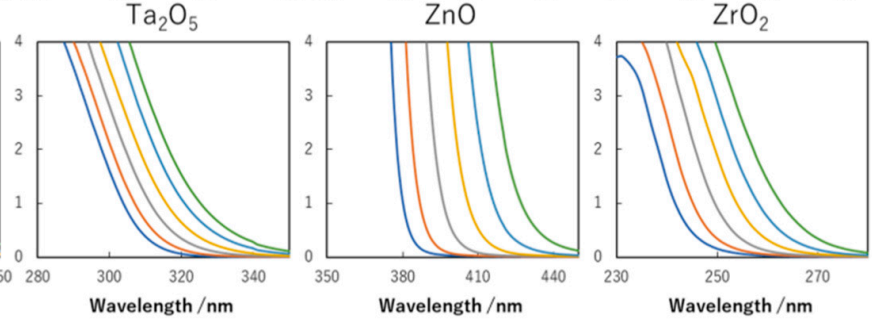

$-300^{\circ} \mathrm{C}$

$-400^{\circ} \mathrm{C}$

$-500{ }^{\circ} \mathrm{C}$

Figure 57. Temperature dependence of the UV-vis absorption spectra for various semiconductors. Reprinted from [73] with permission of AIP Publishing.
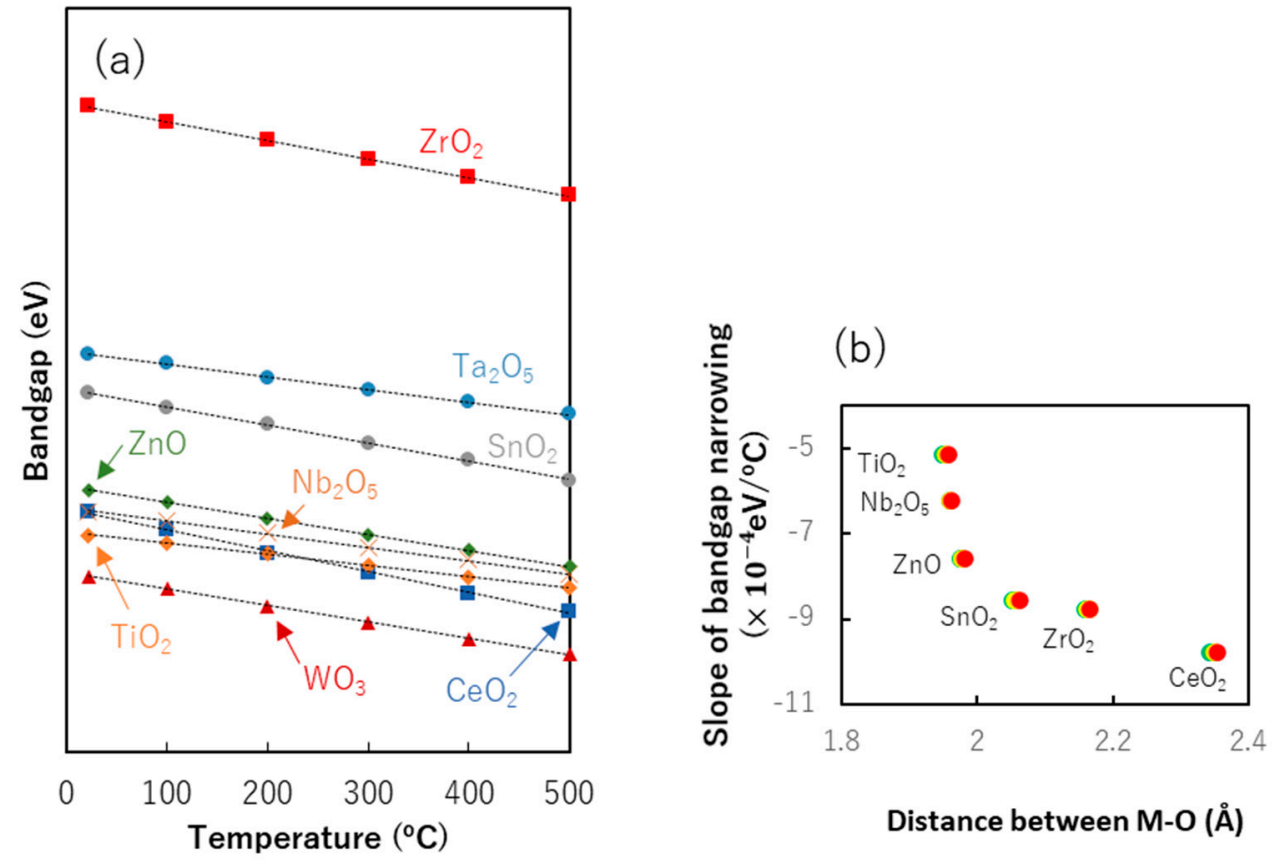

Figure 58. (a) Relationship between the bandgap values and temperature for various semiconductors. (b) The relationship between the slope obtained in (a) and the metal-oxygen (M-O) ion distance. Reprinted from [73] with permission of AIP Publishing.

In summary, there are two issues to be considered while performing methane reforming. First, there is another mechanism for excitation apart from bandgap excitation, namely, hot carriers. The hot carriers excite metals at a dependent wavelength from the semiconductor support. Thus, there is a certain wavelength where both the bandgap is excited and hot carriers coexist, and only one exists. Second, the temperature dependence of the bandgap must be considered because it narrows significantly as temperature increases, and many studies on photocatalytic methane reforming are performed at high temperatures, either intentionally or unintentionally. As the surface temperature of the catalyst increases as light is irradiated onto the photocatalyst in the gas phase, it is impossible to achieve photocatalytic phenomena apart from the photo-thermal phenomenon. In most cases of photocatalytic methane reforming, the temperature increase has a positive effect on the activity. Therefore, optimizing each parameter to achieve high photocatalytic and photo- 
thermal activity is important when practical use is considered. From a scientific viewpoint, we must always be careful about all these effects.

\section{Conclusions}

In this review, we have introduced recent studies related to photocatalytic methane reforming. With respect to the history of the catalyst development for methane reforming, it began with thermal catalysts and has seen great advances since. It is good news that light has promoted photocatalytic activity, resulting in different product selectivities or anticoking effects. Thus, it seems that light-irradiation solved crucial problems that thermal energy alone holds.

As for materials, various photocatalysts have been applied to photocatalytic methane reforming. Many photocatalysts, such as $\mathrm{TiO}_{2}, \mathrm{ZnO}, \mathrm{CeO}_{2}, \mathrm{Ta}_{2} \mathrm{O}_{5}, \mathrm{WO}_{3}, \mathrm{SrTiO}_{3}, \mathrm{NaTaO}_{3}$, $\mathrm{K}_{2} \mathrm{Ti}_{6} \mathrm{O}_{13}$, and g- $\mathrm{C}_{3} \mathrm{~N}_{4}$, were used. From various results, it can be concluded that the appropriate conduction band position should be chosen by considering the redox potentials of the reductant molecules. In addition, like thermal catalysts, the basicity of the semiconductor is quite important in photocatalytic methane reforming.

The mechanism of photocatalytic methane reforming remains controversial. As it is known, the mechanism for methane reforming in dark conditions is so complicated that the detailed mechanism is still studied in thermal catalysis. In photocatalytic methane reforming, photon energy is additionally supplied, and its mechanism is very complicated. However, many papers reported that the excited carriers in semiconductors react with reactants; electron reduces $\mathrm{H}_{2} \mathrm{O}, \mathrm{O}_{2}$, or $\mathrm{CO}_{2}$, and holes oxidize $\mathrm{CH}_{4}$. In addition, the mediators in these photocatalytic reactions have multiple possibilities. There are reports that the oxygen ion is the mediator, and in some reports, protons are the mediators. In addition, there is evidence that $\left[\mathrm{CH}_{2} \mathrm{O}\right]_{n}$ is one possibility for a mediator. The type of mediator depends on the surface structure of the catalysts and the type of methane reforming reaction. Hot carrier generation should also be considered for development. If the photon energy that causes hot carrier generation is smaller than the bandgap, there will be two carrier excitation types under irradiation with larger photon energies. The surface kinetics are also important, as we mentioned in this review paper. It should also be considered that the surface temperature of the photocatalyst is higher than the temperature measured in the reactor. As the quantum efficiency is usually a few percent, the energy of the photon is mostly converted to heat energy. Thus, the heat contribution is not negligible in the gas-phase reaction. In addition, the physical properties of the semiconductor will change as the temperature increases.

We propose two prospects for this field. One is the detailed study of the mechanism by manufacturing simple and understandable structures and conditions of catalysis. Previous studies were complex, and there were too many hypotheses. Understanding the reaction mechanism using either a simulation or experimental approach enables us to advance our research and development more strategically. For example, a spectroscopic method together with a well-defined surface, such as a single crystal, makes it possible to further discuss the reaction mechanism by observing the reaction intermediates. It can also be beneficial to fabricate a series of samples while holding one interpretable parameter; then, we can systematically compare their activity, stoichiometry, and/or stability. As there are so many parameters in photocatalytic methane reforming, an investigation of each parameter's effect on the catalytic activity should be an important study for the future of this field. The second is to pursue higher activities; in particular, the visible-light activity is indispensable for utilizing solar energy effectively. By developing a photocatalyst that remains highly active and is composed of abundant and nontoxic elements, photocatalytic methane reforming may replace the current thermal system. As the shale gas revolution enables more methane to be produced, the technology for utilizing methane will become more important. From the standpoint of a hydrogen society, methane conversion is further important. On the other hand, as the Paris Agreement represents, global warming is one of the most serious problems humans face. Hence, methane must be activated without 
further $\mathrm{CO}_{2}$ emissions. Photons are one solution to solve the double-binding problem. To solve these difficult but important problems, we expect more researchers to join this field.

Author Contributions: Experimental work in this review, Y.C.; writing-original draft preparation, Y.C.; writing — review and editing, A.Y. and M.M.; project leader, M.M. All authors have read and agreed to the published version of the manuscript.

Funding: This research was supported by JST SICROP and JST CREST (grant no. JPMJCR15P1).

Institutional Review Board Statement: Not applicable.

Informed Consent Statement: Not applicable.

Conflicts of Interest: The authors declare no conflict of interest.

\section{References}

1. Liu, C.; Ye, J.; Jiang, J.; Pan, Y. Progresses in the Preparation of Coke Resistant Ni-based Catalyst for Steam and $\mathrm{CO}_{2}$ Reforming of Methane. ChemCatChem 2011, 3, 529-541. [CrossRef]

2. Tang, S.-B.; Qiu, F.-L.; Lu, S.-J. Effect of supports on the carbon deposition of nickel catalysts for methane reforming with $\mathrm{CO}_{2}$. Catal. Today 1995, 24, 253-255. [CrossRef]

3. Aramouni, N.A.K.; Touma, J.G.; Tarboush, B.A.; Zeaiter, J.; Ahmad, M.N. Catalyst design for dry reforming of methane: Analysis review. Renew. Sustain. Energy Rev. 2018, 82, 2570-2585. [CrossRef]

4. Lavoie, J.-M. Review on dry reforming of methane, a potentially more environmentally-friendly approach to the increasing natural gas exploitation. Front. Chem. 2014, 2, 81. [CrossRef]

5. Chen, X.; Li, Y.; Pan, X.; Cortie, D.; Huang, X.; Yi, Z. Photocatalytic oxidation of methane over silver decorated zinc oxide nanocatalysts. Nat. Commun. 2016, 7, 12273. [CrossRef] [PubMed]

6. Meng, X.; Cui, X.; Rajan, N.P.; Yu, L.; Deng, D.; Bao, X. Direct Methane Conversion under Mild Condition by Thermo-, Electro-, or Photocatalysis. Chem 2019, 5, 2296-2325. [CrossRef]

7. Gordon, S.; Mcbride, B.J. Computer Program for Calculation of Complex Chemical Equilibrium Compositions and Application; NASA Reference Publication: Washington, DC, USA, 1994.

8. Tomishige, K.; Himeno, Y.; Matsuo, Y.; Yoshinaga, Y.; Fujimoto, K. Catalytic Performance and Carbon Deposition Behavior of a $\mathrm{NiO}-\mathrm{MgO}$ Solid Solution in Methane Reforming with Carbon Dioxide under Pressurized Conditions. Ind. Eng. Chem. Res. 2000, 39, 1891-1897. [CrossRef]

9. Guo, X.; Fang, G.; Li, G.; Ma, H.; Fan, H.; Yu, L.; Ma, C.; Wu, X.; Deng, D.; Wei, M.; et al. Direct, Non-oxidative Conversion of Methane to Ethylene, Aromatics, and Hydrogen. Science 2014, 344, 616-619. [CrossRef] [PubMed]

10. Xu, Y.; Bao, X.; Lin, L. Direct conversion of methane under non-oxidative conditions. J. Catal. 2003, 216, 386-395. [CrossRef]

11. Redondo, A.B.; Troussard, E.; van Bokhoven, J.A. Non-oxidative methane conversion assisted by corona discharge. Fuel Process. Technol. 2012, 104, 265-270. [CrossRef]

12. Fujishima, A.; Honda, K. Electrochemical Photolysis of Water at a Semiconductor Electrode. Nature 1972, 238, 37-38. [CrossRef] [PubMed]

13. Qu, Y.; Duan, X. Progress, challenge and perspective of heterogeneous photocatalysts. Chem. Soc. Rev. 2013, 42, 2568-2580. [CrossRef] [PubMed]

14. Kudo, A.; Miseki, Y. Heterogeneous photocatalyst materials for water splitting. Chem. Soc. Rev. 2009, 38, 253-278. [CrossRef] [PubMed]

15. Web of Science. Analyze search Results for methane Reforming and methane Reforming Photo. Available online: https:/ / apps.webofknowledge.com/WOS_GeneralSearch_input.do?product=WOS\&search_mode=GeneralSearch\&SID= F3OWgDOUyyDPjOy2WTg\&preferencesSaved = (accessed on 11 November 2020).

16. Maeda, K.; Teramura, K.; Lu, D.; Takata, T.; Saito, N.; Inoue, Y.; Domen, K. Photocatalyst releasing hydrogen from water. Nature 2006, 440, 295. [CrossRef] [PubMed]

17. Low, J.; Cheng, B.; Yu, J. Surface modification and enhanced photocatalytic $\mathrm{CO}_{2}$ reduction performance of TiO 2 : A review. Appl. Surf. Sci. 2017, 392, 658-686. [CrossRef]

18. Ye, S.; Wang, R.; Wu, M.-Z.; Yuan, Y.-P. A review on g-C3N4 for photocatalytic water splitting and $\mathrm{CO}_{2}$ reduction. Appl. Surf. Sci. 2015, 358, 15-27. [CrossRef]

19. Wang, H.Y.; Ruckenstein, E. Carbon dioxide reforming of methane to synthesis gas over supported rhodium catalysts: The effect of support. Appl. Catal. A Gen. 2000, 204, 143-152. [CrossRef]

20. Dębek, R.; Radlik, M.; Motak, M.; Galvez, M.E.; Turek, W.; Da Costa, P.; Grzybek, T. Ni-containing Ce-promoted hydrotalcite derived materials as catalysts for methane reforming with carbon dioxide at low temperature-On the effect of basicity. Catal. Today 2015, 257, 59-65. [CrossRef]

21. García, V.; Fernández, J.J.; Ruíz, W.; Mondragón, F.; Moreno, A. Effect of $\mathrm{MgO}$ addition on the basicity of $\mathrm{Ni} / \mathrm{ZrO}_{2}$ and on its catalytic activity in carbon dioxide reforming of methane. Catal. Commun. 2009, 11, 240-246. [CrossRef] 
22. Cho, Y.; Shoji, S.; Yamaguchi, A.; Hoshina, T.; Fujita, T.; Abe, H.; Miyauchi, M. Visible-light-driven dry reforming of methane using a semiconductor-supported catalyst. Chem. Commun. 2020, 56. [CrossRef]

23. Shimura, K.; Kato, S.; Yoshida, T.; Itoh, H.; Hattori, T.; Yoshida, H. Photocatalytic Steam Reforming of Methane over Sodium Tantalate. J. Phys. Chem. C 2010, 114, 3493-3503. [CrossRef]

24. Shimura, K.; Kawai, H.; Yoshida, T.; Yoshida, H. Bifunctional Rhodium Cocatalysts for Photocatalytic Steam Reforming of Methane over Alkaline Titanate. ACS Catal. 2012, 2, 2126-2134. [CrossRef]

25. Li, D.; Nakagawa, Y.; Tomishige, K. Methane reforming to synthesis gas over Ni catalysts modified with noble metals. Appl. Catal. A Gen. 2011, 408, 1-24. [CrossRef]

26. Rezaei, M.; Alavi, S.M.; Sahebdelfar, S.; Yan, Z.-F. Syngas Production by Methane Reforming with Carbon Dioxide on Noble Metal Catalysts. J. Nat. Gas. Chem. 2006, 15, 327-334. [CrossRef]

27. Pakhare, D.; Spivey, J. A review of dry $\left(\mathrm{CO}_{2}\right)$ reforming of methane over noble metal catalysts. Chem. Soc. Rev. 2014, 43, 7813-7837. [CrossRef]

28. László, B.; Baán, K.; Varga, E.; Oszkó, A.; Erdőhelyi, A.; Kónya, Z.; Kiss, J. Photo-induced reactions in the $\mathrm{CO}_{2}$-methane system on titanate nanotubes modified with Au and Rh nanoparticles. Appl. Catal. B Environ. 2016, 199, 473-484. [CrossRef]

29. Shimura, K.; Yoshida, H. Semiconductor Photocatalysts for Non-oxidative Coupling, Dry Reforming and Steam Reforming of Methane. Catal. Surv. Asia 2014, 18, 24-33. [CrossRef]

30. Shoji, S.; Peng, X.; Yamaguchi, A.; Watanabe, R.; Fukuhara, C.; Cho, Y.; Yamamoto, T.; Matsumura, S.; Yu, M.-W.; Ishii, S.; et al Photocatalytic uphill conversion of natural gas beyond the limitation of thermal reaction systems. Nat. Catal. 2020, 3. [CrossRef]

31. Tahir, M.; Tahir, B.; Amin, N.S. Photocatalytic $\mathrm{CO}_{2}$ reduction by $\mathrm{CH} 4$ over montmorillonite modified $\mathrm{TiO}_{2}$ nanocomposites in a continuous monolith photoreactor. Mater. Res. Bull. 2015, 63, 13-23. [CrossRef]

32. Shi, D.; Feng, Y.; Zhong, S. Photocatalytic conversion of $\mathrm{CH}_{4}$ and $\mathrm{CO}_{2}$ to oxygenated compounds over $\mathrm{Cu} / \mathrm{CdS}-\mathrm{TiO} 2 / \mathrm{SiO} 2$ catalyst. Catal. Today 2004, 98, 505-509. [CrossRef]

33. Lang, J.; Ma, Y.; Wu, X.; Jiang, Y.; Hu, Y.H. Highly efficient light-driven methane coupling under ambient conditions based on an integrated design of a photocatalytic system. Green Chem. 2020, 22, 4669-4675. [CrossRef]

34. Roy, S.; Bauer, T.; Al-Dahhan, M.; Lehner, P.; Turek, T. Monoliths as multiphase reactors: A review. AIChE J. 2004, 50, 2918-2938. [CrossRef]

35. Tahir, M.; Tahir, B.; Zakaria, Z.Y.; Muhammad, A. Enhanced photocatalytic carbon dioxide reforming of methane to fuels over nickel and montmorillonite supported $\mathrm{TiO}_{2}$ nanocomposite under UV-light using monolith photoreactor. J. Clean. Prod. 2019, 213, 451-461. [CrossRef]

36. Tahir, M. Enhanced photocatalytic $\mathrm{CO}_{2}$ reduction to fuels through bireforming of methane over structured $3 \mathrm{D} \mathrm{MAX} \mathrm{Ti}_{3} \mathrm{AlC}_{2} / \mathrm{TiO}_{2}$ heterojunction in a monolith photoreactor. J. $\mathrm{CO}_{2}$ Util. 2020, 38, 99-112. [CrossRef]

37. Li, X.; Zhang, X.; Everitt, H.O.; Liu, J. Light-Induced Thermal Gradients in Ruthenium Catalysts Significantly Enhance Ammonia Production. Nano Lett. 2019, 19, 1706-1711. [CrossRef]

38. Ohno, T.; Sarukawa, K.; Tokieda, K.; Matsumura, M. Morphology of a $\mathrm{TiO}_{2}$ Photocatalyst (Degussa, P-25) Consisting of Anatase and Rutile Crystalline Phases. J. Catal. 2001, 203, 82-86. [CrossRef]

39. Park, H.; Park, Y.; Kim, W.; Choi, W. Surface modification of $\mathrm{TiO}_{2}$ photocatalyst for environmental applications. J. Photochem. Photobiol. C Photochem. Rev. 2013, 15, 1-20. [CrossRef]

40. Yoshida, H.; Hirao, K.; Nishimoto, J.; Shimura, K.; Kato, S.; Itoh, H.; Hattori, T. Hydrogen Production from Methane and Water on Platinum Loaded Titanium Oxide Photocatalysts. J. Phys. Chem. C 2008, 112, 5542-5551. [CrossRef]

41. Choudhary, V.R.; Mondal, K.C. $\mathrm{CO}_{2}$ reforming of methane combined with steam reforming or partial oxidation of methane to syngas over $\mathrm{NdCoO}_{3}$ perovskite-type mixed metal-oxide catalyst. Appl. Energy 2006, 83, 1024-1032. [CrossRef]

42. Li, Y.; Wang, Y.; Zhang, X.; Mi, Z. Thermodynamic analysis of autothermal steam and $\mathrm{CO}_{2}$ reforming of methane. Int. J. Hydrogen Energy 2008, 33, 2507-2514. [CrossRef]

43. Wibowo, S.; Yamaguchi, A.; Shoji, S.; Fujita, T.; Abe, H.; Miyauchi, M. Photo-assisted Dry Reforming of Methane over Strontium Titanate. Chem. Lett. 2018, 47, 935-937. [CrossRef]

44. Teramura, K.; Tanaka, T.; Ishikawa, H.; Kohno, Y.; Funabiki, T. Photocatalytic Reduction of $\mathrm{CO}_{2}$ to $\mathrm{CO}$ in the Presence of $\mathrm{H}_{2}$ or $\mathrm{CH}_{4}$ as a Reductant over MgO. J. Phys. Chem. B 2003, 108, 346-354. [CrossRef]

45. Chang, S.; Li, M.; Hua, Q.; Zhang, L.; Ma, Y.; Ye, B.; Huang, W. Shape-dependent interplay between oxygen vacancies and $\mathrm{Ag}-\mathrm{CeO}_{2}$ interaction in $\mathrm{Ag} / \mathrm{CeO}_{2}$ catalysts and their influence on the catalytic activity. J. Catal. 2012, 293, 195-204. [CrossRef]

46. Pan, F.; Xiang, X.; Du, Z.; Sarnello, E.; Li, T.; Li, Y. Integrating photocatalysis and thermocatalysis to enable efficient $\mathrm{CO}_{2}$ reforming of methane on $\mathrm{Pt}$ supported $\mathrm{CeO}_{2}$ with $\mathrm{Zn}$ doping and atomic layer deposited $\mathrm{MgO}$ overcoating. Appl. Catal. B Environ. 2020, 260, 118189. [CrossRef]

47. Lei, J.; Chen, Y.; Shen, F.; Wang, L.; Liu, Y.; Zhang, J. Surface modification of $\mathrm{TiO}_{2}$ with g-C3N4 for enhanced UV and visible photocatalytic activity. J. Alloys Compd. 2015, 631, 328-334. [CrossRef]

48. Tahir, B.; Tahir, M.; Amin, N.A.S. Photo-induced $\mathrm{CO}_{2}$ reduction by $\mathrm{CH}_{4} / \mathrm{H}_{2} \mathrm{O}$ to fuels over Cu-modified g-C3N4 nanorods under simulated solar energy. Appl. Surf. Sci. 2017, 419, 875-885. [CrossRef]

49. Tahir, B.; Tahir, M.; Amin, N.A.S. Silver loaded protonated graphitic carbon nitride (Ag/pg-C3N4) nanosheets for stimulating $\mathrm{CO}_{2}$ reduction to fuels via photocatalytic bi-reforming of methane. Appl. Surf. Sci. 2019, 493, 18-31. [CrossRef] 
50. Han, B.; Wei, W.; Chang, L.; Cheng, P.; Hu, Y.H. Efficient Visible Light Photocatalytic $\mathrm{CO}_{2}$ Reforming of CH . ACS Catal. 2015, 6, 494-497. [CrossRef]

51. Han, B.; Wei, W.; Li, M.; Sun, K.; Hu, Y.H. A thermo-photo hybrid process for steam reforming of methane: Highly efficient visible light photocatalysis. Chem. Commun. 2019, 55, 7816-7819. [CrossRef]

52. Kushida, M.; Yamaguchi, A.; Cho, Y.; Fujita, T.; Abe, H.; Miyauchi, M. Gas-Phase Photoelectrocatalysis Mediated by Oxygen Ions for Uphill Conversion of Greenhouse Gases. ChemPhotoChem 2020. [CrossRef]

53. Wang, B.; Albarracín-Suazo, S.; Pagán-Torres, Y.; Nikolla, E. Advances in methane conversion processes. Catal. Today 2017, 285, 147-158. [CrossRef]

54. Sari, F.N.I.; Lu, S.-H.; Ting, J.-M. Wide-bandgap $\mathrm{HfO}_{2}-\mathrm{V}_{2} \mathrm{O}_{5}$ nanowires heterostructure for visible light-driven photocatalytic degradation. J. Am. Ceram. Soc. 2020, 103, 2252-2261. [CrossRef]

55. Murcia-López, S.; Villa, K.; Andreu, T.; Morante, J.R. Improved selectivity for partial oxidation of methane to methanol in the presence of nitrite ions and BiVO4 photocatalyst. Chem. Commun. 2015, 51, 7249-7252. [CrossRef] [PubMed]

56. Hu, Y.; Nagai, Y.; Rahmawaty, D.; Wei, C.; Anpo, M. Characteristics of the Photocatalytic Oxidation of Methane into Methanol on V-Containing MCM-41 Catalysts. Catal. Lett. 2008, 124, 80. [CrossRef]

57. Villa, K.; Murcia-López, S.; Andreu, T.; Morante, J.R. Mesoporous WO3 photocatalyst for the partial oxidation of methane to methanol using electron scavengers. Appl. Catal. B Environ. 2015, 163, 150-155. [CrossRef]

58. Murcia-López, S.; Villa, K.; Andreu, T.; Morante, J.R. Partial Oxidation of Methane to Methanol Using Bismuth-Based Photocatalysts. ACS Catal. 2014, 4, 3013-3019. [CrossRef]

59. Murcia-López, S.; Bacariza, M.C.; Villa, K.; Lopes, J.M.; Henriques, C.; Morante, J.R.; Andreu, T. Controlled Photocatalytic Oxidation of Methane to Methanol through Surface Modification of Beta Zeolites. ACS Catal. 2017, 7, 2878-2885. [CrossRef]

60. Choudhary, T.V.; Aksoylu, E.; Wayne Goodman, D. Nonoxidative Activation of Methane. Catal. Rev. 2003, 45, 151-203. [CrossRef]

61. Wu, S.; Tan, X.; Lei, J.; Chen, H.; Wang, L.; Zhang, J. Ga-Doped and Pt-Loaded Porous $\mathrm{TiO}_{2}-\mathrm{SiO}_{2}$ for Photocatalytic Nonoxidative Coupling of Methane. J. Am. Chem. Soc. 2019, 141, 6592-6600. [CrossRef]

62. Yuliati, L.; Hamajima, T.; Hattori, T.; Yoshida, H. Nonoxidative Coupling of Methane over Supported Ceria Photocatalysts. J. Phys. Chem. C 2008, 112, 7223-7232. [CrossRef]

63. Yuliati, L.; Hattori, T.; Itoh, H.; Yoshida, H. Photocatalytic non-oxidative coupling of methane on gallium oxide and silicasupported gallium oxide. J. Catal. 2008, 257, 396-402. [CrossRef]

64. Singh, S.P.; Anzai, A.; Kawaharasaki, S.; Yamamoto, A.; Yoshida, H. Non-oxidative coupling of methane over Pd-loaded gallium oxide photocatalysts in a flow reactor. Catal. Today 2020. [CrossRef]

65. Clavero, C. Plasmon-induced hot-electron generation at nanoparticle/metal-oxide interfaces for photovoltaic and photocatalytic devices. Nat. Photonics 2014, 8, 95-103. [CrossRef]

66. Cui, J.; Li, Y.; Liu, L.; Chen, L.; Xu, J.; Ma, J.; Fang, G.; Zhu, E.; Wu, H.; Zhao, L.; et al. Near-Infrared Plasmonic-Enhanced Solar Energy Harvest for Highly Efficient Photocatalytic Reactions. Nano Lett. 2015, 15, 6295-6301. [CrossRef] [PubMed]

67. Zhou, L.; Swearer, D.F.; Zhang, C.; Robatjazi, H.; Zhao, H.; Henderson, L.; Dong, L.; Christopher, P.; Carter, E.A.; Nordlander, P.; et al. Quantifying hot carrier and thermal contributions in plasmonic photocatalysis. Science 2018, 362, 69-72. [CrossRef]

68. Zhang, X.; Li, X.; Reish, M.E.; Zhang, D.; Su, N.Q.; Gutiérrez, Y.; Moreno, F.; Yang, W.; Everitt, H.O.; Liu, J. Plasmon-Enhanced Catalysis: Distinguishing Thermal and Nonthermal Effects. Nano Lett. 2018, 18, 1714-1723. [CrossRef]

69. Tian, Y.; Tatsuma, T. Mechanisms and Applications of Plasmon-Induced Charge Separation at TiO 2 Films Loaded with Gold Nanoparticles. J. Am. Chem. Soc. 2005, 127, 7632-7637. [CrossRef]

70. Jiang, H.; Peng, X.; Yamaguchi, A.; Ueda, S.; Fujita, T.; Abe, H.; Miyauchi, M. Photocatalytic Partial Oxidation of Methane on Palladium-Loaded Strontium Tantalate. Sol. RRL 2019, 3, 1900076. [CrossRef]

71. Jiang, H.; Peng, X.; Yamaguchi, A.; Fujita, T.; Abe, H.; Miyauchi, M. Synergistic photo-thermal and photochemical partial oxidation of methane over noble metals incorporated in mesoporous silica. Chem. Commun. 2019, 55, 13765-13768. [CrossRef]

72. Song, H.; Meng, X.; Wang, Z.; Wang, Z.; Chen, H.; Weng, Y.; Ichihara, F.; Oshikiri, M.; Kako, T.; Ye, J. Visible-Light-Mediated Methane Activation for Steam Methane Reforming under Mild Conditions: A Case Study of $\mathrm{Rh} / \mathrm{TiO}_{2}$ Catalysts. ACS Catal. 2018, 8, 7556-7565. [CrossRef]

73. Cho, Y.; Yamaguchi, A.; Uehara, R.; Yasuhara, S.; Hoshina, T.; Miyauchi, M. Temperature dependence on bandgap of semiconductor photocatalysts. J. Chem. Phys. 2020, 152, 231101. [CrossRef] [PubMed] 